\title{
The application of data innovations to geomorphological impact analyses in coastal areas: an East Anglia, UK, case study
}

\begin{abstract}
Rapidly advancing surveying technologies, capable of generating high resolution bathymetric and topographic data, allow precise measurements of geomorphological change and deformation. This permits great accuracy in the characterisation of volumetric change, sediment and debris flows, accumulations and erosion rates. However, such data can be utilised inadequately by coastal practitioners in their assessments of coastal change, due to a lack of awareness of the appropriate analytical techniques and the potential benefits offered by such data-driven approaches. This was found to be the case for the region of East Anglia, UK, which was analysed in this study. This paper evaluates the application of innovative geomorphological change detection (GCD) techniques for analysis of coastal change. The first half of the paper contains an extensive review of GCD methods and data sources used in previous studies. This leads to the selection and recommendation of an appropriate methodology for calculation of volumetric GCD, which has been subsequently applied and evaluated for 14 case study sites in East Anglia. This has involved combining open source point cloud datasets for broad spatial scales, covering an extended temporal period. The results comprise quantitative estimates of volumetric change for selected locations. This allows estimation of the sediment budgets for each stretch of coastline focused upon, revealing fluctuations in their rates of change. These quantitative results were combined with qualitative outputs, such as visual representations of change and we reveal how combining such methods assists identification of patterns and impacts linked to specific events. The study demonstrates how high-resolution point cloud data, which is now readily available, can be used to better inform coastal management practices, revealing trends, impacts and vulnerability in dynamic coastal regions. The results also indicate heterogeneous impacts of events, such as the 2013 East Coast Storm Surge, across the study area of East Anglia.
\end{abstract}

Authors: Alexander Rumson ${ }^{\mathrm{a},}{ }^{*}$, Stephen H. Hallett ${ }^{\mathrm{a}}$ and Timothy R. Brewer ${ }^{\mathrm{a}}$

\author{
Affiliations \\ a School of Water, Energy and Environment, Cranfield University, Bedford, UK \\ *Corresponding author. E-mail address: al.rumson@cranfield.ac.uk
}

\section{Keywords}

Geomorphological change detection; coastal management; open source data; point cloud data; volumetric change; impact analysis 


\subsection{Introduction}

Decision-making and environmental management in coastal areas requires the ability to understand and quantify the variability of change and deformation of beaches and cliffs over time. An understanding of their drivers may be gained through the quantification of such changes (Schimel et al., 2015). Typically, this involves characterisation of debris flows, accumulations and erosion rates. However, many coastal organisations, such as those in the UK, are not currently utilising the range of advanced and appropriate techniques and technologies, which are now readily available. Emergent remote sensing technologies are able to generate far higher resolution measurements for coastal areas than have been previously available, in both the vertical and horizontal planes. Such methods can allow more precise measurements of coastal retreat to be undertaken than those extrapolated from traditional topographic maps or aerial photos (Poulton et al., 2006). Analyses of such measurements can lead to the production of derivative data products that can provide, for example, retreat rates directly from volumetric change calculations (Esposito et al., 2018). Additionally, data with a higher temporal resolution is also becoming available (Kromer et al., 2017). This can reveal dynamic coastal processes with increased granularity, assisting in the identification of both vulnerable and stable locations. Furthermore, when such morphological data is combined with other measurements, causation of change can be determined (Leyland et al., 2017; Rosser et al., 2005). This can improve our ability to model coastal processes and to make informed projections on future coastal change scenarios.

Understanding the processes operating in coastal zones requires the ability to compare datasets from different epochs ${ }^{1}$, and the consequent generation of quantitative and qualitative representation of areas where loss and gain of beach and cliff material has occurred (Earlie et al., 2015). This can enhance our understanding of processes, such as the contribution of beach sediment to littoral cells (Young and Ashford, 2006). A wide range of methods exist for geomorphological change detection (GCD), and the selection of appropriate methods requires consideration as to the local environment, context, type of output desired, i.e. volumetric change and/or linear change, output format (qualitative/quantitative), and level of detail required from the subsequent analysis. For example, the monitoring of granular deformations of hard rock cliffs (Rosser et al., 2005; Westoby et al., 2018) necessitates separate survey and analytical data approaches than do studies that are restricted to determining wider-scale cliff-top recession rates, or those monitoring beach levels (Shrestha et al., 2005), or near-shore sediment movements (Burningham and French, 2011). Airborne survey techniques can reveal cliff top retreat, however, for vertical cliffs, such approaches are not capable of revealing cliff toe erosion and overhangs which can often lead to cliff failure (Michoud et al., 2015; Obu et al., 2017). For this, survey techniques with a horizontal aspect (ground or vessel based) are required (Michoud et al., 2015; Rosser et al., 2013). Yet, to date, a comprehensive discussion on the suitability of different coastal GCD methods has not yet been completed.

The main issue addressed by this research is that of the utilisation of point cloud based GCD techniques by the coastal practitioner community. Outside academia, only limited adoption of such methods has been witnessed. Despite a large archive of morphological point cloud data existing for the many regions, coastal change analysis is most commonly based on more

\footnotetext{
${ }^{1}$ For the purpose of this study an epoch is defined as the date and time in which a survey was completed at one specific site.
} 
rudimentary methods, such as extraction of cliff edges from aerial imagery. Reasons why more advanced point cloud-based methods have been underutilised include: a lack of awareness of the available and appropriate analytical techniques, and inadequate knowledge of the potential advantages that utilisation of such GCD approaches can generate. This paper seeks to address these challenges through an initial discussion of point cloud based GCD methods, and a subsequent practical GCD for a number of case study sites in East Anglia, UK. East Anglia has a highly dynamic, vulnerable coastline, comprising soft cliffs and sandy beaches, on which extraordinary rates of geomorphological change have been experienced, (Brooks and Spencer, 2010). The region has been studied extensively, and many morphological datasets representing its coasts are now freely available. These factors combined, render this region especially suitable for analysis. As such, using a single GCD method, centred on triangulated irregular network (TIN) model creation and planar surface comparisons, datasets for 14 case study sites were combined and compared, for periods ranging between 6 to 10 years. The sites selected were identified based on consultations with those public sector bodies tasked with monitoring and managing the coastline of the region e.g. Coastal Partnership East (CPE) and the Environment Agency (EA). The sites further represent locations where a requirement exists to provide high temporal and spatial resolution change analysis.

In this study we evaluate many GCD techniques and methods to assess their application in different scenarios. A key objective was to evaluate the practical suitability of a point cloud based GCD method for coastal change detection applications. In doing so, we demonstrate how successful combination and analysis of point cloud data can reveal change and evolution of coastal environments. In line with this, a second objective was to generate increased understanding of recent morphological changes occurring at selected vulnerable stretches of the East Anglian coastline. The GCD method utilised within this study was capable of producing volumetric change estimates. Results generated through application of this technique allowed quantification of the sediment budgets at each study site. Such outputs are especially relevant to the coastal region of East Anglia and other recent studies have sought to generate similar (Brooks and Spencer, 2010; Burningham and French, 2016). It is envisaged that the outcomes generated from this study may raise awareness of the possibilities presented by point cloud data analysis for studies focussing on coastal change and deformation, and potentially assist practitioners and researchers in the selection of appropriate GCD methods. Additionally, the quantitative results may form an input to future research or decision-making processes. Many 'state of the art' developments in geomorphological change analysis, relevant to coastal analysis, are underway in areas of research outside the direct sphere of coastal studies, in areas such as analysis of fluvial systems (Lague et al., 2013; Leyland et al., 2017) and non-coastal rock faces (Kromer et al., 2017). Accordingly, note is given to a selection of these studies within this work.

\subsection{Review of coastal GCD techniques}

\subsubsection{Monitoring the coast, beaches and cliffs}

In attempting to understand coastal dynamics, an appreciation of processes operating across coastal environments is essential; past studies have generally divided their focus between cliffs and beaches. However, when modelling coastal cliff environments, data on the 
foreshore should also be included (Hobbs et al., 2010). Monitoring each environment separately can require different data acquisition techniques and processing workflows. Yet a number of studies exist that combine such techniques (Eisemann et al., 2018; Leyland et al., 2017; Seker et al., 2003). Processes operating on the near-shore seabed are linked to erosion and deposition events occurring on beaches (Sergeev et al., 2018). As such, an understanding and integration of the influence of the offshore environment, is essential when modelling future recession rates (Poulton et al., 2006). There are many drivers for monitoring the nearshore environment, resulting in datasets becoming available that are able to reveal the dynamic evolution of these areas. For example, seabed surveys can result from channel dredging requirements, marine aggregate resource monitoring, and engineering works related to undersea cables, pipelines and energy infrastructure (Schimel et al., 2015). As a consequence, monitoring of the subsea domain has progressed rapidly, and now detailed point cloud datasets are routinely generated by multibeam echosounder (MBES) surveys. Moreover, repeat MBES surveys have facilitated change analysis to be completed for nearshore environments (Kemp and Brampton, 2007; Leyland et al., 2017; Quinn and Boland, 2010; Schimel et al., 2015). Such studies can expose dynamic 'live bed processes', including the migration of seabed features (Quinn and Boland, 2010). This current study included one case study site (Case Study 10: Nearshore Lowestoft) for which MBES data from 11 epochs were analysed. Compared to topographic datasets, such as derived from airborne lidar, the number of Open Source MBES datasets available to download, are more limited. The costs associated with completion of MBES surveys is one barrier, preventing many commercial organisations who hold this data, making it available for free. However, there are initiatives in place seeking to overcome such hurdles. For the UK, the Crown Estate stipulate that datasets generated from seabed surveys related to offshore wind farms, must be made available to the public after a 2 year period, this data should then be accessible via their Marine Data Exchange (The Crown Estate, 2019).

Obtaining data for intertidal areas is challenging, there are limitations imposed on the ability to acquire MBES in these areas, due to the draft of vessels upon MBES systems are mounted on. However the growing use of unmanned surface vessels is reducing such limitations (Iwen and WAz, 2019). A number of alternative methods of acquiring intertidal data exist, and continual progress is being made in this field. Satellite derived bathymetry is one such rapidly evolving method (Kulawiak and Chybicki, 2018; Sagar et al., 2016), as is the use of X-band radar (Atkinson et al., 2018; Bell et al., 2016). However, the spatial resolution and accuracy of data obtainable by these methods is lower than that possible using MBES. Another alternative, is bathymetric Lidar (Andersen et al., 2017; Eisemann et al., 2018), this is can provide higher resolution data than satellite or X-band radar, yet is limited by meteorological and ocean conditions.

The use of remote sensing data offers significant accuracy improvements over the more manual and traditional methods required to analyse historic analogue datasets, which also rely on the skills of an individual, and can lead potentially to high levels of uncertainty (Burningham and French, 2011). Furthermore, the ability to combine point cloud data, revealing the complex spatial patterns of sand redistribution (both on beaches and in the near-shore environment), is recognised as essential in attempts to represent adequately the evolution of coastal processes (Mitasova, 2015; Mitasova et al., 2002). Traditional techniques relying on manual interpretation and digitisation (Seker et al., 2003), can prove efficient in 
summarising change rates on a larger scale, yet can omit important site-specific details (Earlie et al., 2015; Krolik-Root et al., 2015). A number of common GIS-based analysis techniques such as the Digital Shoreline Analysis System (DSAS) (Appeaning Addo et al., 2008; Thieler et al., 2009) and AMBUR (Jackson et al., 2012), also involve manual shoreline digitisation. Yet, in comparing an approach based on DSAS, with more advanced, point cloud based methods, Leyland et al. (2017) found it to be 'error prone at high temporal resolution'. Methods used to complete morphodynamic analyses of coasts can vary widely in complexity, from simple approaches involving visual interpretation (Amaro et al., 2015), to surface comparisons based on gridded or meshed datasets (Williams, 2012), and more advanced point cloud analysis (Williams et al., 2018). It is in the field of cloud to cloud (C2C) comparison that some of the most significant contemporary advances are being made. As such, $\mathrm{C} 2 \mathrm{C}$ analysis offers an optimal method for quantifying erosion (Lindenbergh and Pietrzyk, 2015). Automation of processes and data workflows is now becoming a common feature associated with many techniques (Esposito et al., 2018; Halls et al., 2018; Kromer et al., 2017; Kulawiak and Chybicki, 2018). In some cases this enables data to be processed at the rate of acquisition (Williams et al., 2018). Ultimately, the techniques adopted for use should be dictated by the nature of the coastline, the phenomena monitored and level of detail required (Westoby et al., 2018).

\subsubsection{Coastal terrain data acquisition}

There are a wide range of data capture methods available, for surveying coastal areas; a clear distinguishing factor between these is the means of their deployment: airborne, ground or vessel based. Airborne techniques benefit from their ability to cover large areas and to gain coverage of otherwise difficult or inaccessible locations (Earlie et al., 2015; Young, 2018), conversely they are hampered by drawbacks such as a decline in accuracy as the inclination of the terrain surveyed increases (Obu et al., 2017; Young et al., 2010; Young and Ashford, 2006). Additional limitations can be imposed on the use of satellite data by inconsistencies generated by rapid changes in coastal topography (Hobbs, 2008). Terrestrial laser scanning (TLS) methods and ground-based photogrammetric methods are more capable of capturing details on vertical cliff faces at higher resolution, with some allowing $10 \mathrm{~cm}$ gridding of data (Sergeev et al., 2018). However, these approaches can suffer drawbacks associated with shadowing (occlusions) when used to survey complex cliff faces, due to scanning angles (Hobbs et al., 2010). Mobile laser scanning (MLS), undertaken from moving platforms such as boats, can partially overcome these issues, with multiple angles used to observe given points (Leyland et al., 2017; Lindenbergh and Pietrzyk, 2015; Michoud et al., 2015). Methods that generate dense point clouds are generally capable of producing more comprehensive representations of topography and bathymetry than more sparse data acquisition methods, such as GPS surveys, beach transects, and single-beam sonar surveys. Such methods can require extensive interpolation to address large areas that lack coverage (Shrestha et al., 2005). There are benefits that can arise in combining methods, for example, surfaces derived from laser scanning techniques are frequently and usefully ground-truthed using GPS transect data (Halls et al., 2018; Kaliraj et al., 2017; Pollard et al., 2019; Shrestha et al., 2005; White and Wang, 2003).

\subsubsection{Geomorphological Change Detection (GCD)}

Depending on which data acquisition method is employed, varying levels of complexity and interpolation are required to enable change analyses to be completed. A common option for GCD involves the use of shoreline transects (Burningham and French, 2011; Environment 
Agency, 2013; Gorman et al., 1998; Halls et al., 2018; Obu et al., 2017). These transects represent 2D beach and cliff profiles, generated through GPS surveys or derived from surfaces extracted from raw survey data i.e. digital elevation models (DEM) (Eisemann et al., 2018). However, high levels of uncertainty are inherent in the calculations derived through this method, as surface heights between transects are interpolated, and are often derived by multiplying profile end areas by the transect separation distance (Cantrill and Kruimel, 2013; Corbí et al., 2018; Shrestha et al., 2005). Nevertheless, transect-based methods are still frequently used in many studies and by coastal management bodies (especially for cliff retreat calculations (Young, 2018)); they have also been combined with methods such as linear regression (Appeaning Addo et al., 2008). One change comparison method (both 2D distance and volumetric) which can be used with both transect-based calculations and those involving surfaces, requires construction of a planar reference surface (or a geometric primitive) (Lindenbergh and Pietrzyk, 2015). Estimates of change are then derived by comparing the distances between survey points and the planar surface (for different epochs), along a static vector (either a horizontal or vertical distance) (Figure 1).

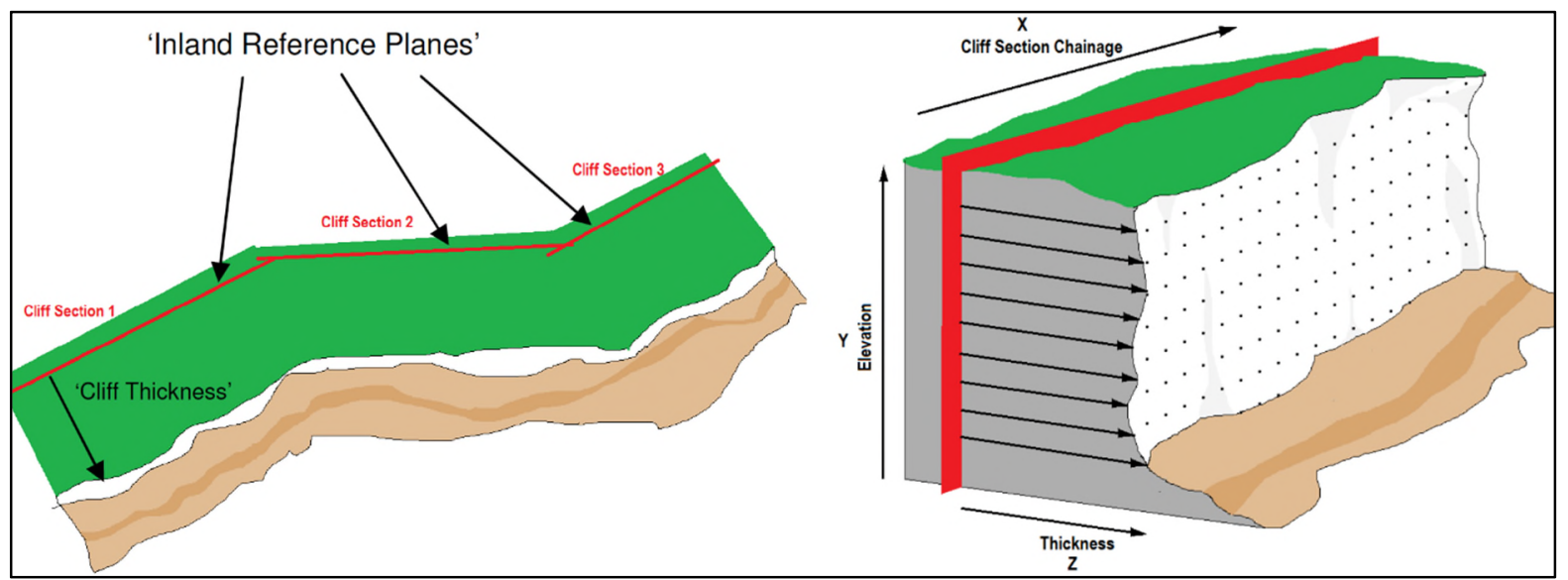

Figure 1: Planar change comparison method along a horizontal vector (image reproduced with permission from the Channel Coastal Observatory (2016))

If DEMs or topographical meshes are created from survey data, then direct comparisons can be made between surfaces (for different epochs), either by using the reference plane method, or more directly by simply subtracting elevation values of one surface from the other (Abellán et al., 2014; Mitasova et al., 2002; Sergeev et al., 2018). Volume calculations are derived through a summation of the change values of all pixels (or cells) within a given area of interest (Kemp and Brampton, 2007; Obu et al., 2017; Zhou and Xie, 2009). This can reveal a 'mosaic of morphological change' (Williams, 2012), and can also allow calculation of cliff recession rates (Esposito et al., 2018). This kind of GCD method is imperfect yet is widely used and reliable (Earlie et al., 2015). Variations of this technique have been termed DEM of Difference (DoD) (Williams, 2012).

\subsubsection{Surface creation}

Most contemporary studies involving GCD for the coast involve some form of DEM creation. Therefore, understanding the options for, and processes involved in DEM creation is important. Converting an irregular cloud of data points into a cohesive surface is not straightforward and requires interpolation. This can involve creation of a regularly spaced raster grid. For coastal GCD, some common methods used for this include: nearest neighbour 
(Michoud et al., 2015), kriging (Quinn and Boland, 2010), splining (Mitasova et al., 2009), linear interpolation (Eisemann et al., 2018), inverse distance weighting (IDW) (Halls et al., 2018), and more software-specific methods such as 'Topo to Raster' (in ArcGIS) (Burningham and French, 2011; Esposito et al., 2018), or CUBE ${ }^{2}$ in Caris HIPS/SIPS (Calder, 2003; Schimel et al., 2015). Alternatively, DEMs can be formed from vector-based representations such as TIN models (Amaro et al., 2015). TINs have been termed the 'most common and reliable form of representing high-resolution topographic data' (Wheaton et al., 2010, p.152) and have proven popular in coastal studies as the precision of the input data is preserved. TIN models incorporate the original data points, limiting interpolation to areas between these (Aragonés et al., 2016; Dawson and Smithers, 2010). This method encompasses 'modelling the surface as a collection of small (triangular) planes' (Cantrill and Kruimel, 2013) and can account for irregular and complex geometries, and micro-topographical irregularities (Krolik-Root et al., 2015), for which a regular gridded surface proves inadequate. TIN models can also prove beneficial in allowing complex topographic surfaces with varying levels of spatial variability to be described (Gorman et al., 1998). Yet problems can be encountered where data is lacking, and where oversized polygons are created (Hobbs et al., 2010), and misrepresentation errors can contribute to surface uncertainty (Wheaton et al., 2010). Aside from DEMs, another popular surface creation method is meshing, being most commonly applied to vertical cliff faces (Rosser et al., 2005). Meshing also involves interpolation between points, but irregular meshes can allow varying levels of resolution in surfaces, thus being able to capture more complex morphologies and geometries (Zischg et al., 2018).

Analysis of DEMs using DoD was quoted to be the most popular method for point cloud comparison in earth sciences (Lague et al., 2013). Yet despite the method's popularity it holds a number of drawbacks, such as high levels of interpolation, and artefacts can be generated through the creation of surfaces (Kromer et al., 2015). It is inadequate for application to rough surfaces and ultimately the technique is not 3D (Lague et al., 2013). It can be termed '2.5D', in that only a single height value is represented in the z-coordinate plane (Williams, 2012). This can introduce bias when attempting to represent complex vertical surfaces such as overhangs (Lague et al., 2013). Tracking surface change along a static vector (which the DoD methods involve) is also regarded by Mitasova (2015) as simplistic, in that it fails to 'capture the complexity of elevation surface dynamics' such as movements which combine both vertical and horizontal components.

\subsubsection{Point cloud data}

For more comprehensive 3D analytics it is necessary to consider $\mathrm{C} 2 \mathrm{C}$ comparisons, using point cloud data which has not been triangulated, meshed or gridded. Consequently, analysis is not restricted to planar comparisons. C2C comparisons can overcome many uncertainties and inaccuracies introduced by triangulation/meshing/gridding. Using cloud-based techniques, it is possible to register vertical and overhang components of cliffs. Additionally options exist for calculating slope-dependent change vectors, or surface normals, for comparisons (Kromer et al., 2017). This can result in efficiency gains through the correct points being compared between two point clouds (Williams et al., 2018). This method is particularly suited to rough

\footnotetext{
2 CUBE: Combined Uncertainty and Bathymetric Estimator
} 
surfaces and complex geometries, where an assumption that all changes take place in the same direction can be a gross simplification, misrepresenting reality. Continual progress is being made in relation to point cloud comparison methods and novel workflows and algorithms have been devised for GCD, such as M3C2 (Multiscale Model to Model Cloud Comparison) (Lague et al., 2013). The M3C2 algorithm, first estimates surface normals (detects change orientation) then generates mean surface change distances along normal directions (including an uncertainty component), and 'assigns a level of significance to calculated changes' (Leyland et al., 2017). A number of adaptations of M3C2 (Kromer et al., 2015; Williams et al., 2018), and similar methods (Abellán et al., 2014), have been implemented in studies centring on GCD. A typical application of this type of method is where small detailed changes/deformations need to be monitored.

\subsubsection{Inconsistencies and errors}

In calculating coastal change, high levels of uncertainty are inherent in the methods used. However, in many studies, errors appear to be overlooked (Abellán et al., 2014). This is especially so where more simplistic, manual approaches are employed. Yet errors can act as 'the main controlling factor in the ability to detect change' (Kromer et al., 2015). As such, for change estimates to be reliable, it is important to differentiate actual geomorphic change from that generated by errors (Williams, 2012). Errors can arise through a variety of means, including: data collection methods, processing techniques, surface type, surface roughness, vegetation, variability in point density, atmospheric conditions, incidence angle, heterogeneity of point spacing, topographic complexity (Kromer et al., 2017, 2015; Williams, 2012), and (mis)registration of the surfaces compared (Miller et al., 2008). The use of remote techniques such as Lidar can necessitate establishing a minimum threshold for errors, which may thereby increase confidence in consequent change estimates (Young et al., 2010). As such, many GCD methods can involve establishment and application of volumetric confidence intervals, as well as minimum threshold values for change detection (Abellán et al., 2014). Such threshold values can be termed the limit of detection (LoD), whereby changes smaller than the LoD are discounted as they could be attributed to system errors or noise (Schimel et al., 2015). Threshold methods such as the LoD approach are not perfect solutions. There is a danger in applying LoD methods (as other error accounting techniques) of removing too much data, which can result in eliminating real geomorphological change, and potentially important features (Young, 2018; Young et al., 2010). As such, careful consideration is required in the selection of appropriate techniques. For example, for DoD methods, probabilistic approaches are reported to generate more reliable estimates than those based on LoD alone (Williams, 2012). For some DoD methods, uncertainties and errors are accounted for directly within calculations. For example, Wheaton et al. (2010) have developed a technique to account for errors that involves a 'fuzzy inference system' ${ }^{3}$, addressing spatially variable uncertainties (related to differing slope, point density, and point quality across a comparison area). LoD calculation are also regarded by Williams et al. (2018) to be improved through using 3D point cloud methods and by techniques allowing spatially variable confidence intervals (Kromer et al., 2017). Moreover the M3C2 algorithm (and other similar methods) directly integrates an error component within its calculations (Lague et al., 2013).

\footnotetext{
${ }^{3}$ This technique is freely available for download and has been utilised within this study.
} 


\subsubsection{Temporal resolution of data}

The ability to detect spatial patterns of coastal terrain evolution is directly influenced by how frequently surveys are undertaken (Mitasova et al., 2009). Generally, for change analysis to represent dynamic coastal processes more accurately, frequent monitoring is required. This can provide a 'methodological understanding' of change mechanisms (Rosser et al., 2005). A number of studies have successfully revealed change processes and drivers through comparison and modelling of near-continuous, high temporal resolution data (Rosser et al., 2013; Williams et al., 2018). This would be difficult to establish, with any degree of certainty, through isolated surveys, each providing no indication of change between survey epochs (Kemp and Brampton, 2007). Additionally data collected infrequently can be unrepresentative, due to it being prone to bias introduced as a result of specific events, such as those resulting from severe weather which can, for example, introduce temporary objects (Lindenbergh and Pietrzyk, 2015; Obu et al., 2017). As such, the separation between survey epochs is an important consideration. Short term variability is not captured when comparing datasets representing distant epochs. This can lead to simplification of complex geomorphological behaviour and change patterns being wrongly interpreted as episodic (Rosser et al., 2013). There are a range of novel interpretation and visualisation techniques which can be employed to represent dynamic changes, derived through comparison of high temporal resolution datasets. For example, variable spatio-temporal stability can be revealed through multi-temporal, per-cell, raster statistics (Mitasova et al., 2009) or creation of isosurfaces, used to sum elevation changes across multiple periods (Mitasova, 2015).

\subsubsection{GCD technique selection}

The requirements for GCDs depend on the phenomena being monitored and can range from the need to establish general trends of long term 2D coastal change, to high spatial and temporal resolution 3D morphological monitoring of cliff faces, revealing, for example, individual rock fall events. For monitoring large and obvious changes, simpler, more efficient methods can be used (Lindenbergh and Pietrzyk, 2015). Yet if granular details need to be focused on, precise in-situ measurement techniques can be required (Ganju et al., 2017), necessitating more complex workflows (Williams et al., 2018). In such cases, more simplistic, commonly used methods can generate errors larger than the changes or rates of retreat being measured (Ganju et al., 2017; Rosser et al., 2005). Table 1 provides an overview of the various GCD methods discussed. Ultimately though, the method selected is dependent on what datasets are already available, or can be acquired.

Many organisations responsible for managing risk in coastal areas, have been concerned primarily with generalised linear erosion rates, so have settled for basic level change comparisons centred on visual interpretation of aerial images and digitised shorelines (Stanley and Staley, 2017), and beach profile comparisons based on GPS transects (Environment Agency, 2013). In such cases, shifting to an approach deriving linear retreat rates from comparisons of DEM surfaces, such as DoD (Williams, 2012), can offer clear improvements over existing methods. In many other instances, linear retreat or analyses of change limited to one plane or vector is inadequate, particularly where small changes need to be monitored in areas of complex geometry. Furthermore, where causation of change is sought, this level of abstraction may over-simplify complex changes. In such instances, high temporal and spatial resolution C2C techniques are more applicable (Kromer et al., 2015), and can permit change detection based on dynamic surface normals, as opposed to static 
vectors. The scale at which changes must be monitored, also imposes restraints on GCD method selection. It may not be adequate to focus on change in one location for example, so scanning methods generating high-resolution point clouds, may not be feasible, and lower resolution techniques based on surface creation may be more appropriate.

This study seeks to address the coastal GCD requirements of a broad range of the stakeholder parties who wish to model such heterogeneous phenomena. However, the study is limited in scope, so focuses on a single aspect of GCD. Based on feedback received from coastal practitioners ${ }^{4}$, in which their most immediate requirements and current challenges were outlined, a decision was made to focus on broad-scale general trends of morphological change. Previously reported change analyses for East Anglia have mainly focussed on linear change estimates, largely neglecting quantification of loss/gain of coastal material (Environment Agency, 2013, 2012, 2011). Yet many past studies for the region have highlighted the importance of deriving quantitative estimates of sediment budgets (Brooks and Spencer, 2010; Burningham and French, 2016). Recent analysis undertaken for East Anglia also outlines a requirement for future incorporation of volumetric analysis based on Lidar datasets (Stanley and Staley, 2017). The 14 case study sites we selected, contain varying morphological characteristics. Given this, linear change analysis was not deemed suitable by the authors, to adequately capture the diverse morphological processes operating within all study sites (not all of which were characterised by net coastal erosion). A generalised method was required, allowing quantification of net material gain or loss at each location, over multiple epochs. Therefore, for this study a decision was made to focus on the calculation of volumetric change, and based on the criteria detailed in Table 1, a TIN-based differencing, surface comparison method was selected (Cove and Lavoie, 2007). This involves calculation of surface volumes, based on elevation relative to a uniform planar surface. Prior to the selection of this method a number of other options were trialled, for example, those based on regular gridded raster surface creation, as described in Cantrill and Kruimel (2013). The method selected was considered the most suitable, given the nature of the terrain being modelled (generally complex, including steep surfaces), the data types being used (mainly airborne Lidar), and the irregular spacing of data points. The TIN models retained the original elevation at data points, thus minimising interpolation and smoothing, in which actual features could be misinterpreted as noise and so be lost from the analysis.

\footnotetext{
${ }^{4}$ Feedback was received from members of Coastal Partnership East (UK), the Environment Agency, and members of the Anglian Coastal Monitoring Group.
} 
Table 1: Comparison of GCD methods

\begin{tabular}{|c|c|c|c|c|}
\hline Type of GCD & Method & Benefits & Drawbacks & Area of Application \\
\hline \multirow[t]{2}{*}{$\begin{array}{l}\text { Manual } \\
\text { Interpretation / } \\
\text { Digitisation }\end{array}$} & $\begin{array}{l}\text { 2D linear retreat } \\
\text { derived from aerial } \\
\text { images/maps }\end{array}$ & $\begin{array}{l}\text { Simple method. Not reliant on point } \\
\text { cloud data being available; can be } \\
\text { applied to topographic maps/aerial } \\
\text { imagery. Easily applied at varying spatial } \\
\text { scales. }\end{array}$ & $\begin{array}{l}\text { High levels of interpolation required. } \\
\text { Reliant on the skills of the operator. } \\
\text { Error prone at high temporal resolution. } \\
\text { No options for volumetric change } \\
\text { calculation. }\end{array}$ & $\begin{array}{l}\text { Where large obvious changes are } \\
\text { present and general trends } \\
\text { required. Wide scale linear trend } \\
\text { identification. }\end{array}$ \\
\hline & $\begin{array}{l}\text { Linear retreat } \\
\text { derived from } \\
\text { profiles/transects }\end{array}$ & $\begin{array}{l}\text { Volumetric change can be obtained } \\
\text { through interpolation between } \\
\text { transects. Can be based on GPS surveys. } \\
\text { Simple. }\end{array}$ & $\begin{array}{l}\text { Incomplete representation of coastal } \\
\text { areas. Interpolation of data points } \\
\text { between transects reduces accuracy. }\end{array}$ & $\begin{array}{l}\text { General long-term trends of coastal } \\
\text { erosion/accretion. }\end{array}$ \\
\hline \multirow[t]{3}{*}{$\begin{array}{l}\text { Surface } \\
\text { Comparison }\end{array}$} & $\begin{array}{l}\text { DEM of Difference } \\
\text { (DoD) }\end{array}$ & $\begin{array}{l}\text { Most popular and commonly used } \\
\text { method. Simple. Variants allow error } \\
\text { terms to be incorporated in calculations. } \\
\text { DoD surfaces can provide visualisation of } \\
\text { change/qualitative outputs, in addition } \\
\text { to quantitative results. }\end{array}$ & $\begin{array}{l}\text { Comparing data for multiple epochs can } \\
\text { be time consuming and error prone. Not } \\
\text { suitable for vertical cliff face } \\
\text { comparisons. Interpolation required for } \\
\text { surface creation, thus artefacts can be } \\
\text { generated, or real data points } \\
\text { misinterpreted as noise. Not a 3D method } \\
\text { (2.5D), limited to only one elevation value } \\
\text { per raster grid cell. }\end{array}$ & $\begin{array}{l}\text { Beach level comparison, where } \\
\text { simple geometry is present. } \\
\text { Qualitative identification of } \\
\text { patterns of sediment movement. } \\
\text { More suited to a limited number of } \\
\text { epochs. For aerial and subsea } \\
\text { survey datasets. Capable of } \\
\text { application at larger spatial scales. }\end{array}$ \\
\hline & $\begin{array}{l}\text { TIN to TIN } \\
\text { Comparison }\end{array}$ & $\begin{array}{l}\text { TINs account for irregular and complex } \\
\text { geometries, and micro-topographical } \\
\text { irregularities. Original data points } \\
\text { preserved within calculations. Difference } \\
\text { surfaces can provide visualisation of } \\
\text { change. TINs are suitable where spatial } \\
\text { variability of point density is present. }\end{array}$ & $\begin{array}{l}\text { Comparing data for multiple epochs can } \\
\text { be time consuming and error prone. } \\
\text { Limitations imposed on the size of } \\
\text { datasets/number of data points which } \\
\text { can be used in TINs. TINs can be } \\
\text { problematic where there are data gaps } \\
\text { (occlusions). }\end{array}$ & $\begin{array}{l}\text { Suitable for modelling complex } \\
\text { topographic surfaces with varying } \\
\text { levels of spatial variability. Suited to } \\
\text { aerial and subsea survey methods. }\end{array}$ \\
\hline & $\begin{array}{l}\text { Planar Comparison } \\
\text { (TIN/DEM) }\end{array}$ & $\begin{array}{l}\text { Comparison not limited to vertical } \\
\text { change vectors, can use horizontal, } \\
\text { inclined and vertical reference planes. } \\
\text { Distinct volumes obtained for each } \\
\text { epoch; easy to compare data for multiple } \\
\text { epochs. For TINs, the benefits listed } \\
\text { above also apply. }\end{array}$ & $\begin{array}{l}\text { Change analysis along a static vector fails } \\
\text { to capture the complexity of elevation } \\
\text { surface dynamics, and movements which } \\
\text { combine vertical and horizontal } \\
\text { components. Limited to quantitative } \\
\text { outputs. For TINs, the drawbacks listed } \\
\text { above also apply. }\end{array}$ & $\begin{array}{l}\text { Can handle the datasets generated } \\
\text { from survey techniques with a } \\
\text { horizontal aspect (TLS/MLS). Can be } \\
\text { applied where a high number of } \\
\text { epochs are to be compared. Suited } \\
\text { to aerial and subsea survey } \\
\text { methods. }\end{array}$ \\
\hline
\end{tabular}




\begin{tabular}{|c|c|c|c|c|}
\hline & $\begin{array}{l}\text { Mesh Comparison } \\
\text { (Planar/direct) }\end{array}$ & $\begin{array}{l}\text { Can allow varying levels of resolution in } \\
\text { surfaces to be compared; able to capture } \\
\text { complex morphologies and geometries. } \\
\text { Suitable for high density point clouds. }\end{array}$ & $\begin{array}{l}\text { Interpolation required in surface creation. } \\
\text { Time consuming. Limitations on scale of } \\
\text { application. }\end{array}$ & $\begin{array}{l}\text { For vertical and inclined cliff faces. } \\
\text { Higher resolution data. } \\
\text { Identification of smaller changes } \\
\text { over multiple periods. Localised } \\
\text { scale. }\end{array}$ \\
\hline \multirow[t]{2}{*}{$\begin{array}{l}\text { Cloud to Cloud } \\
\text { (C2C) } \\
\text { Comparison }\end{array}$} & Static Vector & $\begin{array}{l}\text { Lower levels of interpolation due to } \\
\text { change estimates based on original data } \\
\text { points. Simpler and quicker to restrict } \\
\text { change to one vector. More suited to 3D } \\
\text { analysis than surface-based techniques, } \\
\text { can overcome many uncertainties and } \\
\text { inaccuracies introduced by } \\
\text { meshing/gridding. Many options for the } \\
\text { orientation of the static change vector. }\end{array}$ & $\begin{array}{l}\text { Drawbacks associated with using a static } \\
\text { change vector. Limitations on spatial scale } \\
\text { of application. High density datasets } \\
\text { required. Method required to account for } \\
\text { any gaps between data points. }\end{array}$ & $\begin{array}{l}\text { Where detailed linear retreat } \\
\text { estimates are. }\end{array}$ \\
\hline & Surface Normals & $\begin{array}{l}\text { Method permits comprehensive error } \\
\text { accounting. Direction of change given, } \\
\text { more complete picture of change; } \\
\text { efficiency gains through the correct } \\
\text { points being compared between two } \\
\text { point clouds. Potentially, lowest level of } \\
\text { interpolation of all methods. The fact } \\
\text { that changes occur in multiple directions } \\
\text { is also accounted for. }\end{array}$ & $\begin{array}{l}\text { Requires high density point cloud data. } \\
\text { User expertise requirements for } \\
\text { application. Limitations of spatial scale of } \\
\text { application. High computation power } \\
\text { requirements, potentially due to larger } \\
\text { datasets. }\end{array}$ & $\begin{array}{l}\text { Optimal method for precise } \\
\text { quantification of erosion at a } \\
\text { localised scale; monitoring of } \\
\text { granular deformations such as that } \\
\text { in hard rock cliffs. Suitable for } \\
\text { determination of change causation, } \\
\text { rough surfaces and complex } \\
\text { geometries. Can be used to reveal } \\
\text { individual rock fall events. }\end{array}$ \\
\hline
\end{tabular}




\subsection{Methods}

\subsubsection{Application of a GCD technique to the case study region}

The 14 case study sites encompassed over $24 \mathrm{~km}$ of coastline (Figure 2). The sites are widely distributed across the region, and each site contained unique features in terms of coastal change parameters, erosion/accretion methods, geology and vulnerability characteristics. Table 2 lists the case study sites with their rationale for selection and the datasets obtained for each site.

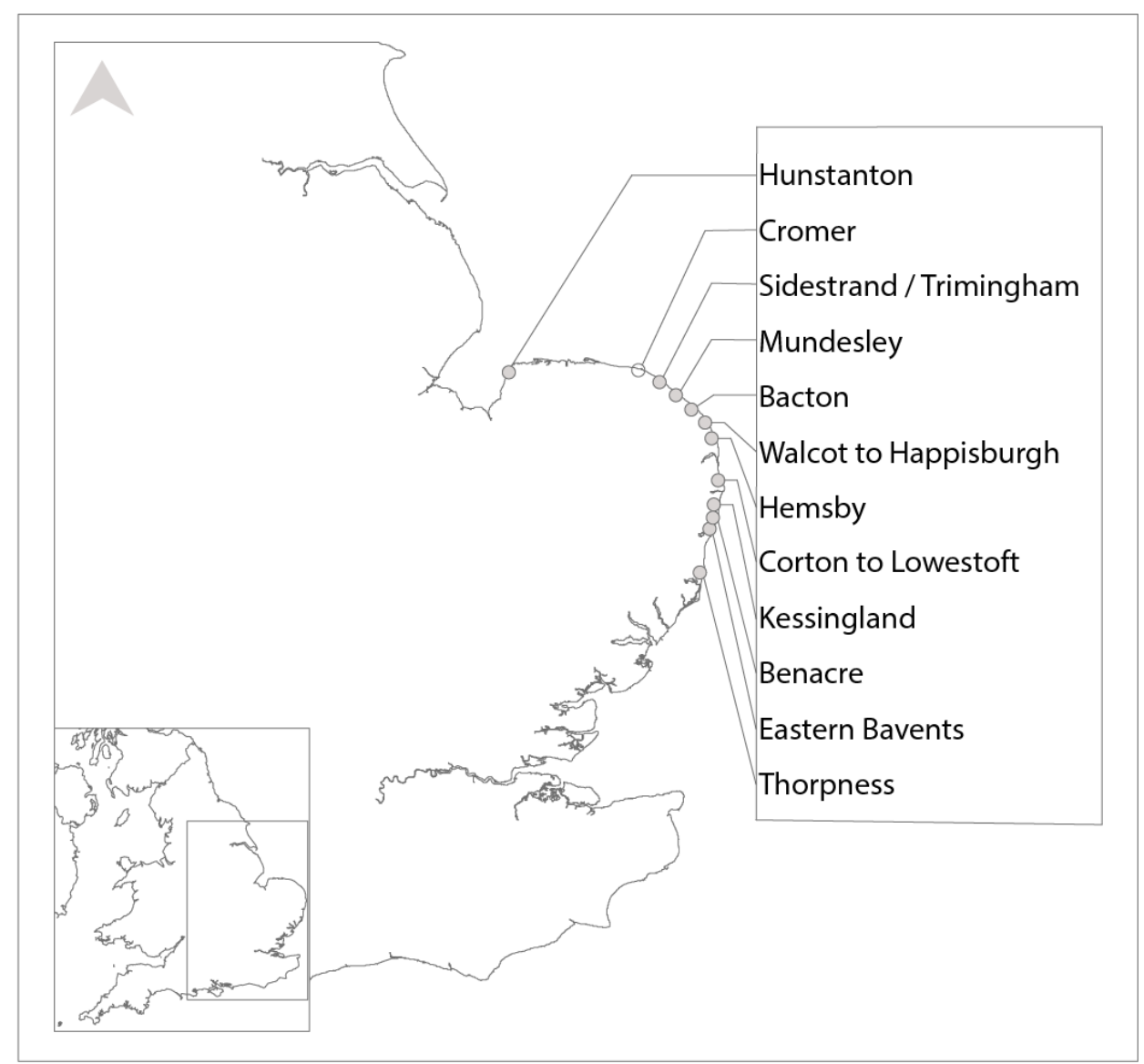

Figure 2: Location of study sites 
Table 2: Case study sites

\begin{tabular}{|c|c|c|}
\hline Location & Reason for Selection & $\begin{array}{l}\text { Datasets Obtained (collection } \\
\text { method and epochs) }\end{array}$ \\
\hline $\begin{array}{l}\text { Hunstanton North \& } \\
\text { Hunstanton South }\end{array}$ & Rapid erosion of vertical cliff faces. & $\begin{array}{l}\text { Lidar:2008, 11, 12, 13, 14, 15, 16, } 17 \\
\text { TLS: 2012, } 17\end{array}$ \\
\hline Cromer & $\begin{array}{l}\text { Partially defended coast. Eroding } \\
\text { chalk cliffs fronted by sand and } \\
\text { shingle beach. }\end{array}$ & Lidar: 2008, 11, 12, 13, 14, 15, 17, 18 \\
\hline Sidestrand to Trimingham & $\begin{array}{l}\text { Undefended. Complex landslide, } \\
\text { erosion, unpredictable, better } \\
\text { information on erosion rates } \\
\text { needed. }\end{array}$ & $\begin{array}{l}\text { Lidar: } 2008,11,12,13,14,15,17,18 \\
\text { TLS: } 2000,01,02,03,04,05,06,07 \\
16\end{array}$ \\
\hline Mundesley & High water erosion trends. & Lidar: $2011,12,13,14,15,17,18$ \\
\hline Bacton Gas Terminal & $\begin{array}{l}\text { Eroding coast, property (critical } \\
\text { national infrastructure) at risk. }\end{array}$ & Lidar: $2011,12,13,14,15,17,18$ \\
\hline Walcot to Happisburgh & $\begin{array}{l}\text { Complex landslides. } \\
\text { Walcott - entire cliff encased in } \\
\text { concrete. High erosion rates; } \\
\text { partially defended; one of the few } \\
\text { sites in the world where coastal } \\
\text { defences have been removed and } \\
\text { policy has shifted from 'Hold the } \\
\text { Line' to 'Managed Retreat'. }\end{array}$ & $\begin{array}{l}\text { Lidar: } 2008,09,12,13,14,15,16,17 \\
18 \\
\text { TLS: } 2001,02,03,04,05,06,07,09 \\
11,16\end{array}$ \\
\hline Hemsby & $\begin{array}{l}\text { Rapid erosion events resulting in } \\
\text { houses collapsing into the sea. }\end{array}$ & $\begin{array}{l}\text { Lidar: } 2009,12,13,15,16,18 \\
\text { MBES, Full Coverage: } 2005,11 \\
\text { Offshore only: } 1990,92,93,94,96, \\
98,99 ; \\
2000,01,02,03,04,07,11,12,13,15\end{array}$ \\
\hline $\begin{array}{l}\text { Corton to Lowestoft \& } \\
\text { Lowestoft Nearshore }\end{array}$ & $\begin{array}{l}\text { Sandy coast, simple failure } \\
\text { mechanism, rapid erosion. }\end{array}$ & $\begin{array}{l}\text { Lidar: } 2008,09,11,12,13,14,15,16, \\
17 \\
\text { MBES: } 1991,92,93,94,96,97,98,99, \\
2000,01,02,03,04,05,07,08,09, \\
10,11,13,15\end{array}$ \\
\hline Kessingland & High erosion rates. & Lidar: $2008,11,12,13,14,15,16,17$ \\
\hline Benacre & $\begin{array}{l}\text { High erosion rates, complex } \\
\text { processes related to migration of } \\
\text { the 'Ness'. }\end{array}$ & Lidar: $2008,11,12,13,14,15,16,17$ \\
\hline Easton Bavents & $\begin{array}{l}\text { Cliff eroding rapidly north of } \\
\text { properties. }\end{array}$ & Lidar: 2008, 11, 12, 13, 14, 15, 16, 17 \\
\hline Thorpness & Defences crumbling, public hazard. & Lidar: $2008,11,12,13,14,15,16,17$ \\
\hline
\end{tabular}

As with other similar contemporary studies, this study is made possible due to the extensive quantities of available open source ${ }^{5}$ coastal datasets (Rumson and Hallett, 2018): bathymetric data was obtained from the UKHO${ }^{6}$; Lidar, TLS and limited bathymetry was obtained from the $\mathrm{EA}^{7}$; and, TLS data was provided by BGS. From the large quantity of seabed data for the region obtained from the UKHO, only two locations had repeat bathymetry data available for multiple epochs in areas sufficiently close to the coastline to warrant inclusion in the subsequent analysis. These locations being in the nearshore areas close to Lowestoft and Hemsby. The horizontal coordinate system used throughout this study was OSGB 1936, and

\footnotetext{
${ }^{5}$ Much of the Open Source data utilised has been made available to the public following a successful 2015 DEFRA initiative to place environmental datasets in the public domain (GOV.UK, 2017).

${ }^{6}$ Data Source: http://aws2.caris.com/ukho/mapViewer/map.action

${ }^{7}$ Data Source: https://data.gov.uk/publisher/environment-agency
} 
the ODN (Ordnance Datum Newlyn) vertical datum. Topographic data required no transformation, whilst bathymetric data was supplied in WGS 84 coordinates and was transformed to OSGB 1936. The main datasets used in this study were EA Lidar, for these the data acquisition dates used for each year are given within 1.8.1 Appendix 4.1.

\subsubsection{Software selection}

A wide range of software, tools, add-ins and toolboxes are available for GCD. In many instances, the methods selected for generating change models in previous studies are a consequence of the options within the available software packages (Hobbs et al., 2010). A common method used in many studies is GIS data analysis (Esposito et al., 2018; Jackson et al., 2012; Mitasova, 2015; Sergeev et al., 2018). Within GIS packages, tailored products are being developed. These can involve the creation of bespoke scripts, and can draw on software specific functionality such as ArcGIS Model Builder (Halls et al., 2018; Zhou and Xie, 2009) or Caris Process Designer (Foster et al., 2017). However, GIS is not suitable for point cloud comparison. It is common for $\mathrm{C} 2 \mathrm{C}$ comparisons to involve the use of tailored scripts and task specific algorithms; many past studies have utilised Matlab for this (Kromer et al., 2017; Michoud et al., 2015; Williams et al., 2018). Examples of software used for point cloud data based GCD include Polyworks (Michoud et al., 2015), Cyclone (Corbí et al., 2018), and CloudCompare (Corbí et al., 2018; Lague et al., 2013; Leyland et al., 2017). The M3C2 algorithm developed specifically for C2C comparisons (Section 1.2.5), now comes complete with the software CloudCompare, as a plugin ("M3C2 (Plugin)", 2018).

Although not widely utilised for this purpose, hydrographic software packages can also present opportunities for GCD analysis. A software tool produced by Teledyne Caris, termed Bathy DataBASE (BDB) has been identified as being particularly suitable, and was selected as the primary software tool utilised within this study. Caris BDB has been used previously for volumetric calculations of material removed from the seabed, such as that associated with dredging operations (Cantrill and Kruimel, 2013), and it is configured to work with a variety of terrestrial point cloud datasets and formats, in particular .laz and .las files (the format in which datasets used for this study were typically supplied). Preconfigured software functionality, such as that utilised for this study, can offer quick and efficient tools for completion of GCD. However, the software used did not provide options for including error accounting techniques within GCD calculations. Due to constraints on time and resources, and only general trends being sought, this limitation of the software functionality was deemed acceptable by the authors. However, efforts have been taken in the selection of methods within the workflow developed (Figure 3 ) to minimise error sources.

\subsubsection{Software methodology}

A workflow was developed in which a standardised series of operations were undertaken (Figure 3). 


\section{STEP 1: SOURCE DATA}

a. Obtain data for selected case study sites

b. Check adequate coverage for each site, for a minimum of 6 epochs

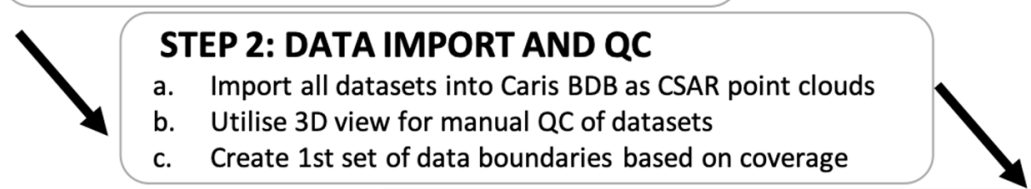

c. Create 1st set of data boundaries based on coverag

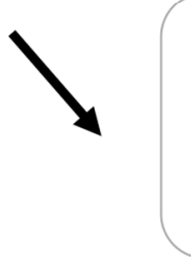

STEP 3: PRELIMINARY CHANGE ASSESSMENT

a. Within the boundaries, create surfaces for the first and last epochs, for each site

b. Complete basic DEM difference calculation for each site

c. 3D analyses of the difference surfaces allowing main areas of change to be identified

d. 2nd set of boundaries created based on change areas
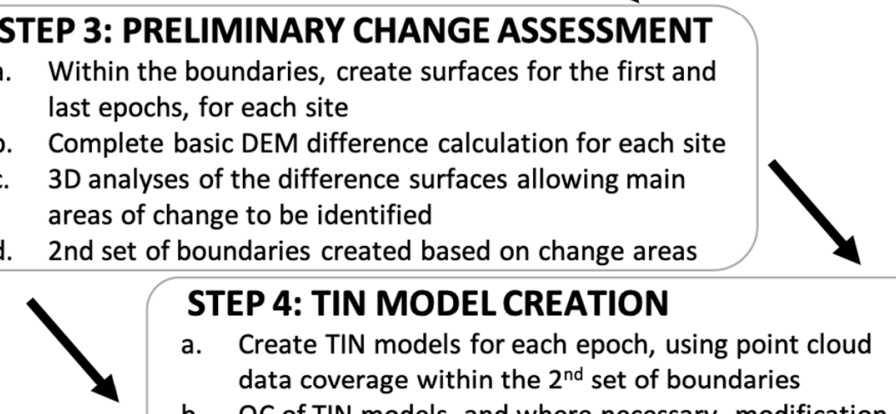

STEP 4: TIN MODEL CREATION

a. Create TIN models for each epoch, using point cloud data coverage within the $2^{\text {nd }}$ set of boundaries

b. QC of TIN models, and where necessary, modification of boundaries

\section{STEP 5: VOLUME CALCULATION}

a. Generate planar horizontal comparison surfaces from final boundaries

b. For each epoch at all sites, calculate TIN surface volumes above the respective planar surfaces

c. Verification of volumes obtained, through manual visual analysis of surfaces in 3D

Figure 3: Software workflow for volume calculations

\subsection{Software workflow}

\section{Step 1: Source Data}

Initially, datasets covering the entire coastline of East Anglia were obtained. From this, data for the selected test sites were extracted based on the corresponding Ordnance Survey (OS) grid cells for each area. The extent of data availability varied by site and by the data acquisition method used. The minimum time period for which data was available, for any site, was 7 years and 6 epochs.

\section{Step 2: Data import and QC}

Processed point cloud data was imported as .las, .pts, .csv, or .ascii file formats. This was converted into Caris' native .csar file format, which enabled the data to be compared visually, and for its coverage to be inspected. Initially, datasets for each case study area were imported in this manner into a BDB BASE Editor project. Data varied in resolution, quality and coverage by year. Therefore, it was necessary to undertake a visual inspection of datasets available for each site, prior to deciding which datasets/epochs would be used for comparison. The 3D viewing option in BASE Editor was utilised for this (Figure 4). When areas with adequate spatial coverage and resolution were identified, a first set of boundaries were created. These were used to extract a single point cloud dataset for each selected epoch. Initially datasets derived from airborne Lidar, TLS and MBES surveys were imported. Visual analysis of the data revealed that for most TLS datasets, large data occlusions (gaps) were present, which would necessitate extensive interpolation. Also, for many of the TLS datasets, coverage was only provided for limited areas, not the entire comparison areas selected. Due to this, a decision was made not to include the TLS datasets within the volumetric change calculations, as 
adequate coverage and data point density was provided by the majority of Lidar datasets. Section 1.2.2 highlighted how airborne Lidar provides inadequate point density for vertical cliff faces, yet among the case study areas, only a limited number of sites contained such vertical cliffs (the most prominent being Hunstanton). Of the two sites for which bathymetric datasets were available, the only site where there was adequate quality and coverage of data, over the required number of epochs, was Lowestoft. Therefore, a nearshore site at Lowestoft was the only location for volumetric comparisons based on MBES data.

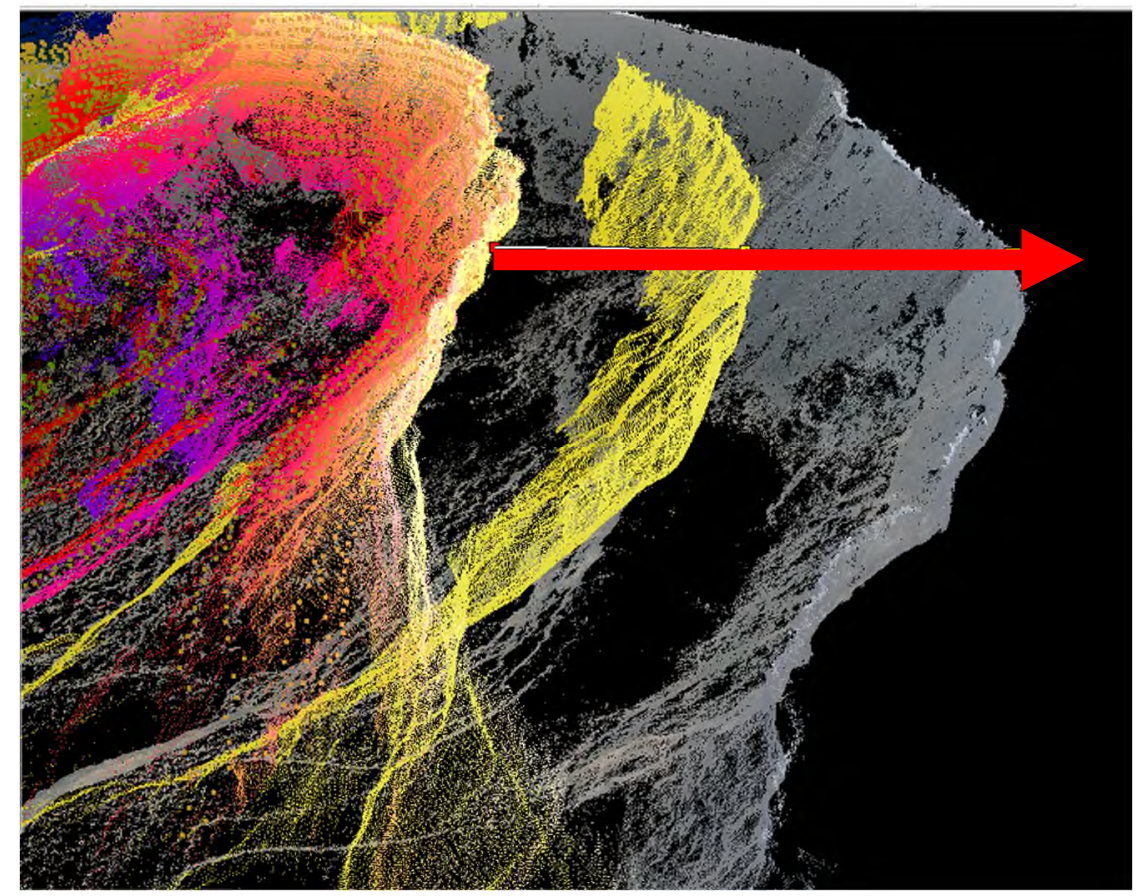

Figure 4: TLS dataset coverage/resolution comparison in BDB software, illustrating cliff retreat left to right (red arrow) for Sidestrand

\section{Step 3: Preliminary change assessment}

Using the extracted point cloud datasets, DEM surfaces were created for the first and last epoch for each site. A DEM differencing function in BDB was used to directly compare the two surfaces to generate a difference dataset. These datasets were displayed using a graduated colour schema based on elevation change, and represented change areas in 2.5D (Appendix 4.2). From this, the main areas of change and deformation could be determined. Subsequently, a second set of boundaries were created for each site, within which the main areas of change were included. Care was taken when creating boundaries to avoid including features which could generate errors in volume calculations. The resulting comparison areas formed a narrow band running along the high-water line for each site. The seaward limits of the boundaries ran as close to the coast as possible, so as to still include all areas of change identified. The reason for excluding obvious intertidal areas was that the Lidar datasets were obtained at different points within the tidal cycle for each area, so returns from the ocean surface could be misinterpreted as land and introduce errors within the calculations. The landward boundaries also did not extend far inland, past cliff edges. This minimised the inclusion of buildings, infrastructure, vegetation, and other error sources, within volume calculations. As a result, the coastline areas and lengths contained within comparison areas differ for each case study site (Table 5). 


\section{Step 4: TIN model creation}

For data to be compared within the BDB software, surfaces were created using TIN models. TINs were found to be the most reliable and accurate method for surface comparison, following experimentation with other methods such as gridded raster surfaces. Additionally, working directly with TINs bypassed errors associated with the process of resampling TINs onto a regular raster grid, to create DEMs (Wheaton et al., 2010). Using point cloud data contained within the second set of boundaries, TIN models were created for each epoch at every site. The TIN models were inspected visually to identify areas where data was lacking and where large triangles with long vertices were thereby created. In some cases, this related to areas of vegetation, missing data or other errors. Where possible and necessary, boundaries were altered to remove areas where excessive interpolation had been completed, and new TIN models were subsequently created. A software function was also utilised to remove triangles with long vertices, along the outer edges of the TIN models.

\section{Step 5: Volume Calculation}

Using the Engineering Analysis Module in the BDB software, horizontal planar surfaces were created using the final boundaries for each comparison area and stored as templates (Figure 5). The BDB Triangular Volume Calculation tool was used to calculate volumes between the TIN surfaces for each epoch and the associated reference surfaces. The height of all reference surfaces, used for comparison of topographic data, was set as $2 \mathrm{~m}$ below Mean Sea Level (MSL) with reference to ODN and for bathymetric data comparison, the reference surface height used was $10 \mathrm{~m}$ below MSL. Prior to volume calculation a visual check was made to ensure no data points fell below the reference surfaces. Volume estimates for each epoch were stored within a spreadsheet and used to calculate volume changes between sequential epochs, resulting from surface elevation changes (Section 1.4). Once change estimates were obtained, a manual quality control process was undertaken. This involved visual inspection of surfaces associated with irregular volume changes. This enabled errors or missing coverage that might bias the change results, to be identified. In some cases, this necessitated removing datasets from comparisons for certain epochs or altering comparison area boundaries and recreating the associated TIN models. Direct comparisons between TIN models were also completed for all areas, however, the results generated proved unreliable and inconsistent, so all volume calculations were thence made in relation to a fixed planar reference surface.

\subsection{Additional GCD Analysis Methods}

The main software functionality used in this study was that allowing calculation of volumetric change. However, a number of additional analytical and visualisation features in BDB software were tested, and these assisted in analyses of the large number of datasets utilised. Simple comparisons of DEM surfaces were completed through profile or transect creation (Figure 6). Additionally, where a specific focus was required on Top of Cliff or Base of Cliff, then these were calculated roughly using an automated process, within the software, which estimates their respective positions through analysis of surface gradients. Top/Base of cliff values were then compared for two or more epochs (Figure 7). This method bypasses requirements for manual digitisation, as do other recently developed techniques (Payo et al., 2018a). Within the BDB software there is also an option to complete volume calculations relative to a vertical or inclined reference plane. This functionality was tested and proved especially suitable to areas where vertical cliffs were present (Figure 5). However due to the heterogeneous nature of the morphology of the 14 case study sites, this method was 
unsuitable for adequately capturing adequately volume changes in all areas. As the main sources of data drawn upon were from airborne Lidar surveys, in which only 1 elevation point is recorded for each horizontal grid square, a 2.5D analysis method focusing on comparison of elevation changes was more appropriate. Furthermore, using the same comparison method at each site was more conducive to allowing direct comparisons of the results generated for sites across the region (such as those presented in Section 1.4).

A

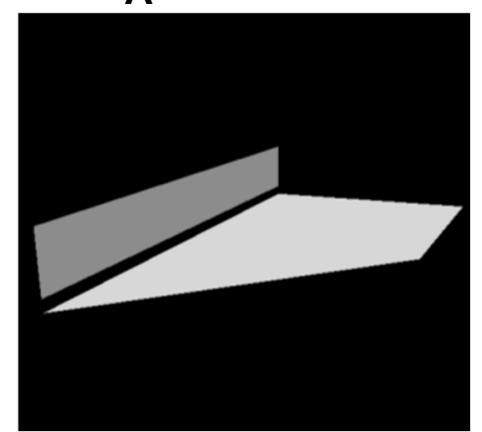

B

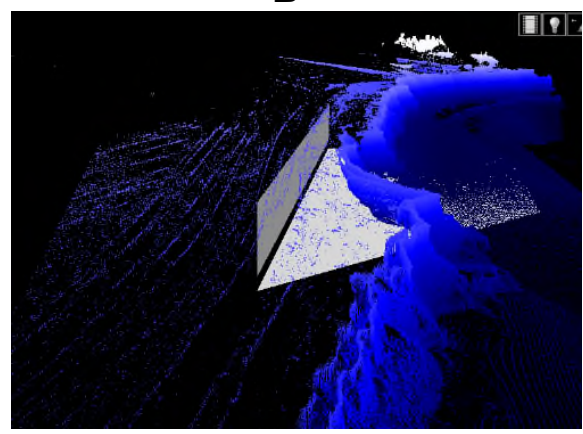

C

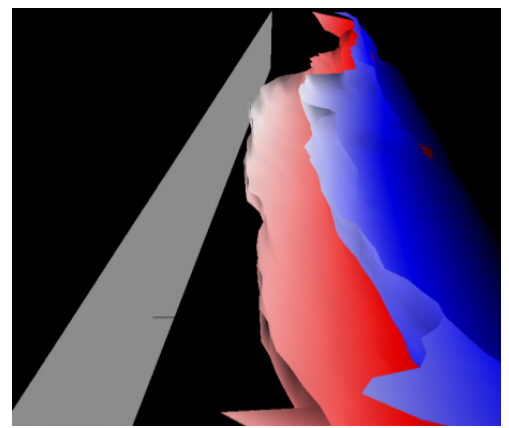

Figure 5: Planar Comparisons in Caris BDB including use of a vertical reference surface, for Happisburgh Case Study Site (A - reference surface creation; B - point cloud data for a single epoch superimposed over reference surface: C - surfaces for two epochs superimposed over a vertical reference surface).

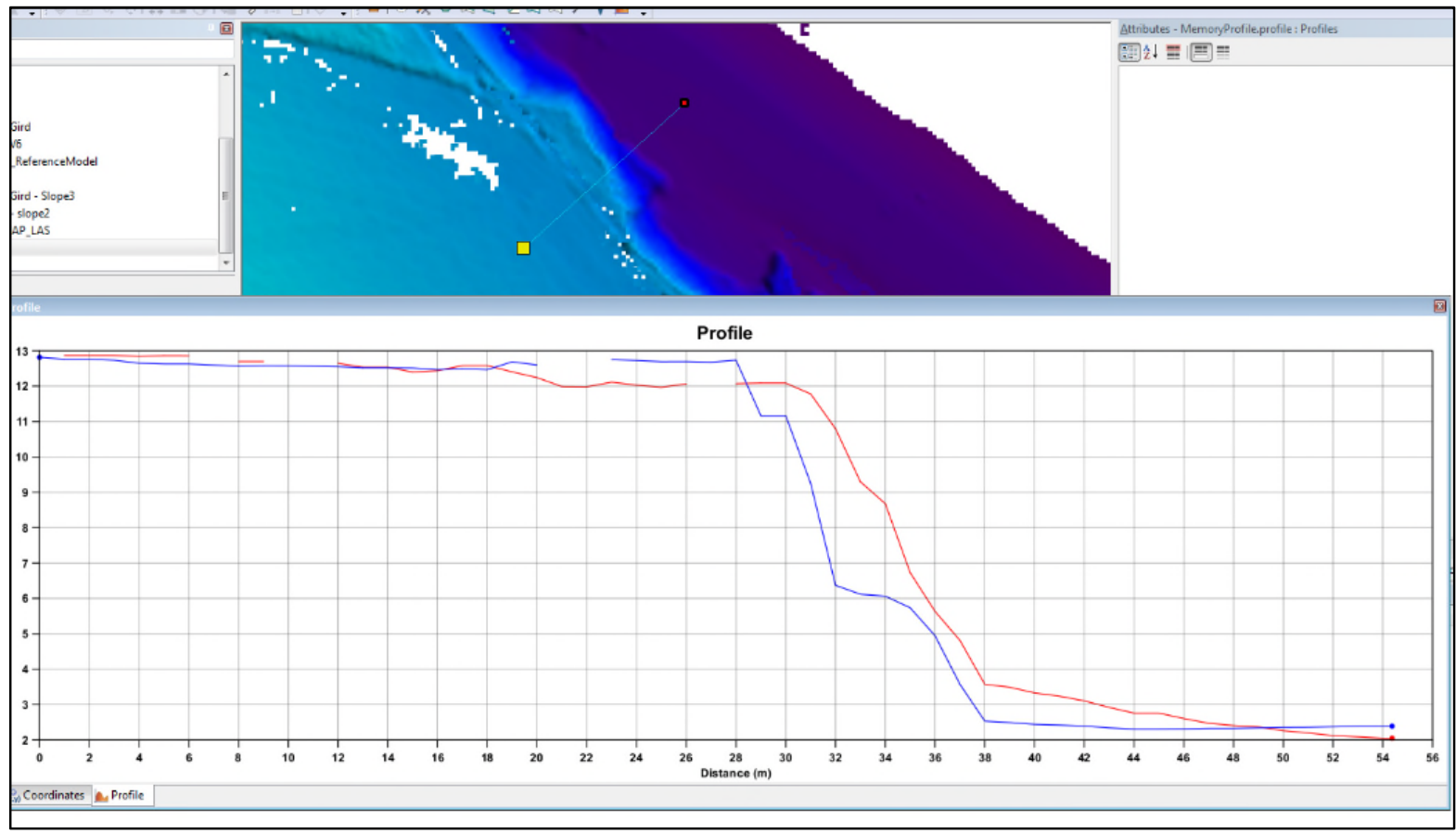

Figure 6: Profile/Transect Creation from DEM in Caris BDB 

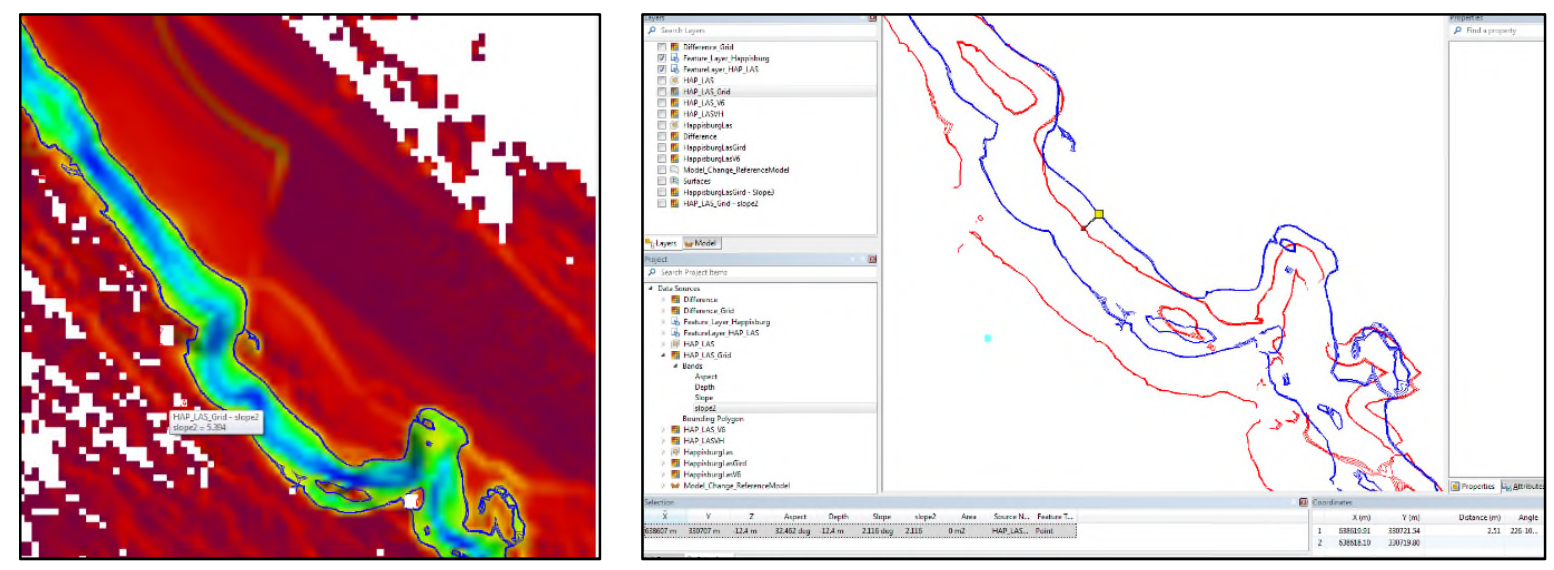

Figure 7: Top and base of cliff, change analysis in Caris BDB

\subsection{Results}

Surface volume estimates were generated for each epoch in which the required coverage and quality of data were available. Table 3 provides an overview of the raw results generated for each area. Cumulative change volumes obtained are presented in Table 4, with the volumes for the first epoch, at each site, listed as zero, as this represents the reference epoch. These results are represented graphically in Figure 8 and Figure 9. Results for each site are also presented individually in Appendix 4.2. This includes visual representations of the results of the initial DEM difference comparisons for each site, displayed as 2D raster images, using colours graduated by change magnitude.

Table 5 provides summary statistics for each case study area. Direct comparison between the results generated for the separate case study sites is problematic due to different lengths and areas of coastline being compared at each site, the sample period being compared, and the number of epochs used. In an effort to account for these factors, a set of summary statistics have been generated, so that comparisons can be made between the case study sites (other than cumulative net volume change). The two new statistical measures generated are labelled: 'Average Yearly Volume Change/ metre of Coastline Sampled', and 'Average Height Change Across Area Sampled / Year'. Separate comparisons of change across the study sites based on these two statistics are presented in Figure 10 and Figure 11.

The raw cumulative net change results (Figure 8 and Figure 9) reveal Trimingham, Hemsby and Happisburgh as the sites experiencing the highest rates of change. However, by separately accounting for (a) length of coast, and (b) period of comparison and area of each site, the relative rates of change alter (Figure 10 and Figure 11). In both sets of statistics Easton Bavents emerges as the site with the highest rate of change, whilst when the area of each site is accounted for (b), Benacre emerges as experiencing the second highest rate of change. The change experienced at the sites, over the entire sample periods, generally takes the form of erosion, except at two locations, Lowestoft near shore and Hunstanton South; the possible causation of this is discussed in Section 1.5. 
Table 3: Annual indicative volumes calculated for all epochs at each case study area (relative to a fixed reference plane)

\begin{tabular}{|c|c|c|c|c|c|c|c|c|c|c|c|c|c|c|}
\hline \multirow[b]{2}{*}{ Area } & \multicolumn{14}{|c|}{ Volume by Year $\left(\mathrm{m}^{3}\right)$} \\
\hline & 2005 & 2006 & 2007 & 2008 & 2009 & 2010 & 2011 & 2012 & 2013 & 2014 & 2015 & 2016 & 2017 & 2018 \\
\hline $\begin{array}{l}\text { Hunstanton } \\
\text { North }\end{array}$ & - & - & - & 193140 & - & - & 189203 & 189338 & 193399 & 186638 & 186981 & 196916 & 183652 & \\
\hline $\begin{array}{l}\text { Hunstanton } \\
\text { South }\end{array}$ & - & - & - & 138434 & - & - & 143976 & 141855 & 145974 & 148112 & 148862 & 153062 & 154341 & - \\
\hline Cromer & - & - & - & 500964 & - & - & 505195 & 503427 & 505664 & 482274 & 482774 & - & 479926 & - \\
\hline Trimmingham & - & - & - & - & - & - & - & 17902336 & 17848229 & 17610944 & 17577588 & - & 17360414 & 17206431 \\
\hline Mundesley & - & - & - & - & - & - & 2345921 & 2352377 & 2340532 & 2298903 & 2302621 & - & 2291523 & 2294828 \\
\hline $\begin{array}{l}\text { Bacton Gas } \\
\text { Terminal }\end{array}$ & - & - & - & - & - & - & - & 706013 & 703679 & 679948 & 686004 & - & 679492 & 679097 \\
\hline Happisburgh & - & - & - & & 1412590 & - & - & 1339946 & 1268277 & 1169700 & 1137102 & 1133140 & 1098229 & \\
\hline Hemsby & - & - & - & & 2338355 & - & - & 2206983 & 2054796 & - & 1979472 & 1992364 & - & 1868003 \\
\hline $\begin{array}{l}\text { Corton to } \\
\text { Lowestoft }\end{array}$ & - & - & - & 2689242 & - & - & 2550845 & 2626298 & 2680332 & 2649146 & 2611697 & - & 2675196 & - \\
\hline $\begin{array}{l}\text { Lowestoft } \\
\text { Nearshore }\end{array}$ & 811172 & 790141 & 814778 & 813311 & 856769 & 874044 & 861102 & 911558 & 931426 & 958281 & 980840 & - & - & - \\
\hline Kessingland & - & - & - & 302287 & & & 299053 & 300549 & 300063 & 293592 & 291062 & 276659 & 260999 & - \\
\hline Benacre & - & - & - & - & - & - & 504103 & 494043 & 490507 & 410487 & 405517 & 362777 & 340006 & - \\
\hline Easton Bavents & - & - & - & 312353 & - & - & 308064 & 306538 & 301535 & 291233 & 262940 & 183715 & 181338 & - \\
\hline Thorpness & - & - & - & 231833 & - & - & 224402 & 228021 & 219167 & 231502 & 217428 & 209478 & 174204 & - \\
\hline
\end{tabular}


Table 4: Annual cumulative volume change for each case study area relative to a reference year

\begin{tabular}{|c|c|c|c|c|c|c|c|c|c|c|c|c|c|c|}
\hline \multirow[b]{2}{*}{ Area } & \multicolumn{14}{|c|}{ Volume change per Year $\left(\mathrm{m}^{3}\right)$} \\
\hline & 2005 & 2006 & 2007 & 2008 & 2009 & 2010 & 2011 & 2012 & 2013 & 2014 & 2015 & 2016 & 2017 & 2018 \\
\hline Hunstanton North & - & - & - & 0 & - & - & -3937 & -3802 & 259 & -6502 & -6159 & 3776 & -9487 & - \\
\hline Hunstanton South & - & - & - & 0 & - & - & 5542 & 3421 & 7540 & 9678 & 10428 & 14628 & 15907 & - \\
\hline Cromer & - & - & - & 0 & - & - & 4231 & 2463 & 4700 & -18690 & -18190 & - & - & -21038 \\
\hline $\begin{array}{l}\text { Sidestrand to } \\
\text { Trimmingham }\end{array}$ & - & - & - & - & - & - & - & 0 & -54107 & -291392 & -324748 & - & -541922 & -695904 \\
\hline Mundesley & - & - & - & - & - & - & 0 & 6456 & -5388 & -47018 & -43300 & - & -54398 & -51093 \\
\hline $\begin{array}{l}\text { Bacton Gas } \\
\text { Terminal }\end{array}$ & - & - & - & - & - & - & - & 0 & -2334 & -26064 & -20009 & - & -26521 & -26916 \\
\hline Happisburgh & - & - & - & - & 0 & - & - & -72644 & -144313 & -242890 & -275489 & -279450 & -314362 & \\
\hline Hemsby & - & - & - & - & 0 & - & - & -131371 & -283558 & & -358882 & -345991 & - & -470352 \\
\hline $\begin{array}{l}\text { Corton to } \\
\text { Lowestoft }\end{array}$ & - & - & - & 0 & & - & -138397 & -62944 & -8910 & -40096 & -77544 & - & -14045 & - \\
\hline $\begin{array}{l}\text { Lowestoft } \\
\text { Nearshore }\end{array}$ & 0 & -21031 & 3606 & 2140 & 45598 & 62872 & 49931 & 100387 & 120254 & 147110 & 169668 & - & - & - \\
\hline Kessingland & - & - & - & 0 & - & - & -3234 & -1738 & -2224 & -8695 & -11226 & -25629 & -41288 & - \\
\hline Benacre & - & - & - & - & - & - & 0 & -10060 & -13596 & -93616 & -98586 & -141326 & -164097 & - \\
\hline Easton Bavents & - & - & - & 0 & - & - & -4290 & -5816 & -10818 & -21120 & -49413 & -128639 & -131015 & - \\
\hline Thorpness & - & - & - & 0 & - & - & -7431 & -3812 & -12667 & -331 & -14405 & -22355 & -57630 & - \\
\hline
\end{tabular}

Note: the first year data was available for (for each area) is taken as a reference year, and displayed as zero. The difference in volume between the reference year and that calculated for subsequent years is given for each year. 


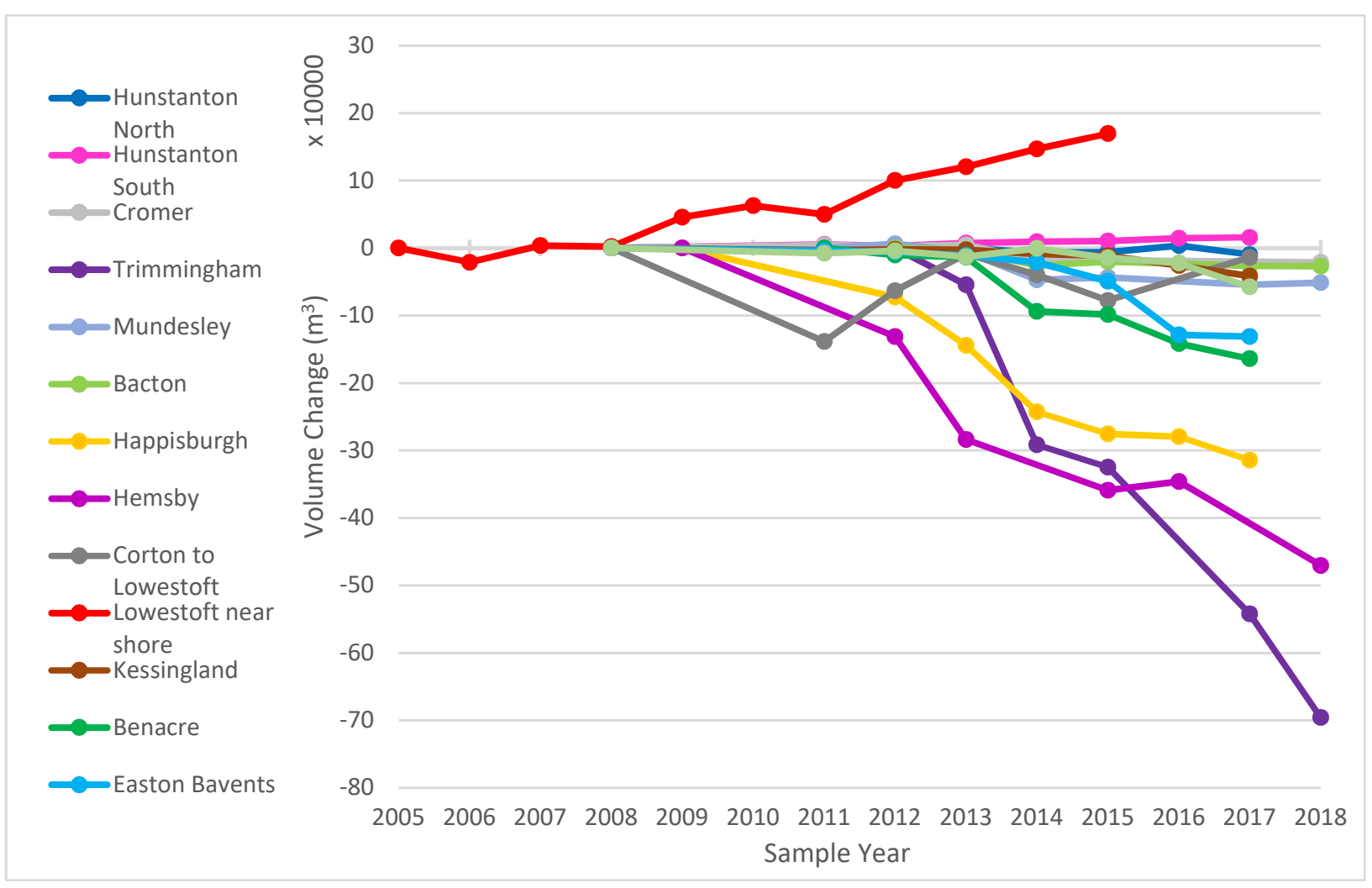

Figure 8: Cumulative net change shown for each area

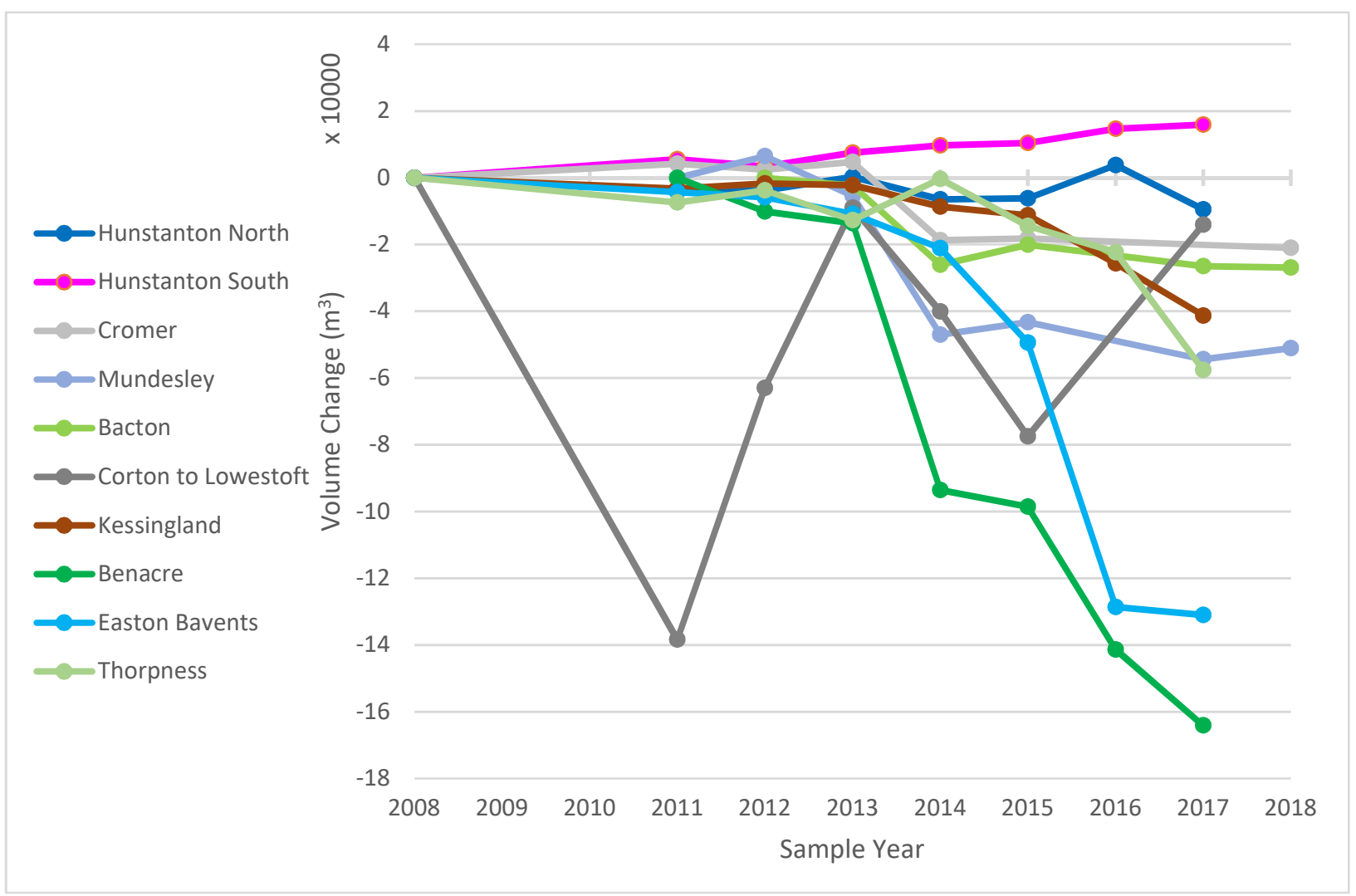

Figure 9: Cumulative net change for areas experiencing lower levels of net change (larger scale version of graph in Figure 8, excluding higher net change areas, to allow remaining profiles to be viewed in greater detail) 
Table 5: Summary statistics for all case study sites

\begin{tabular}{|c|c|c|c|c|c|c|c|c|c|c|c|c|c|}
\hline \multirow[b]{2}{*}{ Area } & \multicolumn{2}{|c|}{$\begin{array}{c}\text { Comparison / } \\
\text { Sample Area Used }\end{array}$} & \multicolumn{4}{|c|}{ Data Sample Period } & \multirow{2}{*}{$\begin{array}{c}\text { Cumulative } \\
\text { Volume } \\
\text { Change } \\
\left(\mathrm{m}^{3}\right)\end{array}$} & \multirow{2}{*}{$\begin{array}{c}\text { Net } \\
\text { Erosion / } \\
\text { Accretion }\end{array}$} & \multirow{2}{*}{$\begin{array}{c}\text { Averaged } \\
\text { Volume } \\
\text { Change / } \\
\text { year }\end{array}$} & \multirow{2}{*}{$\begin{array}{c}\text { Average } \\
\text { Yearly } \\
\text { Volume } \\
\text { Change / } \\
\text { m of } \\
\text { Coastline } \\
\text { Sampled } \\
\end{array}$} & \multirow{2}{*}{$\begin{array}{l}\text { Average } \\
\text { Volume } \\
\text { Change } \\
\text { (per m) } \\
\text { / year } \\
\end{array}$} & \multirow{2}{*}{$\begin{array}{l}\text { Average } \\
\text { Height } \\
\text { Change } \\
\text { Across } \\
\text { Area } \\
\end{array}$} & \multirow{2}{*}{$\begin{array}{c}\text { Average } \\
\text { Height } \\
\text { Change } \\
\text { Across Area } \\
\text { Sampled (m) } \\
\text { / Year }\end{array}$} \\
\hline & $\begin{array}{l}\text { Area } \\
\left(\mathrm{m}^{2}\right)\end{array}$ & $\begin{array}{l}\text { Length of } \\
\text { Coast }(\mathrm{m})\end{array}$ & From & To & Years & Epochs & & & & & & & \\
\hline $\begin{array}{l}\text { Hunstanton } \\
\text { North }\end{array}$ & 14440 & 1200 & 2008 & 2017 & 9 & 8 & -9487 & Erosion & -1054 & $-7,91$ & $-0,88$ & $-0,66$ & $-0,07$ \\
\hline $\begin{array}{l}\text { Hunstanton } \\
\text { South }\end{array}$ & 29594 & 770 & 2008 & 2017 & 9 & 8 & 15907 & Accretion & 1767 & 20,66 & 2,30 & 0,54 & 0,06 \\
\hline Cromer & 31539 & 900 & 2008 & 2018 & 10 & 7 & -21038 & Erosion & -2104 & $-23,38$ & $-2,34$ & $-0,67$ & $-0,07$ \\
\hline Trimmingham & 603287 & 4230 & 2012 & 2018 & 6 & 6 & -695904 & Erosion & -115984 & $-164,52$ & $-27,42$ & $-1,15$ & $-0,19$ \\
\hline Mundesley & 222687 & 2570 & 2011 & 2018 & 7 & 7 & -51093 & Erosion & -7299 & $-19,88$ & $-2,84$ & $-0,23$ & $-0,03$ \\
\hline $\begin{array}{l}\text { Bacton Gas } \\
\text { Terminal }\end{array}$ & 50709 & 1110 & 2012 & 2018 & 6 & 6 & -26916 & Erosion & -4486 & $-24,25$ & $-4,04$ & $-0,53$ & $-0,09$ \\
\hline Happisburgh & 158542 & 2910 & 2009 & 2017 & 8 & 7 & -314362 & Erosion & -39295 & $-108,03$ & $-13,50$ & $-1,98$ & $-0,25$ \\
\hline Hemsby & 265093 & 2340 & 2009 & 2018 & 9 & 6 & -470352 & Erosion & -52261 & $-201,01$ & $-22,33$ & $-1,77$ & $-0,20$ \\
\hline $\begin{array}{l}\text { Corton to } \\
\text { Lowestoft }\end{array}$ & 196653 & 3280 & 2008 & 2017 & 9 & 7 & -14045 & Erosion & -1561 & $-4,28$ & $-0,48$ & $-0,07$ & $-0,01$ \\
\hline $\begin{array}{l}\text { Lowestoft } \\
\text { Nearshore }\end{array}$ & 211548 & 660 & 2005 & 2015 & 10 & 11 & 169668 & Accretion & 16967 & 257,07 & 25,71 & 0,80 & 0,08 \\
\hline Kessingland & 27047 & 650 & 2008 & 2017 & 9 & 8 & -41288 & Erosion & -4588 & $-63,52$ & $-7,06$ & $-1,53$ & $-0,17$ \\
\hline Benacre & 79737 & 2090 & 2011 & 2017 & 6 & 7 & -164097 & Erosion & -27349 & $-78,52$ & $-13,09$ & $-2,06$ & $-0,34$ \\
\hline $\begin{array}{l}\text { Easton } \\
\text { Bavents }\end{array}$ & 29208 & 620 & 2008 & 2017 & 9 & 8 & -131015 & Erosion & -14557 & $-211,31$ & $-23,48$ & $-4,49$ & $-0,50$ \\
\hline Thorpness & 35573 & 640 & 2008 & 2017 & 9 & 8 & -57630 & Erosion & -6403 & $-90,05$ & $-10,01$ & $-1,62$ & $-0,18$ \\
\hline
\end{tabular}




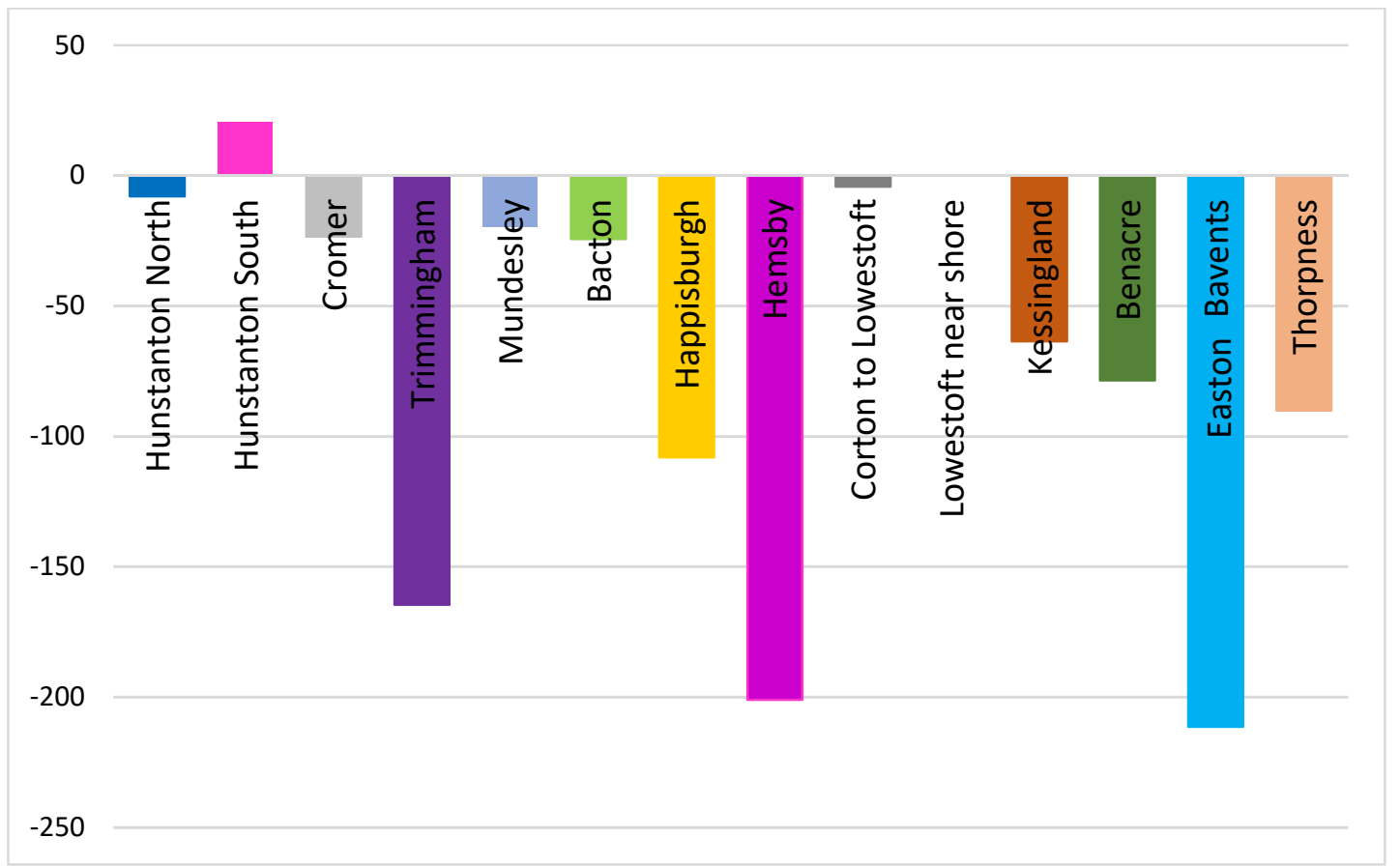

Figure 10: Mean volume change / metre of coast sampled, for each case study area

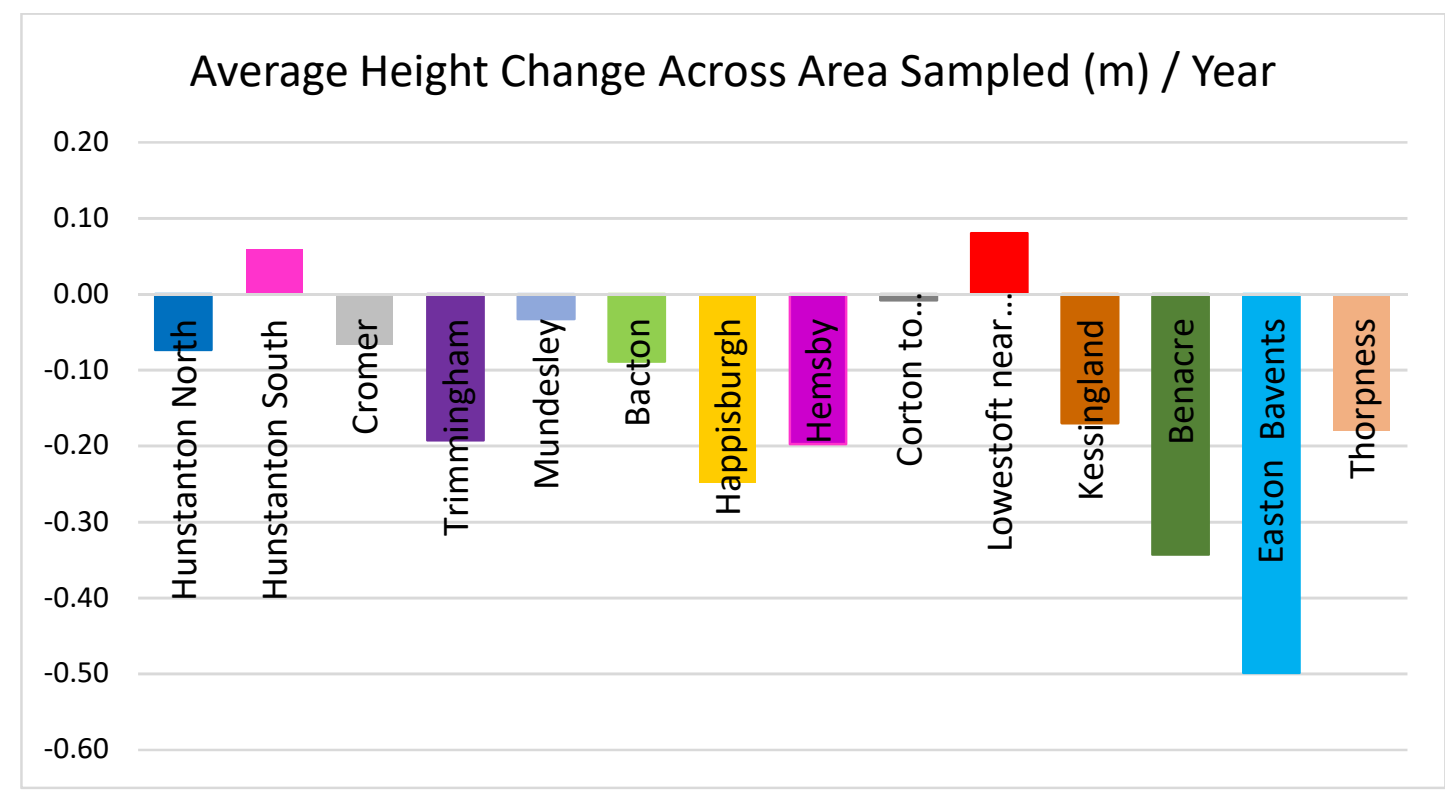

Figure 11: Mean height change across the sampled area ( $m$ / year) for each case study site

\subsection{Discussion}

\subsubsection{GCD Method Evaluation}

This study has sought to evaluate the practical suitability of a point cloud based GCD method for coastal change detection applications. In doing so the case study region of East Anglia was used, noting the approaches are of wider application. The study region benefits from an extensive archive of coastal monitoring data, much of which results 
from the Anglian Coastal Monitoring Programme (Environment Agency, 2016). Yet datasets available for the area have been underutilised in documented GCD studies undertaken by practitioners, and the potential benefits to coastal analysis offered by such terrain data have not been fully realised. Commonly employed methods for coastal GCD based on linear change analysis, derived from comparisons of survey data (such as that generated by topographic surveys), only incorporate a small portion of the extensive quantities of data collected for each site (which includes high resolution point cloud data). However, the volumetric change analyses, undertaken within this study has sought to incorporate all relevant and valid data points collected for a given comparison area. This enabled more comprehensive estimates of geomorphological change and deformation to be obtained, and reduces the requirement for interpolation and the associated uncertainty.

The selected GCD method used in this study, is limited to measuring change along a single vector (horizontal), yet it allows simple comparisons to be made between surface representations for different epochs at each site. This in turn enabled trends to be revealed, and comparisons to be made between sites in different locations. Application of this method seeks to address the requirements of those who need to gain a general understanding of wide-scale impacts and coastal processes. It is acknowledged that the level of detail permitted by such a technique may prove inadequate for monitoring of more granular processes (for which $\mathrm{C} 2 \mathrm{C}$ analysis or similar techniques, using higher resolution data, may be more appropriate). Also, by limiting change analysis to measurement along a horizontal vector, the ability to accurately monitor the deformation of vertical cliff faces is greatly reduced. However, the primary purpose of applying this GCD method was not to determine linear cliff face retreat, but to estimate net volume change, allowing quantification of each case study area's sediment budget. Given this the method was deemed appropriate, and adequate given the spatial scales assessed.

Our estimates of volumetric change for each study site are indicative of levels sediment loss/gain at each location. Other studies focusing on East Anglia have generated similar results for a number of the sites we selected. We calculated the following sediment loss rates ( $\mathrm{m}^{3} /$ year): Easton Bavents 14,557 (2008-2017); Benacre 27,349 (2011-2017); Thorpness 6,404 (2008-2017) (Table 5). Whilst Brooks and Spencer, (2010) focussed on a preceding time period in their study (2001-2008) and calculated sediment volumetric loss rates ( $\mathrm{m}^{3} /$ year) of: Easton Bavents 16,868; Benacre 19,629. Burningham and French (2016), also completed sediment budget estimates for similar areas, and for multiple periods, one of which overlapped with that we studied (1999-2013). They calculated the following sediment loss rates for this period ( $\mathrm{m}^{3} /$ year): Easton Bavents 24,990; Thorpness 4,326. The results generated in these studies are not directly comparable with our results, given we cover a different time period, and the boundaries and shoreline lengths for each site will not be equal. However, the results are within the same order of magnitude, for each area, so this provides some assurance over the validity of our results. The methods used in these previous studies differ to what we employed, and include higher levels of interpolation, drawing on transect data, and 
interpretation of aerial imagery. Given this, and considering the associated issues listed in Table 1, the TIN based methodology we have used appears more robust.

The workflow developed for this study (Figure 3), involves significant levels of manual intervention and interpretation. Therefore, undertaking similar analysis on a large-scale would prove time consuming, and would be reliant on the skills of an individual operator. However, options exist to standardise and automate many of the tasks completed within the workflow by using the 'Process Designer' function in BDB or developing Python scripts to simplify and streamline processes, making execution of the workflow more efficient and reliable. The ability to work with point cloud data and surfaces in 3D was integral to the successful completion of the work. Preconfigured functionality in the BDB software, allowed rapid calculation of volumes and enabled analysis to be undertaken for the multiple sites and epochs included. Comparable functionality did not exist in other software trialled, including a number of commonly used GIS packages.

\subsubsection{Data Use and Availability}

The requirement for interpolation is reduced further when higher resolution datasets are used in analysis. However, there is a trade-off between data density and the scale of analysis possible. The Lidar datasets used in analyses, are on average at a $1 \mathrm{~m}$ resolution, whilst some of the TLS data examined was under $10 \mathrm{~cm}$ in pixel resolution. Use of higher resolution data imposes limits on the size of an area that can be analysed and was therefore deemed unsuitable given the spatial extents associated with this study. Furthermore, surface creation using TIN models was found to be problematic with large, high density datasets. For the level of detail required, the $1 \mathrm{~m}$ Lidar data was found to be adequate to generate general trends at a wider scale. The temporal resolution of data collection was also observed as being critical in determining trends accurately. For East Anglia, the datasets available were limited to annual intervals (see 1.8.1 Appendix 4.1). The annual datasets proved effective for determining general trends, yet for more detailed analysis, such as studies determining causation of change, data collected over shorter intervals might be required. Also, if impacts resulting from successive highenergy events are to be compared, surveys need to be completed pre and post event. This could prove difficult though if data acquisition methods such as airborne Lidar are relied upon. However, using in situ methods such as static TLS monitoring of cliff faces (Williams et al., 2018) could provide the required temporal frequency of data. For the East Anglian datasets utilised in this study, there are examples where larger intervals are present between sequential epochs, for example, from 2008 to 2011 at Corton, from 2009 to 2012 at Hemsby, and from 2008 to 2012 at Thorpness. The only attempt at interpolation between these gaps (Figure 8 and Figure 9) is to link points by a straight line. This method, although indicative of longer-term patterns, is crude, giving no accurate indication of change within the extended interval between sample points, and if more detailed analysis was required, this interpolation could prove inadequate. 


\subsubsection{Evaluation of Results}

This study focussed primarily on the application and evaluation of methods for GCD using point cloud datasets. Given this, the discussion does not provide extensive analysis of the significance of the results generated in relation to the local coastal management context, i.e. that relating to causation of trends, patterns, and impacts. Yet the results generated could form a valuable input to further studies focusing on such aspects. In particular, for each of the sites studied the main areas of coastal change were captured. Estimates of cumulative change over the sample periods provide some indication of the extents of net erosion or accretion occurring at each site, and furthermore, the sites contribution to local sediment cells. The stretch of coast from Sidestrand to Trimmingham stood out as experiencing the largest net loss of material and the highest rates of erosion, followed closely by Hemsby and Happisburgh. These results conform with empirical knowledge, as all 3 sites have witnessed rapid and extensive erosion over the temporal period represented in this study (Nicholls et al., 2015; Payo et al., 2018b). Yet, if the size of sample area and length of coastline for each site was considered, Easton Bavents emerged as the site experiencing the highest rates of erosion (Figure 10 and Figure 11). Again, this conforms with established knowledge, as Easton Bavents has been heavily impacted by coastal erosion and for this reason was focused on within the Coastal Change Pathfinder Programme (as was Happisburgh and Trimingham) (Defra, 2012). The emergence of Eastern Bavents as a heavily impacted area corresponds with what can be deduced from the initial DoD visual results and cross profiles generated from the TIN surfaces. These indicate large sections of coast which have eroded by over $20 \mathrm{~m}$ laterally, at some locations, over the 9 year sample period (Figure 12). The results, presented in Figure 10 and Figure 11, should be viewed with some caution though, as for some sites, such as Kessingland, the comparison area included only a relatively small section of coast, where higher levels of erosion were concentrated, so the results were not representative of change rates across the wider area. Conversely, sites such as Corton to Lowestoft, included a longer stretch of coastline, in which areas of change were more widely dispersed. 


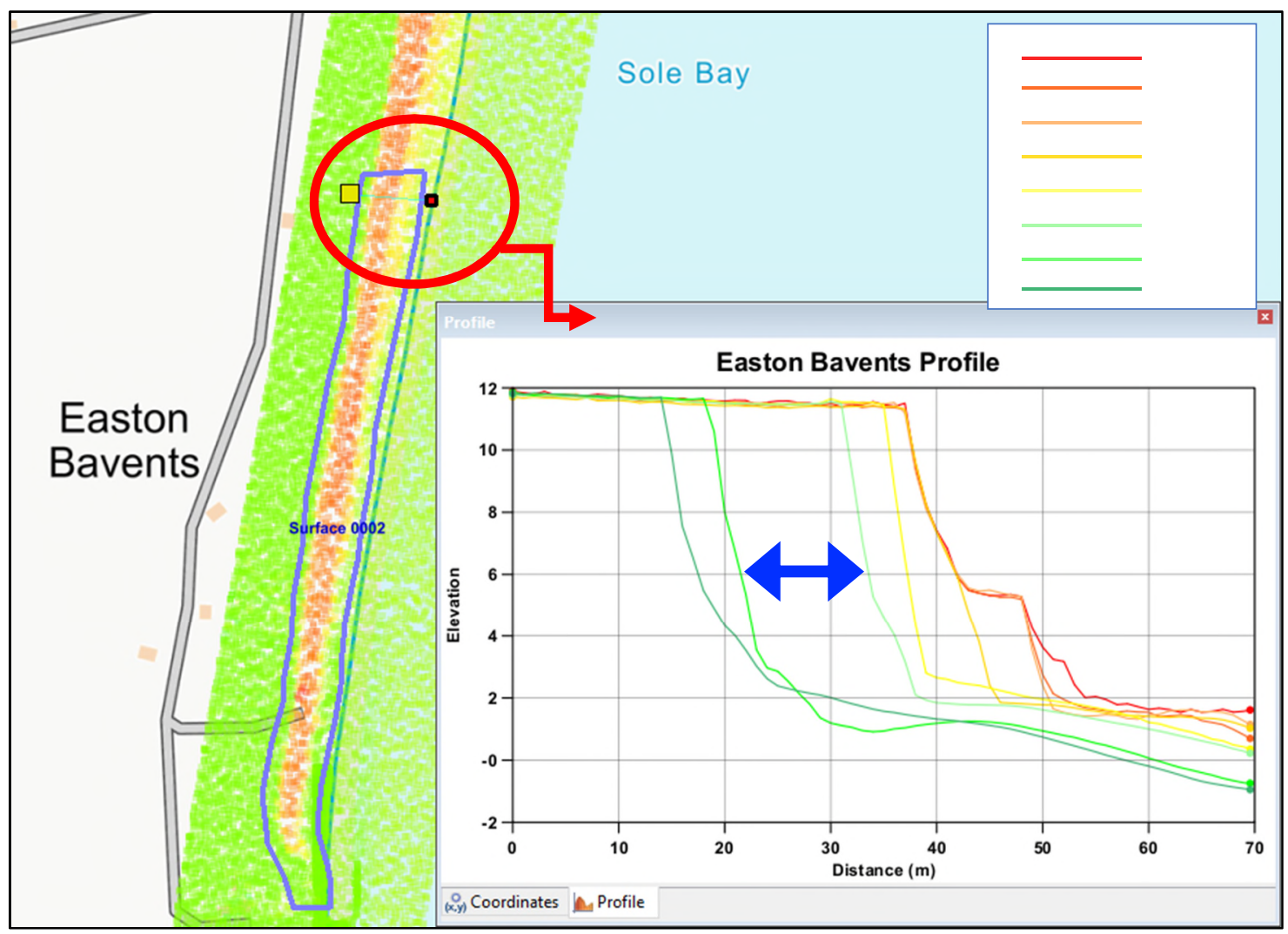

Figure 12: 2D Profile of Easton Bavents TIN surfaces from 2008 - 2017, showing over $20 \mathrm{~m}$ horizontal cliff recession. The plan view image represents areas of accretion/erosion using a graduated colour scheme, with areas of higher erosion coloured red and stable areas green. Profiles generated for sequential years are assigned separate colours, detailed in a legend (not correlated with the plan view), these range from 2008 shown in red through to 2017 displayed as a green line. A blue arrow indicates a period between 2015-2016 where higher rates of erosion were experienced.

Net erosion was experienced at twelve of the case study sites during the period studied, yet the extent of this varied considerably, with locations such as Bacton, Mundesley, Thorpness, and Hunstanton North experiencing lower levels of cumulative material loss. However, in the period between Lidar Surveys being completed in late September 2016 and November/December 2017, Thorpness experienced a dramatic increase in erosion rates (Figure 9 and Appendix 4.2). The quantity of material removed from the Thorpness case study area $\left(35,275 \mathrm{~m}^{3}\right)$, in this period of just over one year, was over $150 \%$ of that removed in the preceding eight years $\left(22,355 \mathrm{~m}^{3}\right)$. This observation ties in with media coverage focusing on the area during that period, where in January 2017, dramatic erosion events and a subsequent cliff collapse resulted in loss of life (BBC, 2017). One site which doesn't conform with the general trend of erosion is Hunstanton South, where our results indicate net accreation. In terms of spatial orientation, this site is noticibly unique in that its coastline is west facing. Here, partial protection is provided from the full force of the North Sea by The Wash.The stretch of coastline between Corton and Lowestoft also stood out due to it fluctuating between states of net erosion and accretion. This case draws attention to how the net volume change figures obtained for the entire sample period (such as generated in the initial DoD calculations) can be 
misleading, and consideration of changes across all epochs sampled is necessary to gain a more complete understanding of actual trends.

The one site for which nearshore bathymetry was analysed (Lowestoft) showed a net accumulation of sediment in the area. The coastline adjacent to this section of seabed is heavily defended by concrete structures, indicating that sediment eroded from locations further along the coast, or discharged from Lake Lothing, is being deposited in this location. This case also demonstrates clearly the need to consider both visual representations of change, in addition to quantitative assessments. The visualisation generated from the initial DEM of difference calculation (Figure 13) reveals an uneven distribution of change across the site. To the east a deepening channel has emerged, in which an elevation reduction of up to $4.6 \mathrm{~m}$ has been observed, whilst to the south west of the area, elevation increases of up to $2.6 \mathrm{~m}$ are present. The deepening channel does not appear to align with known dredging activity in the area, or with documented shipping channels and approaches (VisitMyHarbour.com, 2019), therefore it could be attributed to local coastal processes.

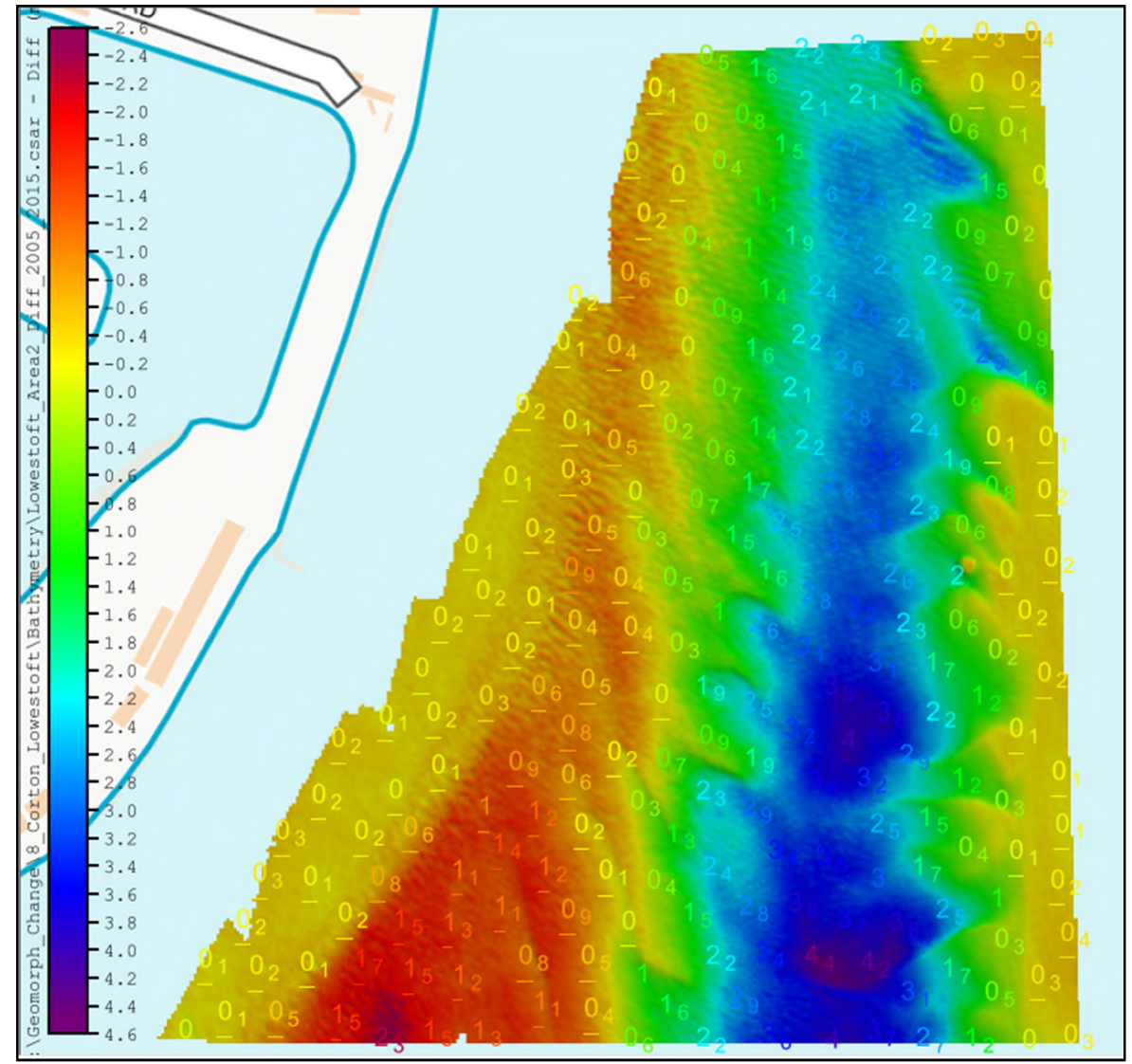

Figure 13: DEM difference surface for Lowestoft representing a comparison of data collected between 2005 and 2015. Change is displayed numerically and via a graduated colour scheme. All changes are given in metres, with areas of accretion assigned negative values, and are coloured orange/red. Numbers depicting spot change values are superimposed over the respective areas. 


\subsubsection{The 2013 East Coast Storm Surge}

The most significant hazard event which impacted the case study region, during the period focussed on in this study was the 2013 East Coast Storm Surge (Environment Agency, 2016). This event took place between on 5-6 December 2013, and resulted in the highest still water levels on record being observed at many sites across the region (Spencer et al., 2015). The dates of acquisition of the Lidar data used in this study (Table 6) indicate that all 2013 datasets were collected prior to this event. Most datasets were acquired shortly before it, in October 2013, however subsequent surveys for most areas were not completed until October or November 2014. Given this, estimates of change for each area, between 2013-14, would not represent the immediate impacts of the event. The 10-11 month gap, post event (prior to resurvey), would have allowed time for sediment to be redistributed in each area. Notwithstanding this, a number of observations were made in relation to results for the period. The most prominent sharp increases in erosion, which could be attributed to this event, were witnessed at Cromer, Mundesley, Bacton Gas Terminal, and Benacre (Appendix 4.2). The shift in the rate of lateral erosion during the period between 2013 and 2014 is clearly evident in the shoreline profile for Benacre, displayed in Figure 14. A noticable difference in the volume change rate between 2013 and 2014, was not visible in the results for a number of sites. There are many possible explanations for this. One could be that coastal change on some stretches of coastline, was heavily influenced by rainfall-induced landslides, in addition to coastal processes. Another could be, that the surge redistributed sediment within the boundaries of a study area (during the interving period between surveys), resulting in minimal change to the net volume of material observed.

The 2013 storm surge is just one high energy event which can be linked to the results for selected sites within this study. Closer inspection of the change estimates generated, especially the cumulative change profiles for individual sites (Appendix 4.2), may reveal additional trends for which causation and correlation with events could be determined. For example, examination of successive coastal profiles for Easton Bavents (Figure 12) indicates a significant increse in the rate of cliff recession in the period between November 2015 and October 2016. 


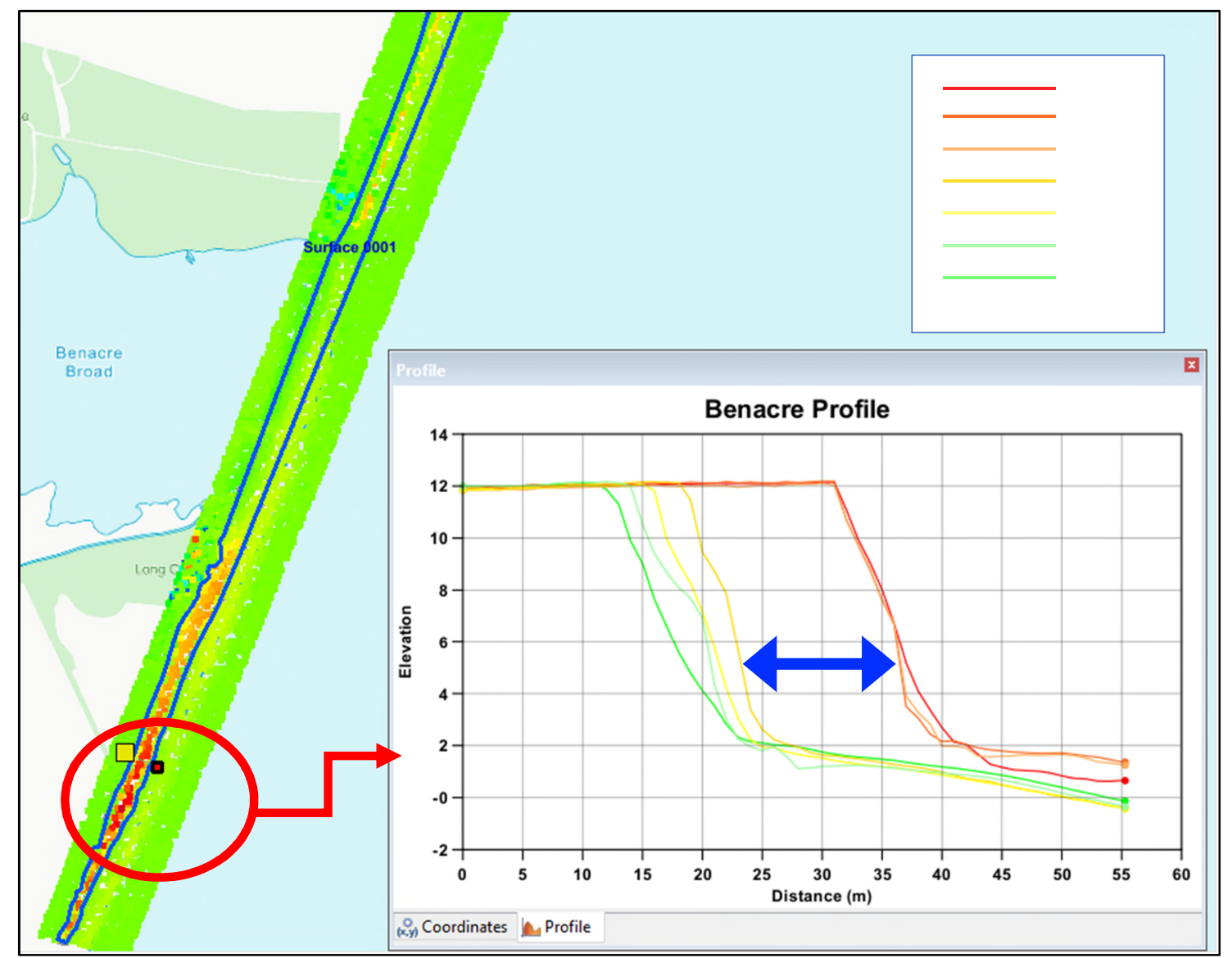

Figure 14: 2D Profile of Benacre TIN surfaces from 2011 - 2017, showing approximately $20 \mathrm{~m}$ horizontal cliff recession. The plan view image represents areas of accretion/erosion using a graduated colour scheme, with areas of higher erosion coloured red and stable areas green. Profiles generated for sequential years are assigned separate colours, detailed in a legend (not correlated with the plan view), these range from 2011 shown in red through to 2017 displayed as a green line. A blue arrow indicates a period between 2013-2014 where higher rates of erosion were experienced.

\subsubsection{Limitations}

The GCD undertaken within this study is primarily based on volume calculations founded on elevation changes. Of the available methods this was deemed by the authors, the most suitable for analysis of such a wide range of datasets, yet there are limitations imposed by this method. Prominent among these is the inability to account for redistribution of cliff or beach material within the boundaries of a comparison area. Such changes could be better identified from the visual representations generated from the DoD surfaces i.e. Figure 13, or in 2D profiles (Figure 12 and Figure 14), yet they were inadequately represented in the quantitative change estimates. For example, where a cliff face has eroded, the eroded material typically accumulates at the toe of the cliff, or is deposited further along the beach. This volume of accreted material would partially offset the volume of eroded material caputured for the whole comparison area. Given this, processes operating in the area would not be fully captured within a single quantitative volume change estimate. If the results of GCD analyses were required to 
enable more precise impacts at specific locations and dates to be determined, then a more general overview method, could obscure important details, thus proving inadequate. A partial solution to this issue could be to isolate material change calculations to limited spatial extents such as a cliff face alone, thereby excluding beach sediment yields. Also, through combining qualitative visual representations of change, generated through DoD calculations, and the quantitative volumetric change results generated by TIN-differencing, more comprehensive change analysis is permitted.

Another limitation which needs to be noted for this study relates to error accounting. The technique we selected for undertaking GCD calculations was based on preconfigured functionality within a commercial software. This limited our ability to directly account for errors and uncertainties, and placed a heavy burden on manual quality control. This proved time consuming and imposed caveats on the reliability of the results produced. For the purposes of this study, this method was deemed adequate, as the results produced are only intended to give indications of general trends. Yet it should be noted that any future attempts to implement a similar methodology should look to options for implementing more systematic and robust error accounting techniques, such as those outlined by Wheaton et al. (2010), or options allowing levels of significance to be assigned to calculated changes (Leyland et al., 2017).

\subsection{Conclusions}

This study presents a critical evaluation of GCD methods based on analysis of point cloud datasets for coastal and nearshore areas, involving the use of Lidar, TLS and MBES datasets. The results provide quantitative estimates of geomorphological impacts, which can be attributed to coastal processes operating across the case study region of East Anglia. 14 case study sites were included in the study, representing differing coastal geologies, morphologies, levels of hazard exposure, and types of adaptive measures in place. Cumulative change results were generated for each study site, revealing the temporal and spatial distribution of coastal erosion and accretion trends. The results presented indicate the suitability of the selected GCD methods, revealing how comparative statistics and visualisations can be generated through creation and analysis of DEMs or TIN surfaces. We also note how advances in both data acquisition and processing technology allow high spatial and temporal resolution morphological data to be combined within coastal change analyses. This can reduce uncertainty, through reducing the requirements for interpolation, which are commonplace in many traditional and in-use techniques, which demand higher levels of manual interpretation.

The methods employed, and the workflows developed, are suited to more general implementation, offering analysis at wider spatial scales. The main analysis undertaken related to cumulative volumetric change, taking place within defined case study sites. The creation of surfaces using TIN models, and volume calculations relative to a horizontal plane, proved adequate in providing quantitative estimates of each site's sediment budget. Site-specific factors influenced selection of this method; the East Anglian coast is predominantly comprised of low gradient soft cliffs, so it was possible to use a volumetric change method based on surface creation from Lidar data. However, 
the authors acknowledge that such analytical approaches are not optimal for estimating other types of change, i.e. linear coastline retreat. In cases where higher levels of detail and granularity are required, or where there is a requirement to precisely identify cliff edges or individual rockfall events, it may be preferable to utilise GCD methods that base calculations of change on individual data points, rather than on interpolated surfaces. The software utilised within this study also lacked functionality allowing systematic errors and uncertainties to be accounted for. Future analysis would benefit from incorporation of explicit methods accounting for spatially variable uncertainties.

The majority of datasets drawn on within this study are open source and so can be obtained with ease. The study benefitted from the required data being available for the sites selected. However, data availability, acquisition method, and frequency of collection, varies considerably depending on location. As such, these factors should be considered in any future selection of an appropriate GCD method. For the GCD method we used, the main software employed was Caris BDB, which is proprietary. However, the workflow developed involves standardised processes, such as TIN model creation and comparison, so could potentially be recreated using alternative means. One clear drawback of the method employed, is the requirement for manual intervention/interpretation. The workflow developed (Figure 3), is reliant on operator skills, and their ability to distinguish potential error sources within datasets, that need to be excluded from calculations (such as vegetation, the ocean surface, buildings, and areas of insufficient data coverage). This places limits on the ability to reproduce the results and reapply the methodology. The next logical step, following on from this work, would therefore be standardisation and automation of the operations detailed as making up our workflow. This could increase the reliability of results generated, and reduce the skills and time required for data analysis. In this study we have provided the basis of such future advances, through revealing the practical suitability of a point cloud based GCD method, for increasing understanding of morphological changes taking place on selected stretches of coastline. This reveals how more effective utilisation of a new generation of high-resolution point cloud datasets, can lead to implementation of more robust and sustainable coastal management practices.

\subsection{Acknowledgements}

The authors acknowledge the staff of Coastal Partnership East, Great Yarmouth Borough, North Norfolk, Suffolk Coastal and Waveney District Councils and, in particular, Bill Parker, for input and guidance to this work. We acknowledge the staff of the Environment Agency who provided input and guidance to this study and provided the datasets which the majority of the work is based on, in particular Philip Staley. We also acknowledge the UK Hydrographic Office, for the provision of bathymetric datasets. Teledyne Caris provided an academic license for the software used within this study, and we acknowledge the support and training provided by Caris staff, especially Mark Pronk. British Geological Survey, in particular Andres Payo Garcia, Lee Jones, Anna Harrison and Katherine Lee, are acknowledged for their guidance. This work was supported by the UK Natural Environment Research Council [NERC Ref: NE/M009009/1], Suffolk Coastal District Council [VGP/00043027], and the British Geological Survey [GA/16S/010]. 


\subsection{Appendices}

\subsubsection{Appendix 4.1 Survey Data Collection Dates}

Table 6: Lidar Survey Collection Dates. For each year the dates on which datasets were acquired are given in the format of day/month for the respective years.

\begin{tabular}{|c|c|c|c|c|c|c|c|c|c|c|c|}
\hline Area & 2008 & 2009 & 2010 & 2011 & 2012 & 2013 & 2014 & 2015 & 2016 & 2017 & 2018 \\
\hline $\begin{array}{l}\text { Hunstanton } \\
\text { North \& South }\end{array}$ & $\begin{array}{l}20 / 05 \\
17 / 06 \\
09 / 07 \\
\end{array}$ & - & - & $\begin{array}{l}04 / 05 \\
26 / 10 \\
\end{array}$ & $\begin{array}{l}26 / 05 \\
27 / 05 \\
13 / 11 \\
\end{array}$ & $03 / 10$ & $\begin{array}{l}27 / 02 \\
28 / 02 \\
09 / 11 \\
\end{array}$ & $\begin{array}{r}05 / 03 \\
07 / 03 \\
11-12 / 11 \\
\end{array}$ & $02 / 11$ & $07 / 11$ & $\begin{array}{l}- \\
-\end{array}$ \\
\hline Cromer & $27 / 02$ & - & - & $\begin{array}{l}23 / 11 \\
26 / 11 \\
\end{array}$ & $\begin{array}{l}12 / 11 \\
15 / 11 \\
\end{array}$ & $05 / 10$ & \begin{tabular}{|l|}
$28 / 10$ \\
$24 / 11$ \\
\end{tabular} & $11 / 11$ & - & $\begin{array}{r}28 / 01 ; 30 / 03 ; \\
06 / 11 \\
\end{array}$ & - \\
\hline Trimmingham & - & - & - & - & $15 / 11$ & $05 / 10$ & $24 / 11$ & $11 / 11$ & - & $28 / 01$ & 08/01 \\
\hline Mundesley & - & - & - & $08 / 02$ & $15 / 11$ & $05 / 10$ & $24 / 11$ & $11 / 11$ & - & $28 / 01$ & 08/01 \\
\hline $\begin{array}{l}\text { Bacton Gas } \\
\text { Terminal }\end{array}$ & - & - & - & - & $15 / 11$ & $05 / 10$ & $24 / 11$ & $\begin{array}{r}27 / 02 ; 11 / 11 ; \\
23 / 11 \\
\end{array}$ & - & $28 / 01$ & 08/01 \\
\hline Happisburgh & & $\begin{array}{l}18 / 01 \\
20 / 01\end{array}$ & - & - & $15 / 11$ & $\begin{array}{r}01 / 04 ; 06 / 04 ; \\
05 / 10\end{array}$ & $24 / 11$ & $\begin{array}{l}11 / 11 \\
23 / 11\end{array}$ & $27 / 10$ & $\begin{array}{l}28 / 01 \\
05 / 11\end{array}$ & \\
\hline Hemsby & & $\begin{array}{l}11 / 01 \\
24 / 01 \\
\end{array}$ & - & - & $\begin{array}{l}11 / 11 \\
12 / 11 \\
\end{array}$ & $\begin{array}{r}01 / 04 ; 06 / 04 ; \\
05 / 10 \\
\end{array}$ & - & $\begin{array}{r}20 / 01 ; 27 / 02 ; \\
23 / 11 \\
\end{array}$ & $27 / 10$ & - & 08/01 \\
\hline $\begin{array}{l}\text { Corton to } \\
\text { Lowestoft }\end{array}$ & $29 / 06$ & - & - & $23 / 11$ & $11 / 11$ & $03 / 10$ & $27 / 10$ & $\begin{array}{r}14 / 01 ; 16 / 01 ; \\
23 / 11 \\
\end{array}$ & - & $\begin{array}{l}04 / 11 \\
05 / 11 \\
\end{array}$ & - \\
\hline Kessingland & $\begin{array}{l}23 / 05 \\
29 / 06 \\
\end{array}$ & & & $23 / 11$ & $\begin{array}{l}11 / 11 \\
18 / 11 \\
\end{array}$ & $\begin{array}{l}03 / 10 \\
06 / 10 \\
\end{array}$ & $27 / 10$ & $\begin{array}{l}14 / 01 \\
16 / 01 \\
\end{array}$ & $\begin{array}{l}27 / 10 \\
11 / 11 \\
\end{array}$ & $\begin{array}{r}27 / 10 ; 05 / 11 ; \\
02 / 12 \\
\end{array}$ & - \\
\hline Benacre & - & - & - & $23 / 11$ & $\begin{array}{l}11 / 11 \\
18 / 11\end{array}$ & $\begin{array}{l}03 / 10 \\
06 / 10\end{array}$ & $\begin{array}{l}27 / 10 \\
06 / 11\end{array}$ & $23 / 11$ & $\begin{array}{l}27 / 10 \\
11 / 11\end{array}$ & $\begin{array}{l}05 / 11 \\
02 / 12 \\
\end{array}$ & - \\
\hline Easton Bavents & $23 / 05$ & - & - & $23 / 11$ & $\begin{array}{r}11 / 11 ; \\
18 / 11 \\
\end{array}$ & $03 / 10 ; 06 / 10$ & $\begin{array}{l}27 / 10 \\
06 / 11 \\
\end{array}$ & $23 / 11$ & $\begin{array}{l}27 / 10 \\
11 / 11 \\
\end{array}$ & $\begin{array}{l}05 / 11 \\
02 / 12 \\
\end{array}$ & - \\
\hline Thorpness & $\begin{array}{l}07 / 02 \\
16 / 06 \\
\end{array}$ & - & - & $23 / 11$ & $19 / 11$ & $06 / 10$ & $27 / 10$ & $23 / 11$ & $30 / 09$ & $\begin{array}{l}05 / 11 \\
02 / 12 \\
\end{array}$ & - \\
\hline
\end{tabular}




\subsubsection{Appendix 4.2 case study site results}

\subsubsection{Case Study Site 1: Hunstanton North}

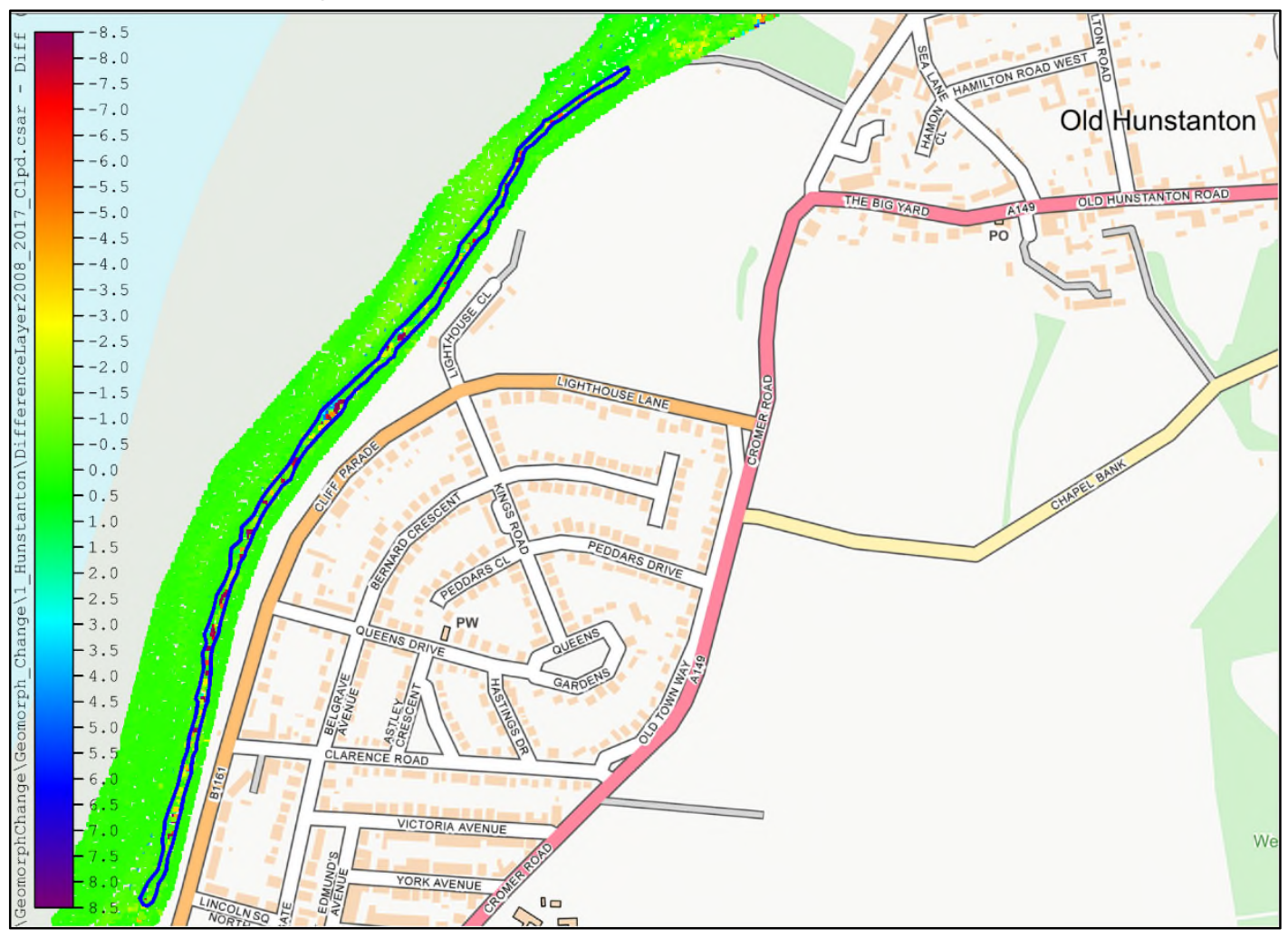

Cumulative Volume Change $\left(\mathrm{m}^{3}\right)$

\begin{tabular}{|c|c|}
\hline 2008 & 0 \\
\hline 2009 & - \\
\hline 2010 & - \\
\hline 2011 & -3937 \\
\hline 2012 & -3802 \\
\hline 2013 & 259 \\
\hline 2014 & -6502 \\
\hline 2015 & -6159 \\
\hline 2016 & 3776 \\
\hline 2017 & -9487 \\
\hline
\end{tabular}

Hunstanton North Cumulative Volume Change $\mathrm{m}^{3}$ (over $1.2 \mathrm{~km}$ of coastline)

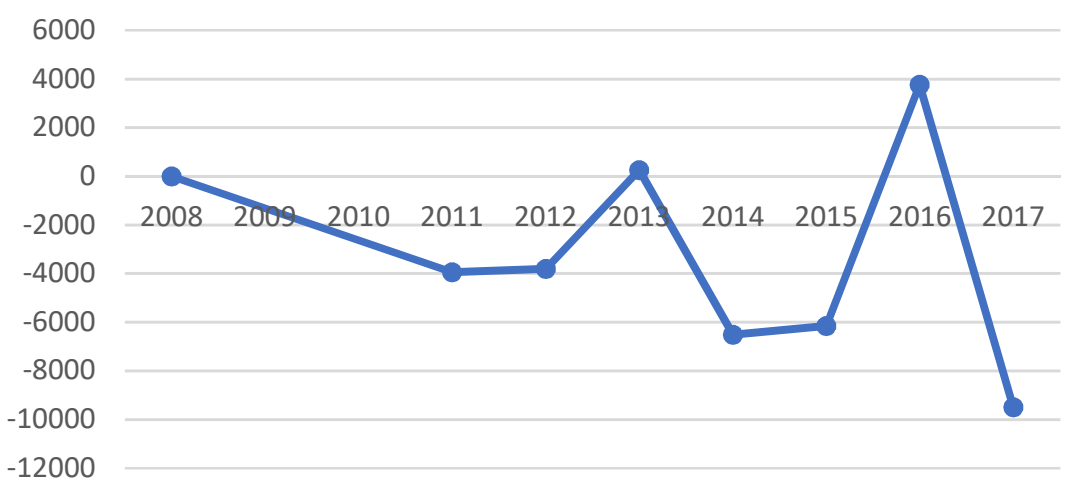


1.8.2.2 Case Study Site 2: Hunstanton South

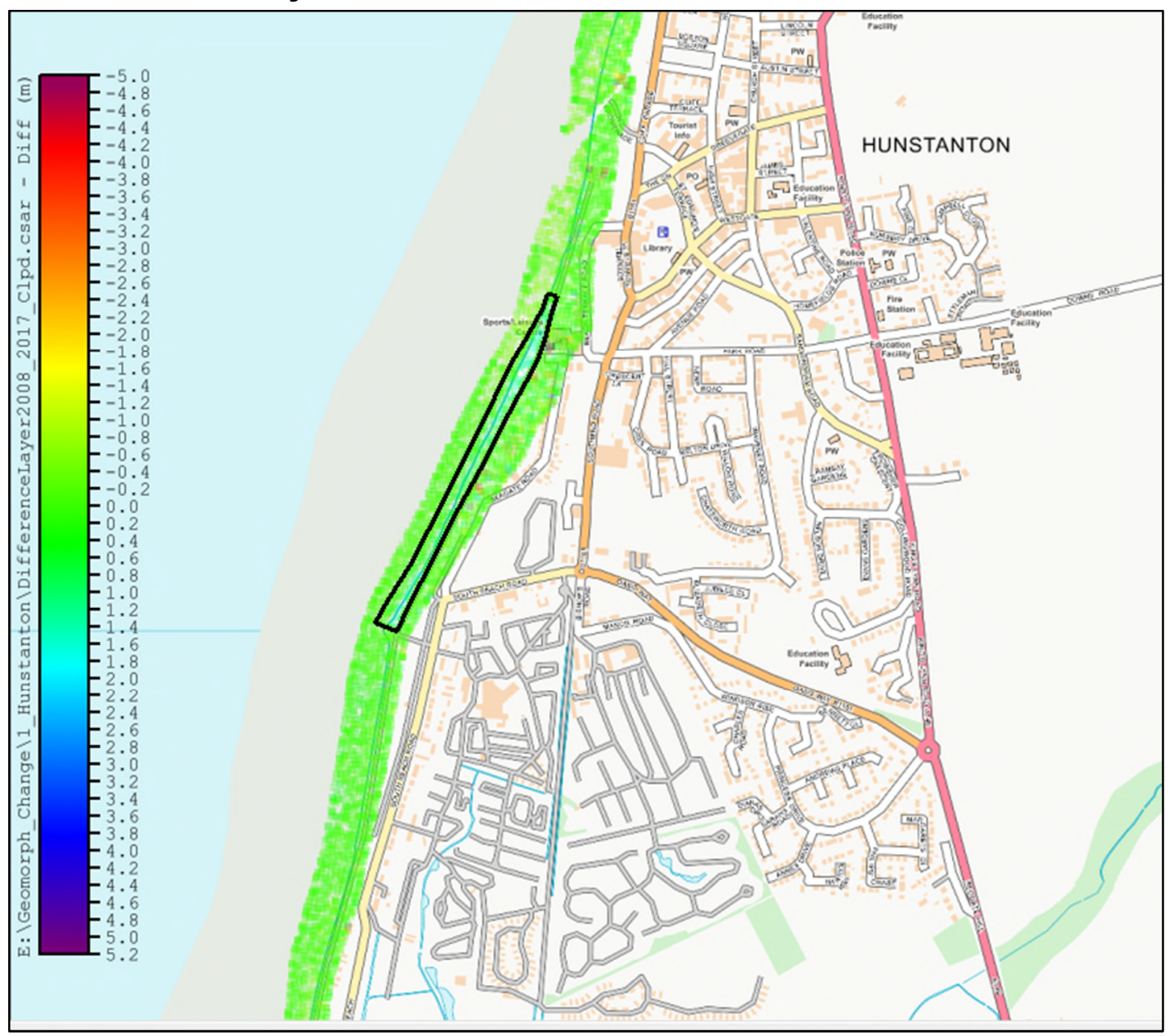

Cumulative Volume Change $\left(\mathrm{m}^{3}\right)$

\begin{tabular}{|c|c|}
\hline 2008 & 0,00 \\
\hline 2009 & - \\
\hline 2010 & - \\
\hline 2011 & 5542 \\
\hline 2012 & 3421 \\
\hline 2013 & 7540 \\
\hline 2014 & 9678 \\
\hline 2015 & 10428 \\
\hline 2016 & 14628 \\
\hline 2017 & 15907 \\
\hline
\end{tabular}

Hunstanton South Cumulative Volume Change $\mathrm{m}^{3}$ (over $0.77 \mathrm{~km}$ of coastline)

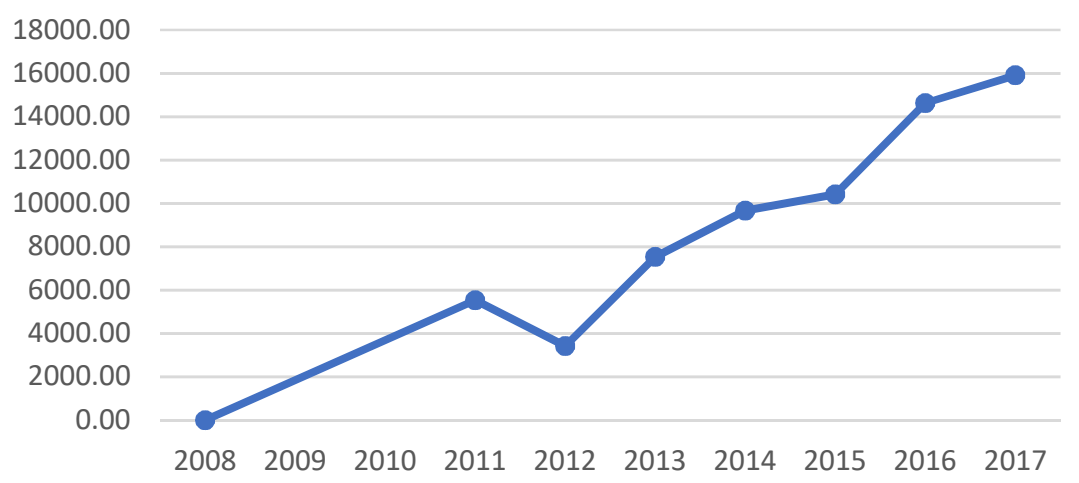




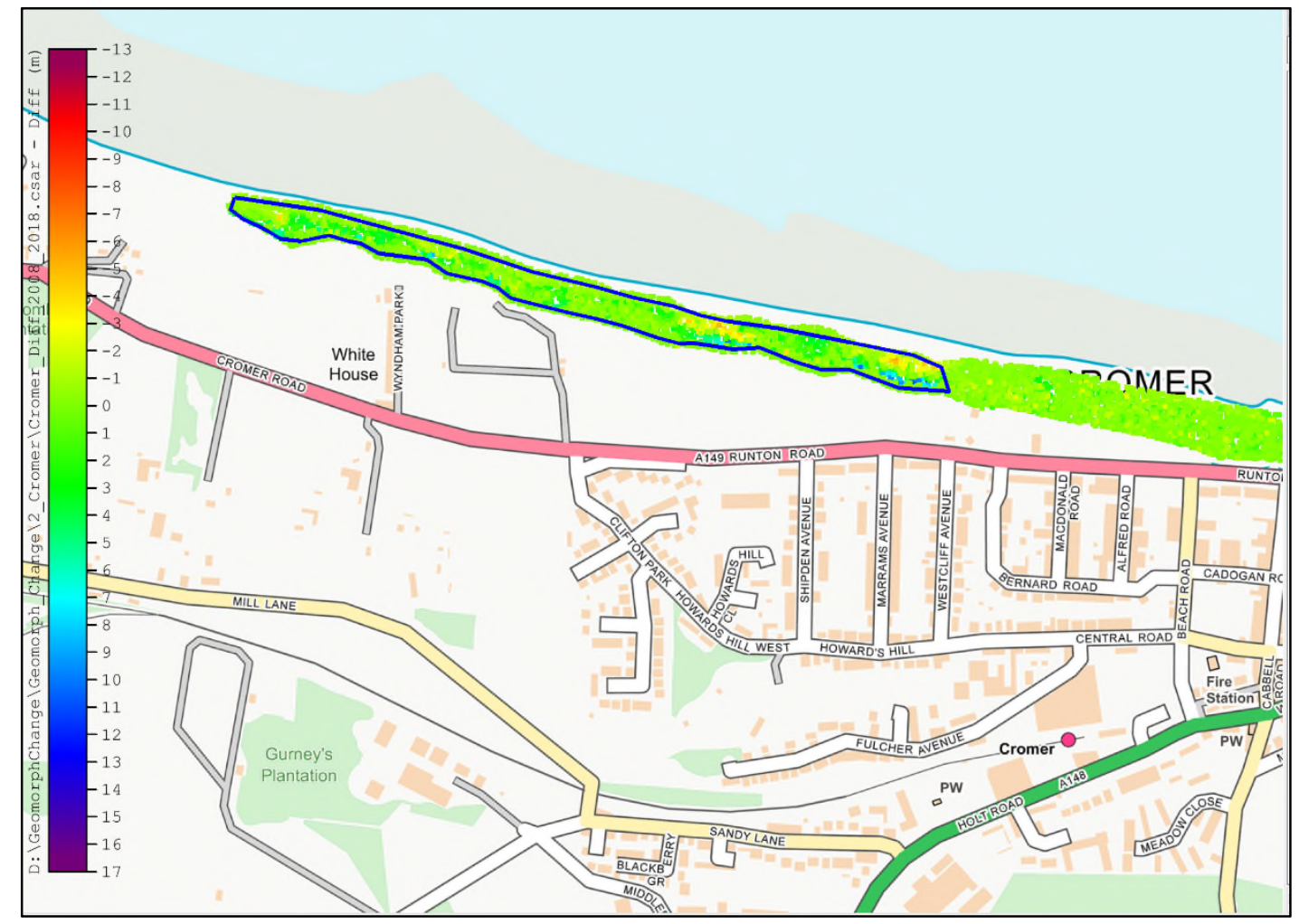

\section{Cumulative Volume Change $\left(\mathrm{m}^{3}\right)$}

\begin{tabular}{|c|c|}
\hline 2008 & 0 \\
\hline 2009 & - \\
\hline 2010 & - \\
\hline 2011 & 4231 \\
\hline 2012 & 2463 \\
\hline 2013 & 4700 \\
\hline 2014 & -18690 \\
\hline 2015 & -18190 \\
\hline 2016 & - \\
\hline 2017 & - \\
\hline 2018 & -21038 \\
\hline
\end{tabular}

Cromer Cumulative Volume Change $\mathrm{m}^{3}$ (over $0.9 \mathrm{~km}$ of coastline)

10000

5000

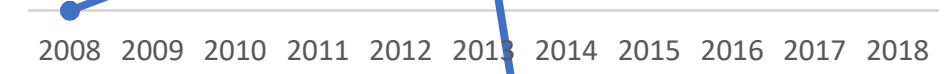

$-5000$

$-10000$

$-15000$

$-20000$

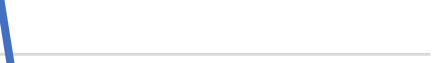




\subsubsection{Case Study Site 4: Sidestrand/Trimingham}

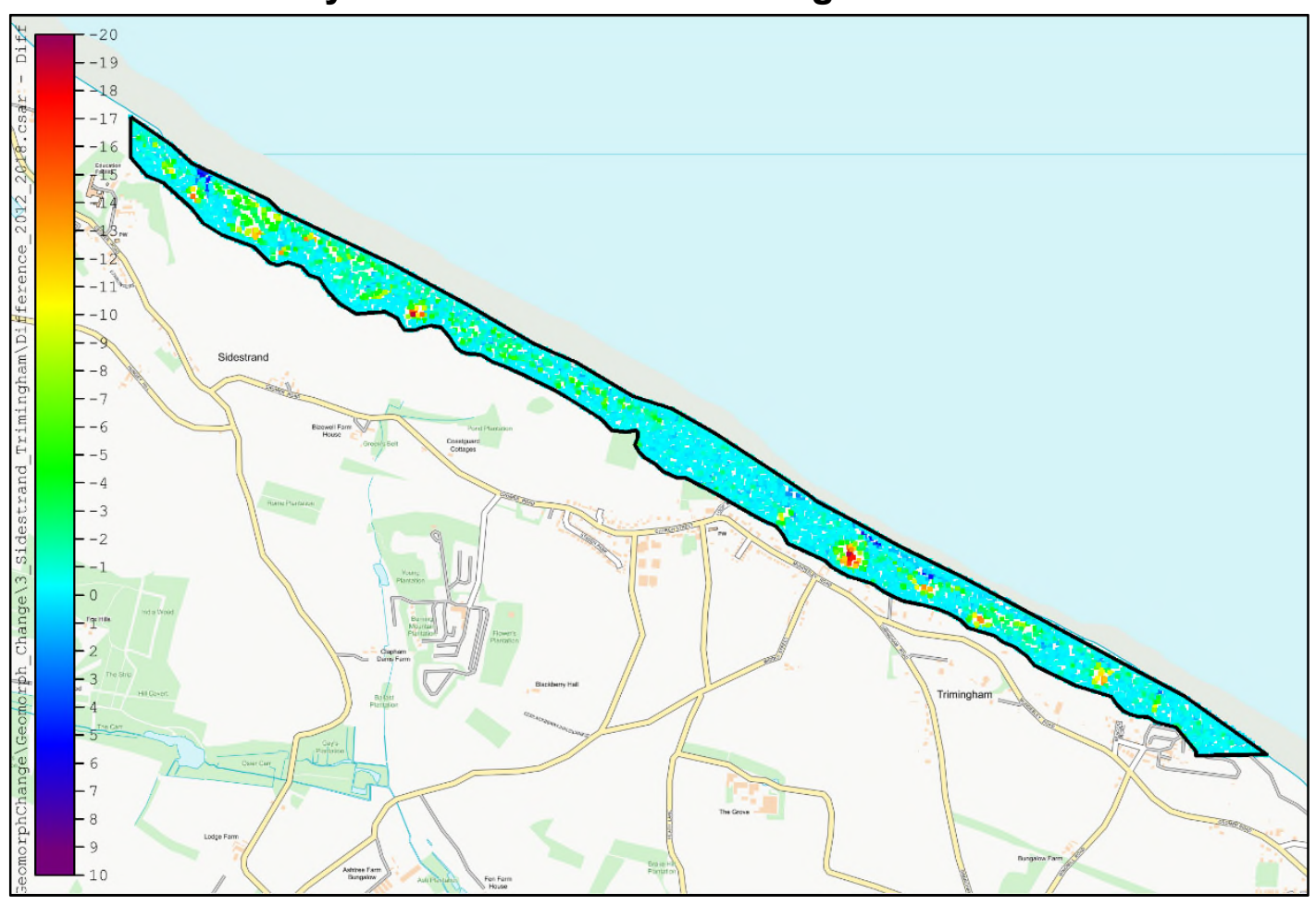

Cumulative Volume Change $\left(\mathrm{m}^{3}\right)$

\begin{tabular}{|c|c|}
\hline 2012 & 0 \\
\hline 2013 & -54107 \\
\hline 2014 & -291392 \\
\hline 2015 & -324748 \\
\hline 2016 & - \\
\hline 2017 & -541922 \\
\hline 2018 & -695904 \\
\hline
\end{tabular}

Sidestrand - Trimmingham Cumulative Volume Change $\mathrm{m}^{3}$ (over $4.23 \mathrm{~km}$ of coastline)

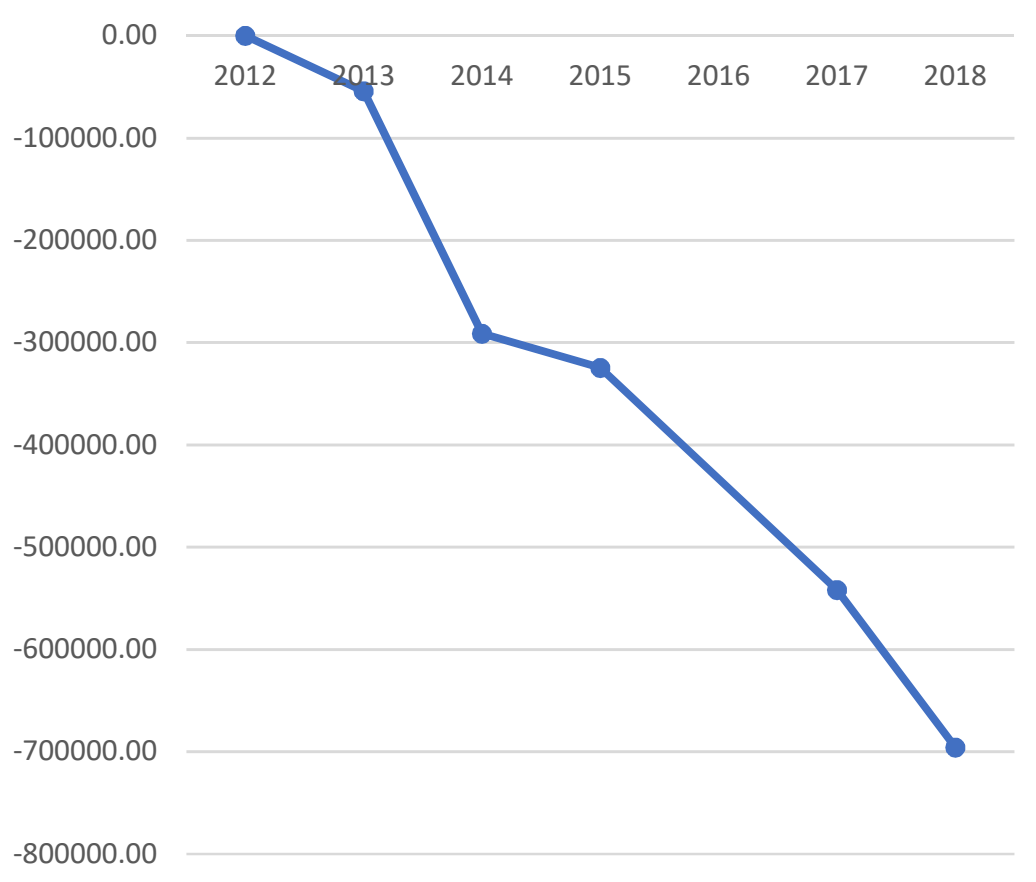




\subsubsection{Case Study Site 5: Mundesley}

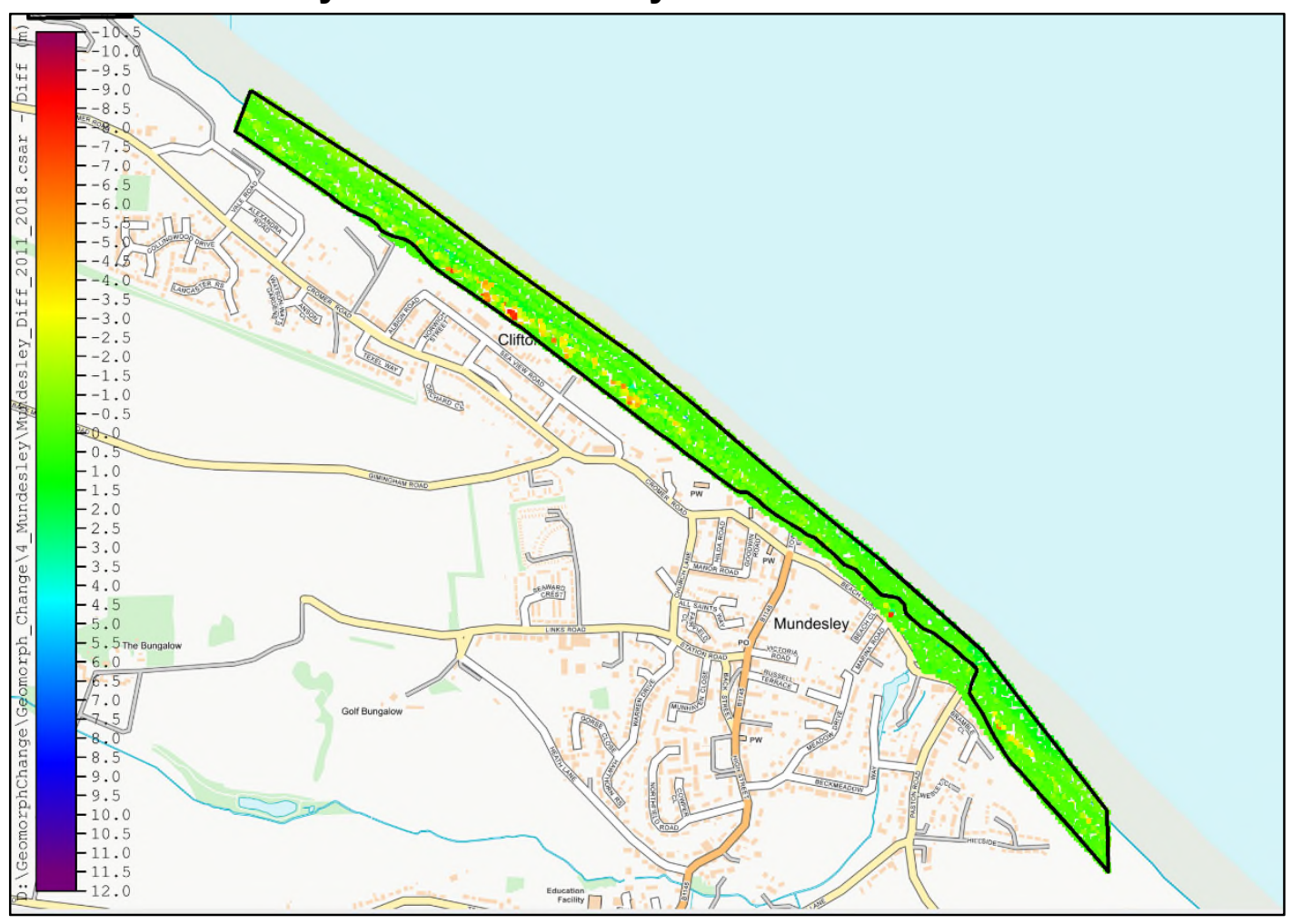

\section{Cumulative Volume Change $\left(\mathrm{m}^{3}\right)$}

\begin{tabular}{|c|c|}
\hline 2011 & 0 \\
\hline 2012 & 6456 \\
\hline 2013 & -5388 \\
\hline 2014 & -47018 \\
\hline 2015 & -43300 \\
\hline 2016 & - \\
\hline 2017 & -54398 \\
\hline 2018 & -51093 \\
\hline
\end{tabular}

Mundesley Cumulative Volume Change $\mathrm{m}^{3}$ (over $2.57 \mathrm{~km}$ of coastline)

10000.00

0.00

$-10000.00$

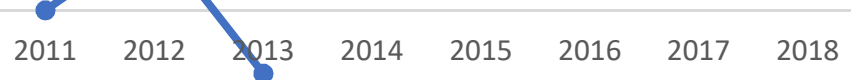

$-20000.00$

$-30000.00$

$-40000.00$

$-50000.00$

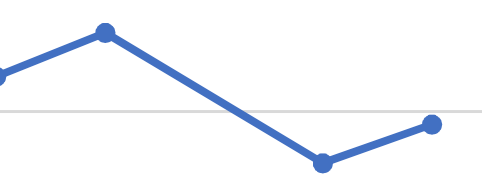

$-60000.00$ 


\subsubsection{Case Study Site 6: Bacton Gas Terminal}

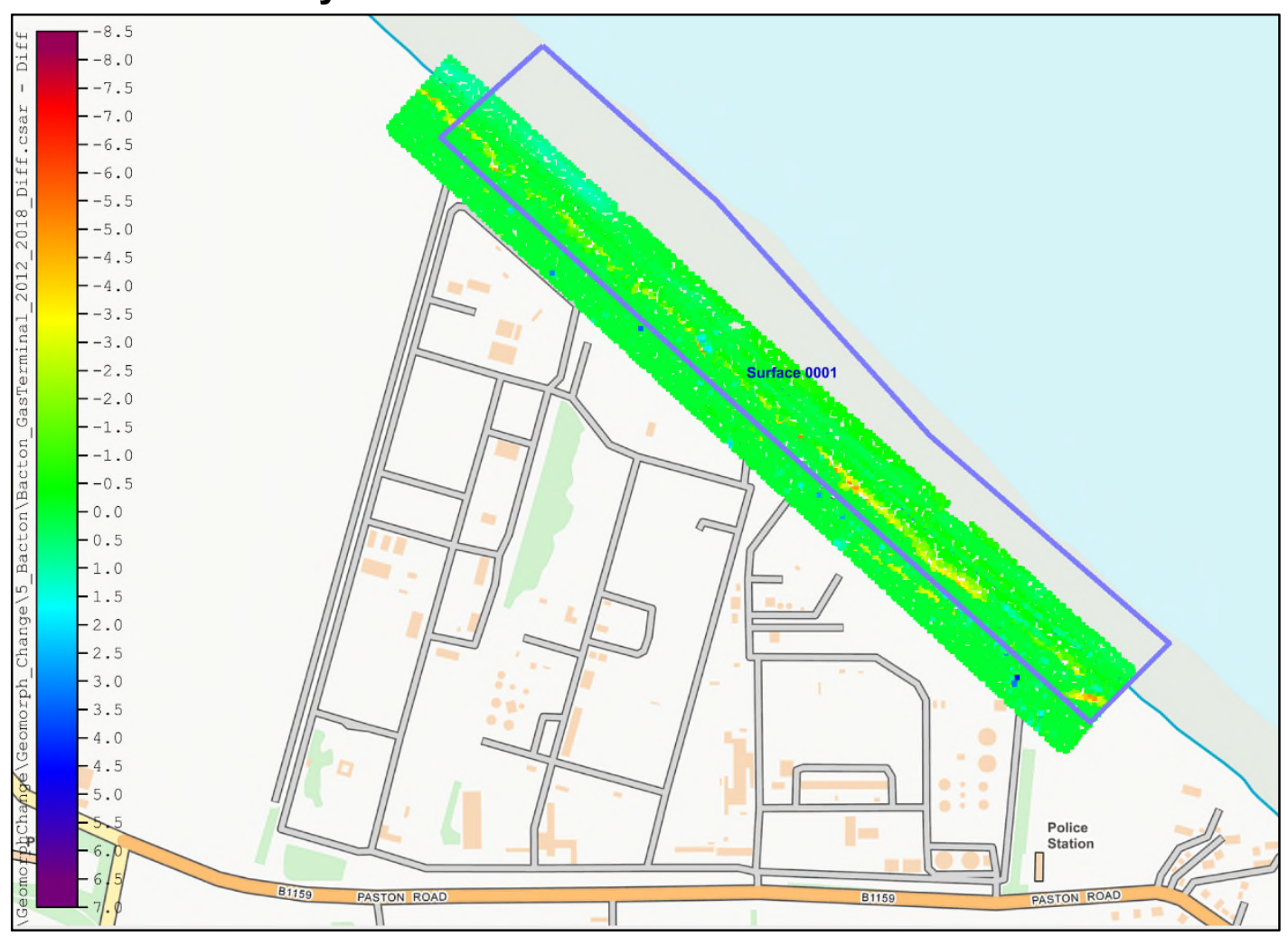

\section{Cumulative Volume Change $\left(\mathrm{m}^{3}\right)$}

\begin{tabular}{|c|c|}
\hline 2012 & 0 \\
\hline 2013 & -2334 \\
\hline 2014 & -26064 \\
\hline 2015 & -20009 \\
\hline 2016 & - \\
\hline 2017 & -26521 \\
\hline 2018 & -26916 \\
\hline
\end{tabular}

Bacton Gas Terminal Cumulative Volume Change $\mathrm{m}^{3}$ (over $1.11 \mathrm{~km}$ of coastline)

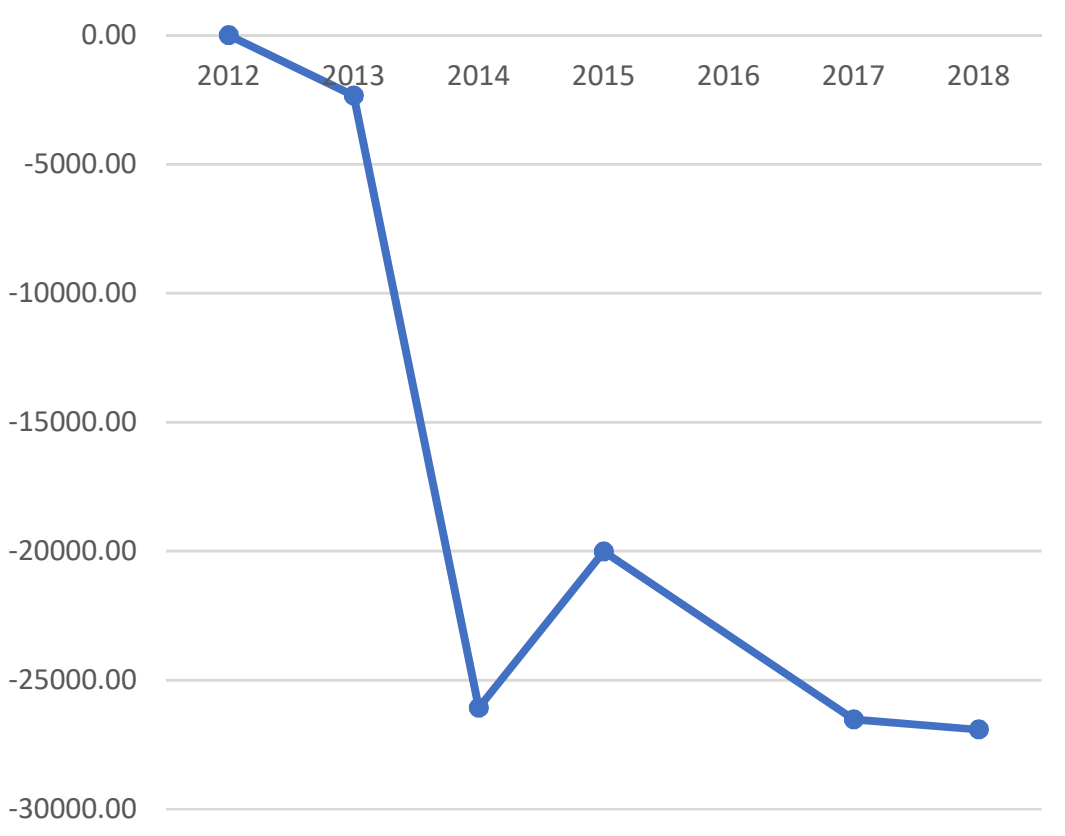


1.8.2.7 Case Study Site 7: Walcot to Happisburgh

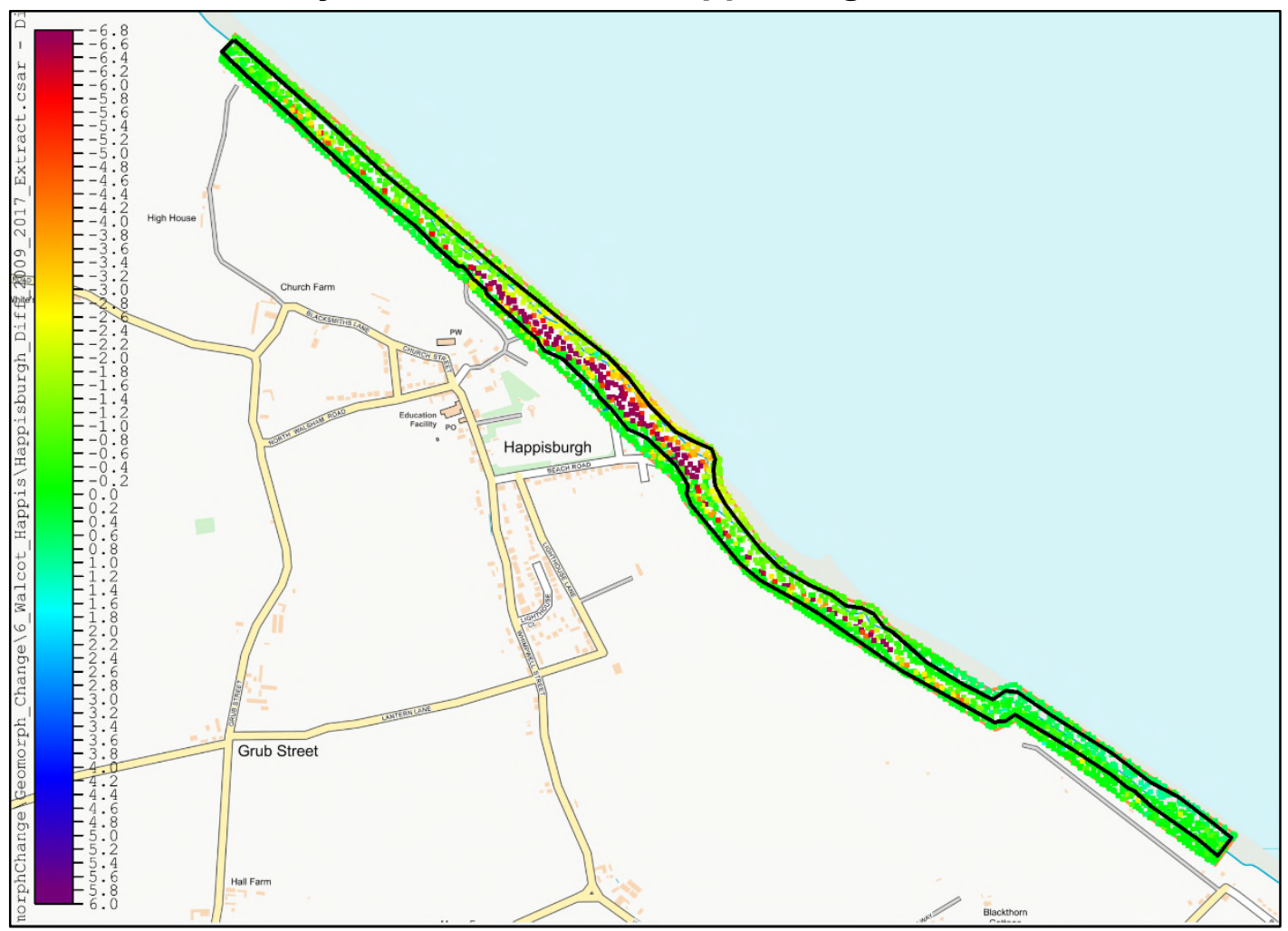

Cumulative Volume
\begin{tabular}{|c|c|}
\hline 2009 & 0 \\
\hline 2010 & - \\
\hline 2011 & - \\
\hline 2012 & -72644 \\
\hline 2013 & -144313 \\
\hline 2014 & -242890 \\
\hline 2015 & -275489 \\
\hline 2016 & -279450 \\
\hline 2017 & -314362 \\
\hline
\end{tabular}

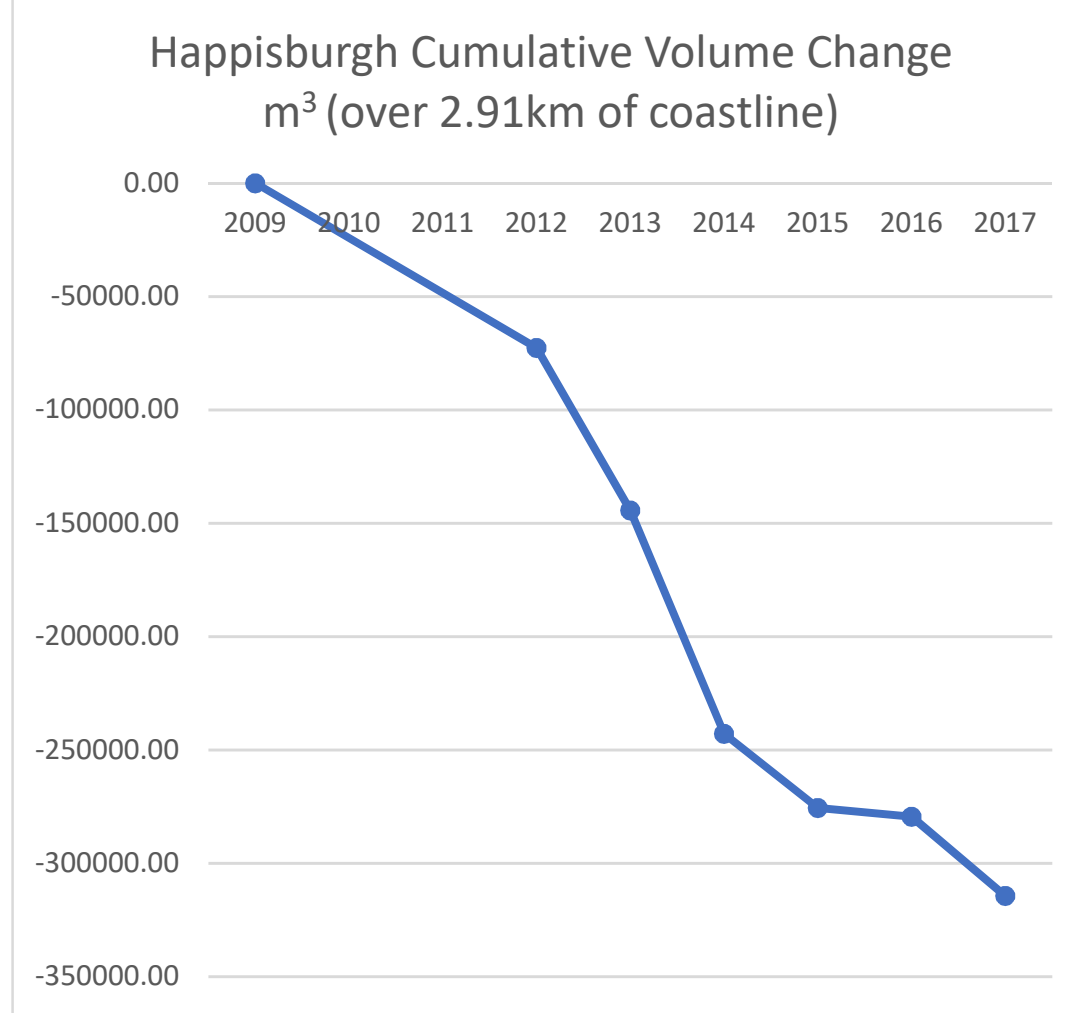


1.8.2.8 Case Study Site 8: Hemsby

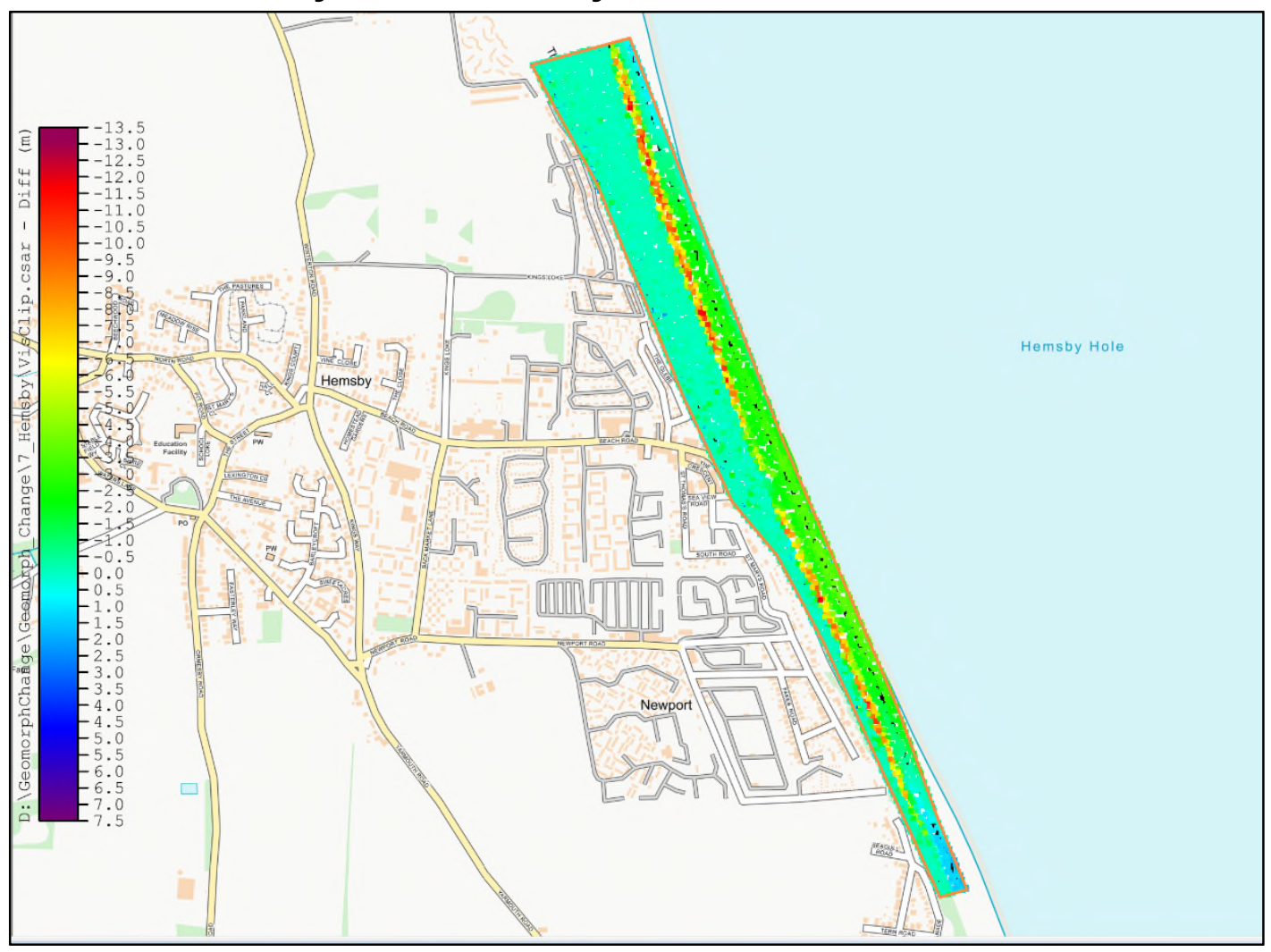

\section{Cumulative Volume Change $\left(\mathrm{m}^{3}\right)$}

\begin{tabular}{|c|c|}
\hline 2009 & 0 \\
\hline 2010 & - \\
\hline 2011 & - \\
\hline 2012 & -131371 \\
\hline 2013 & -283558 \\
\hline 2014 & - \\
\hline 2015 & -358882 \\
\hline 2016 & -345991 \\
\hline 2017 & - \\
\hline 2018 & -470352 \\
\hline
\end{tabular}

Hemsby Cumulative Volume Change $\mathrm{m}^{3}$ (over $2.34 \mathrm{~km}$ of coastline)

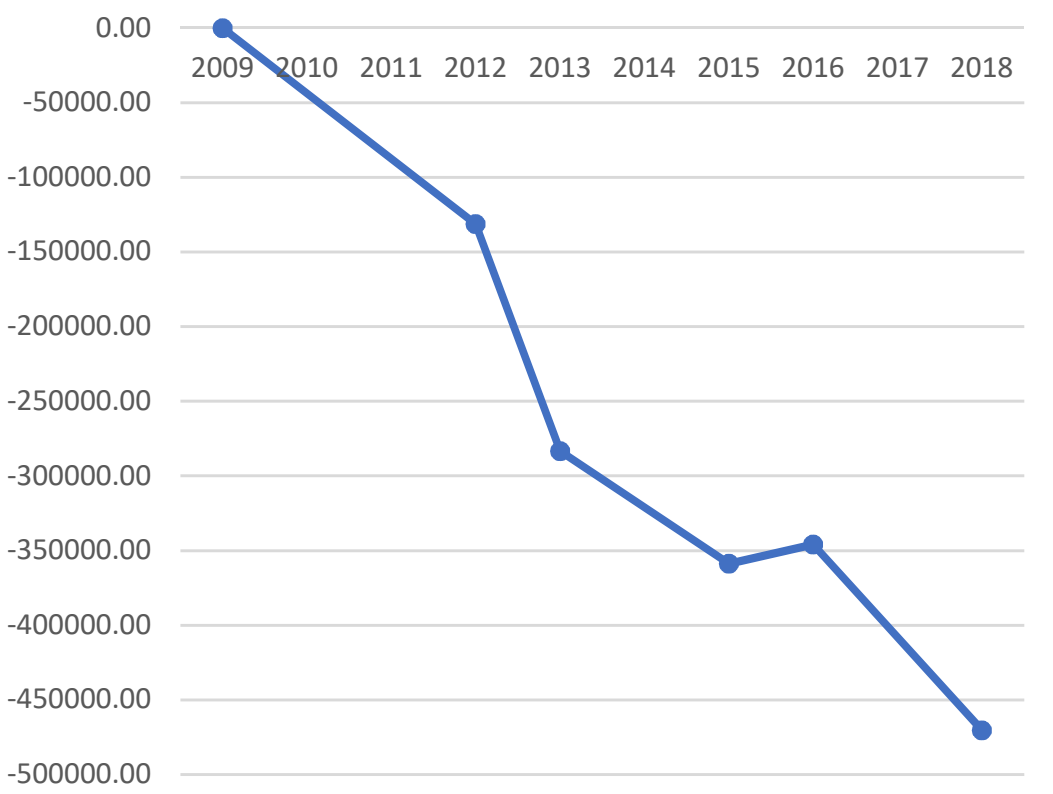


1.8.2.9 Case Study Site 9: Corton to Lowestoft

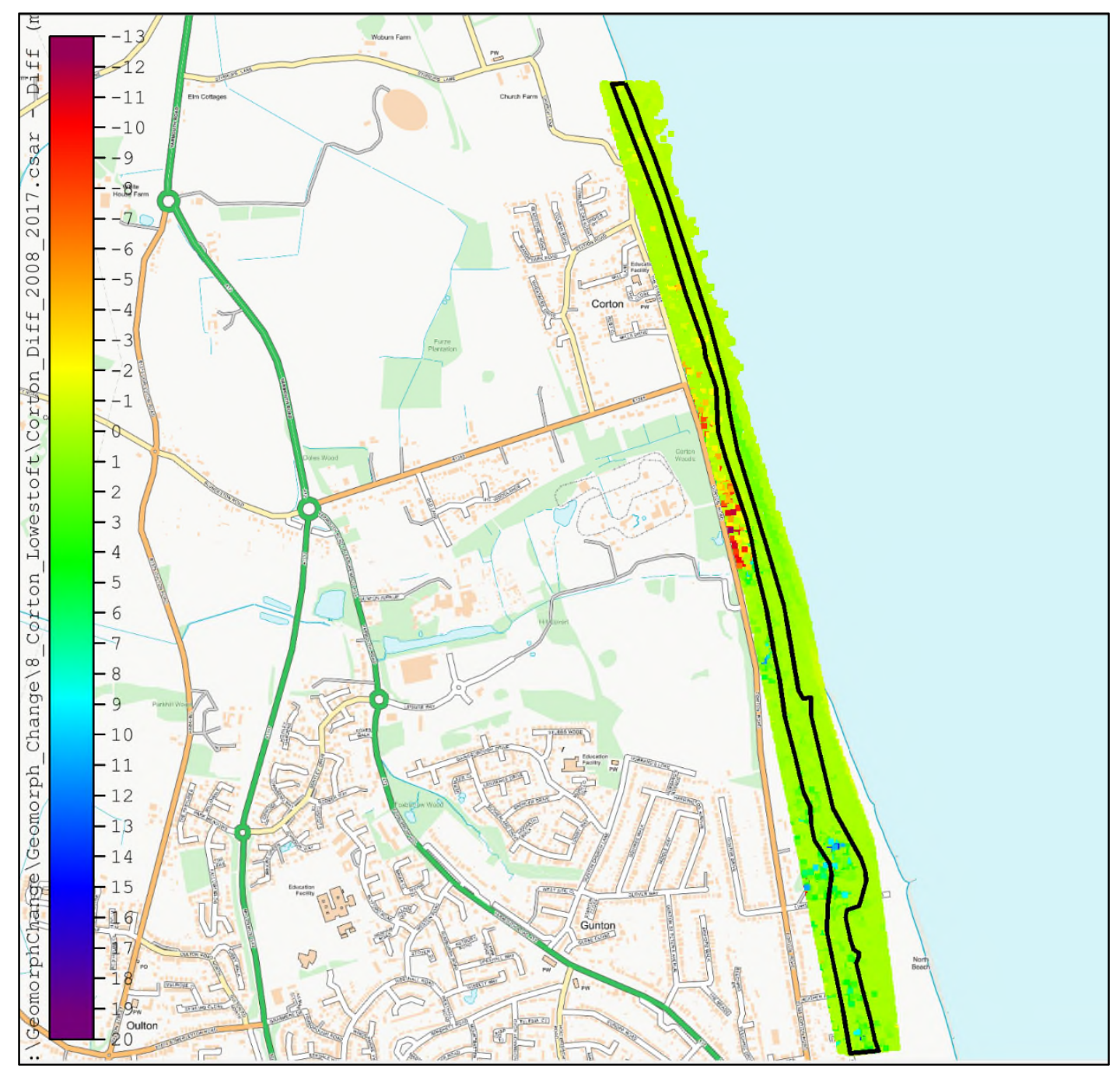

Cumulative Volume
\begin{tabular}{|c|c|}
\hline 2008 & 0 \\
\hline 2009 & - \\
\hline 2010 & - \\
\hline 2011 & -138397 \\
\hline 2012 & -62944 \\
\hline 2013 & -8910 \\
\hline 2014 & -40096 \\
\hline 2015 & -77544 \\
\hline 2016 & - \\
\hline 2017 & -14045 \\
\hline
\end{tabular}

Corton to Lowestoft Cumulative Volume Change $\mathrm{m}^{3}$ (over $3.28 \mathrm{~km}$ of coastline)

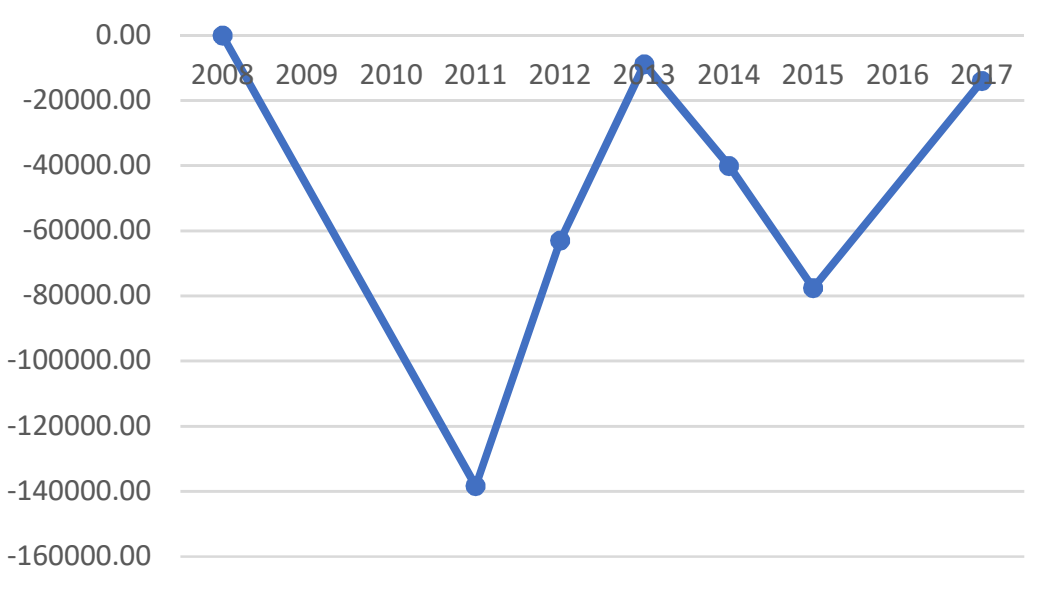


1.8.2.10 Case Study Site 10: Lowestoft NearShore

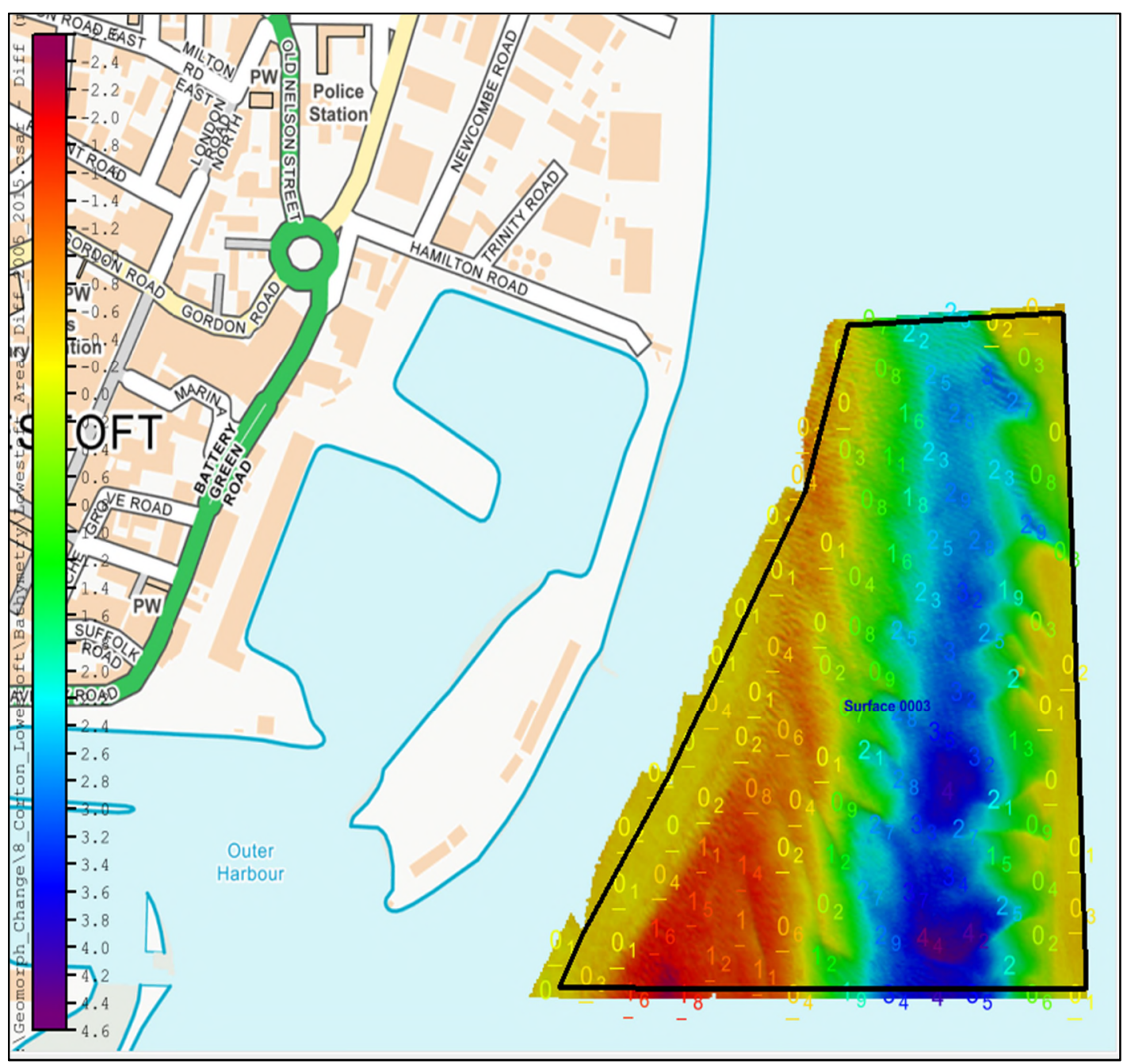

Cumulative Volume
\begin{tabular}{|r|r|}
\hline 2005 & 0 \\
\hline 2006 & -21031 \\
\hline 2007 & 3606 \\
\hline 2008 & 2140 \\
\hline 2009 & 45598 \\
\hline 2010 & 62872 \\
\hline 2011 & 49931 \\
\hline 2012 & 100387 \\
\hline 2013 & 120254 \\
\hline 2014 & 147110 \\
\hline 2015 & 169668 \\
\hline
\end{tabular}

Lowestoft Offshore Cumulative Change $\mathrm{m}^{3}$ (over $0.66 \mathrm{~km}$ of coastline)

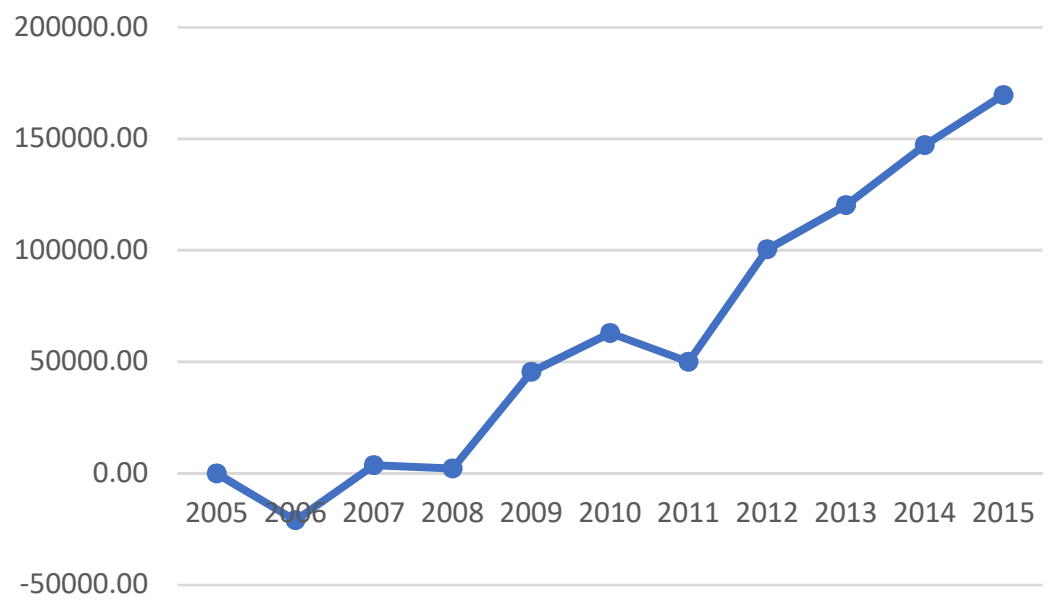


1.8.2.11 Case Study Site 11: Kessingland

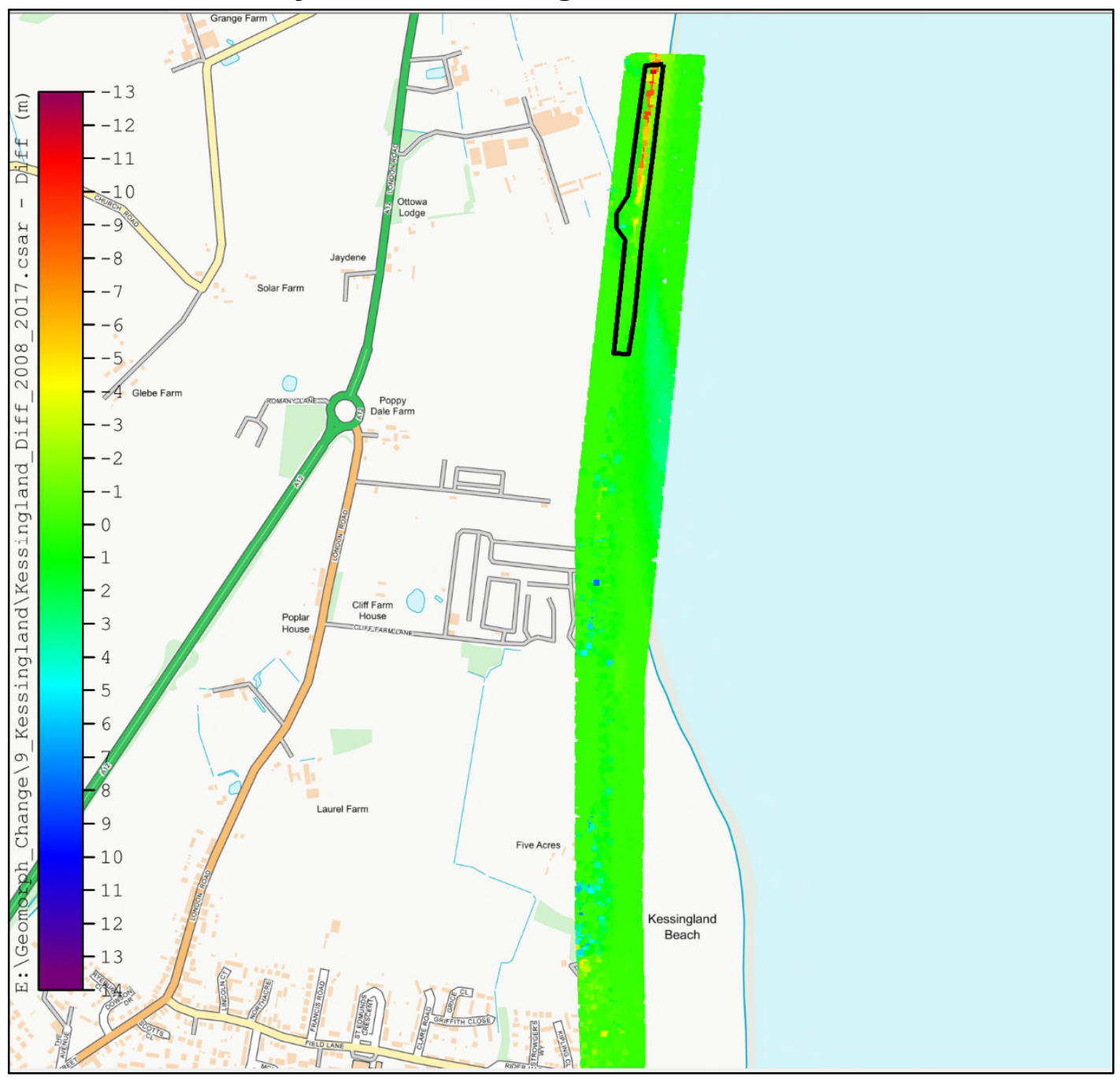

Cumulative Volume Change $\left(\mathrm{m}^{3}\right)$

\begin{tabular}{|c|c|}
\hline 2008 & 0 \\
\hline 2009 & - \\
\hline 2010 & - \\
\hline 2011 & -3234 \\
\hline 2012 & -1738 \\
\hline 2013 & -2224 \\
\hline 2014 & -8695 \\
\hline 2015 & -11226 \\
\hline 2016 & -25629 \\
\hline 2017 & -41288 \\
\hline
\end{tabular}

Kessingland Cumulative Volume Change $\mathrm{m}^{3}$ (over $0.65 \mathrm{~km}$ of coastline)

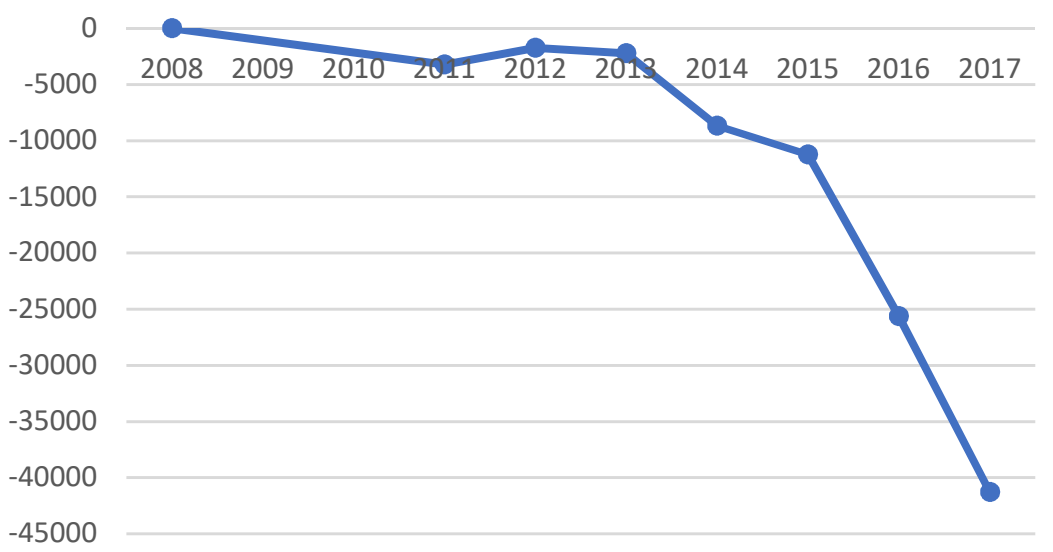


1.8.2.12 Case Study Site 12: Benacre

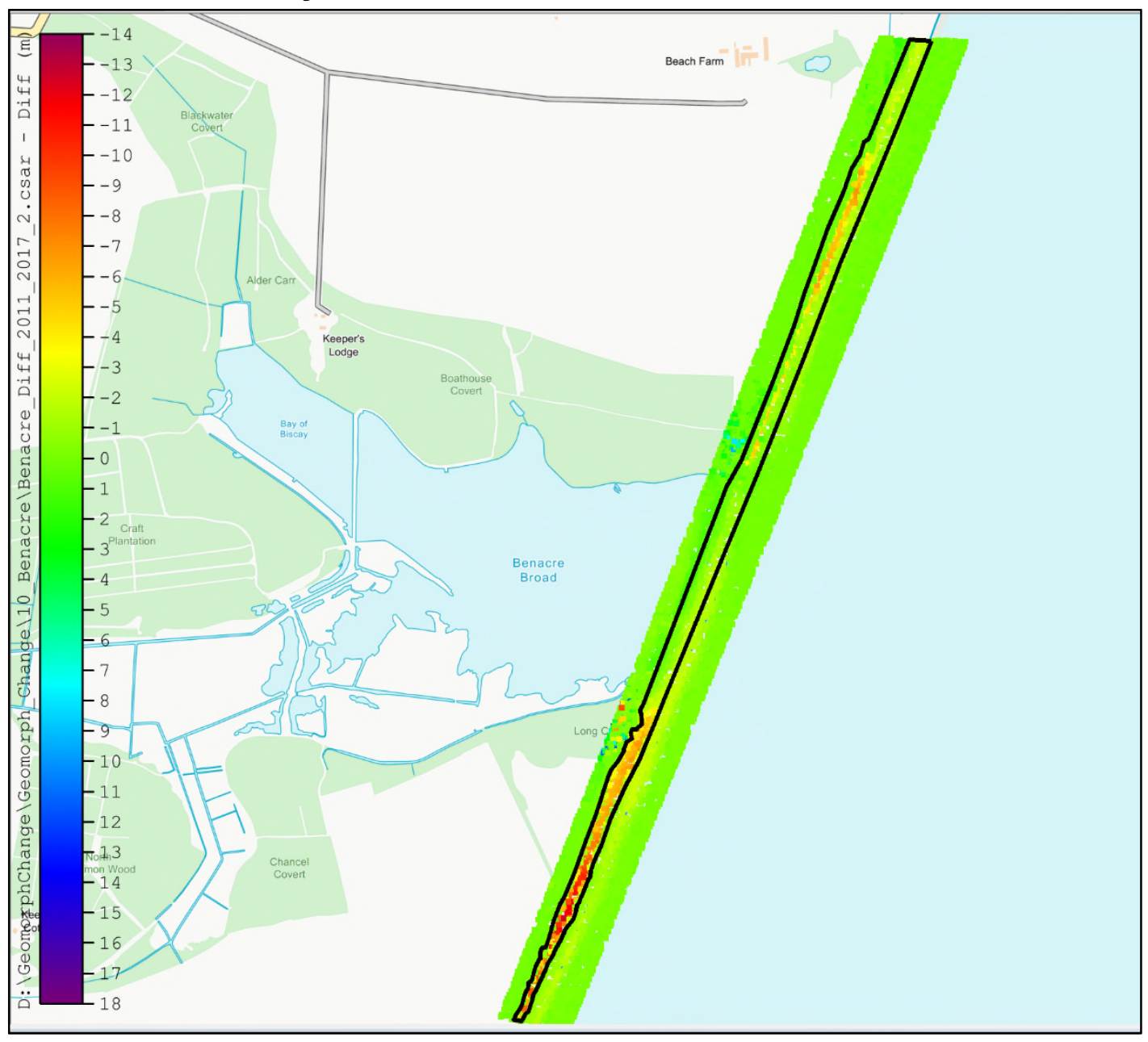

\section{Cumulative Volume Change $\left(\mathrm{m}^{3}\right)$}

\begin{tabular}{|l|c|}
\hline 2011 & 0 \\
\hline 2012 & -10060 \\
\hline 2013 & -13596 \\
\hline 2014 & -93616 \\
\hline 2015 & -98586 \\
\hline 2016 & -141326 \\
\hline 2017 & -164097 \\
\hline
\end{tabular}

Benacre Cumulative Volume Loss $\mathrm{m}^{3}$ (over $2.09 \mathrm{~km}$ of coastline)

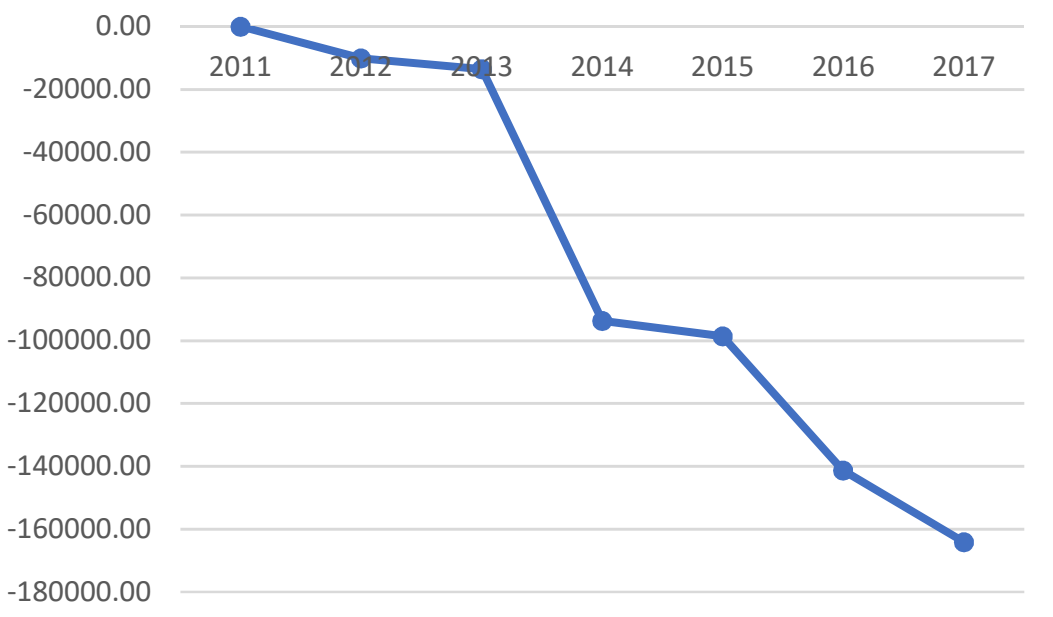


1.8.2.13 Case Study Site 13: Easton Bavents

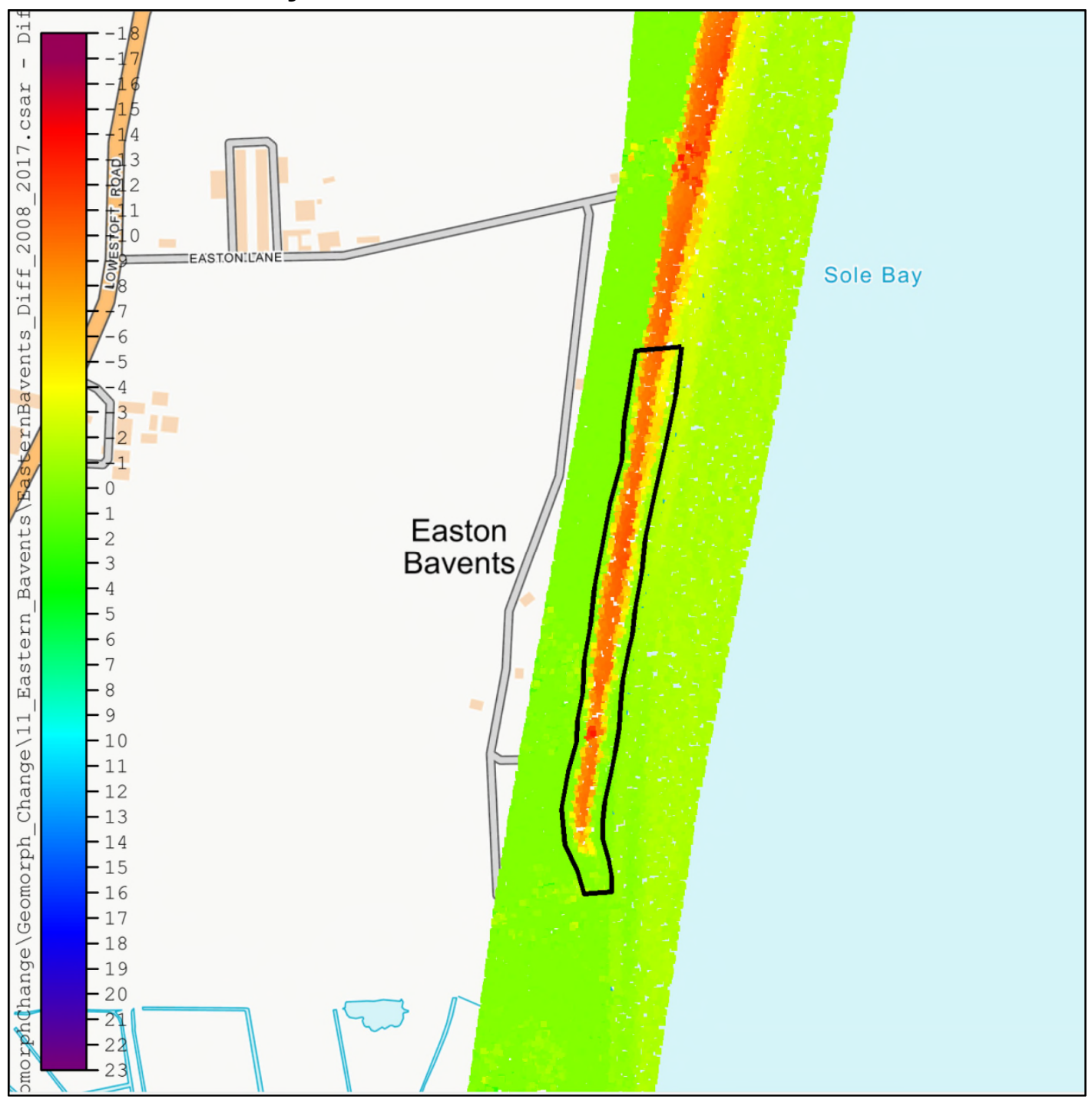

Cumulative Volume Change $\left(\mathrm{m}^{3}\right)$

\begin{tabular}{|c|c|}
\hline 2008 & 0 \\
\hline 2009 & - \\
\hline 2010 & - \\
\hline 2011 & -4290 \\
\hline 2012 & -5816 \\
\hline 2013 & -10818 \\
\hline 2014 & -21120 \\
\hline 2015 & -49413 \\
\hline 2016 & -128639 \\
\hline 2017 & -131015 \\
\hline
\end{tabular}

Easton Bavents Cumulative Volume Change $\mathrm{m}^{3}$ (over $0.62 \mathrm{~km}$ of coastline)

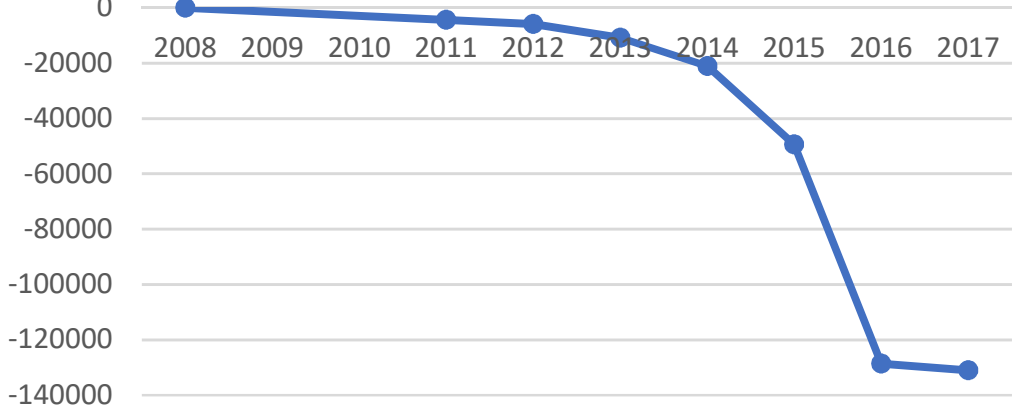




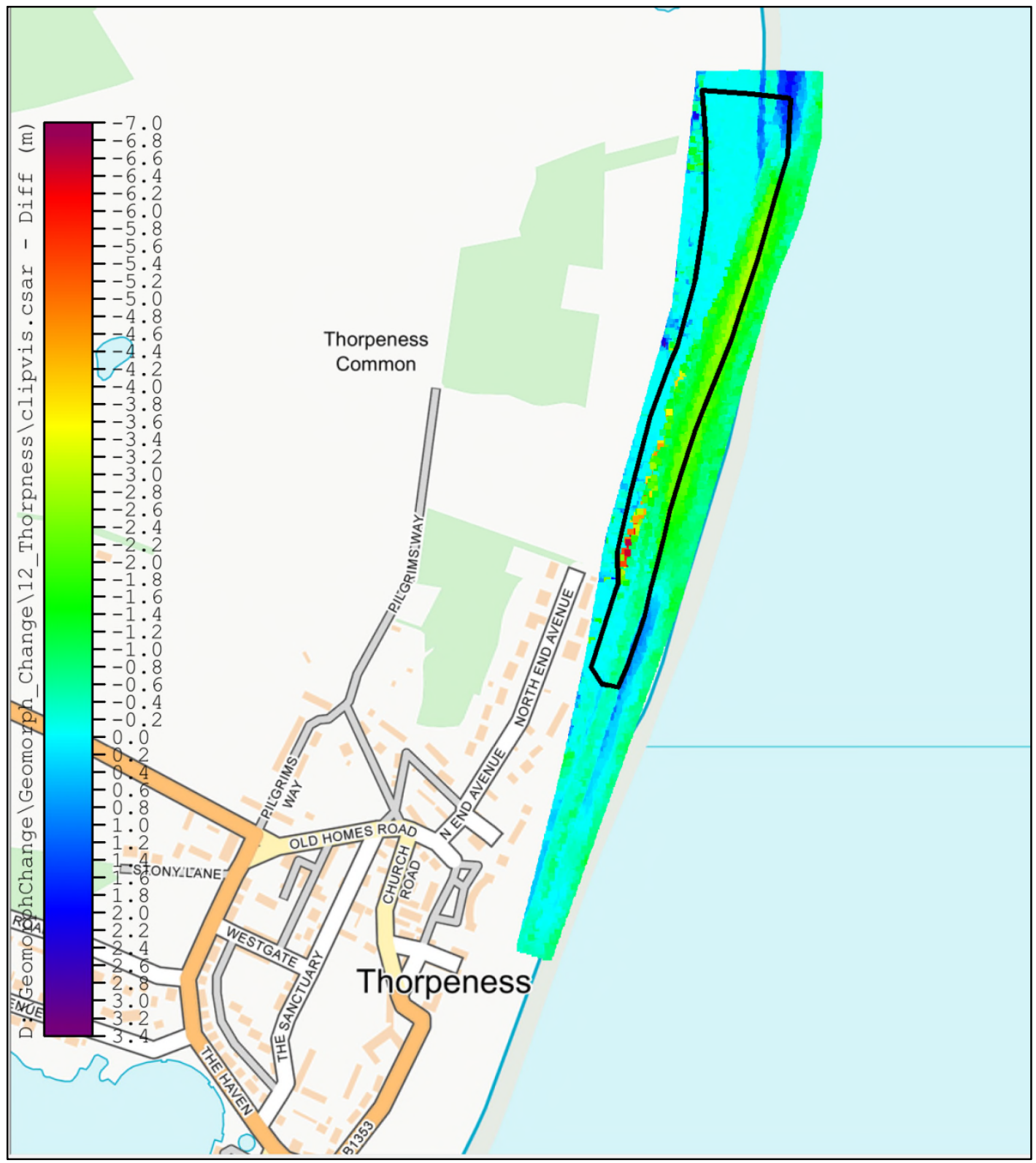

\section{Cumulative Volume Change $\left(\mathrm{m}^{3}\right)$}

\begin{tabular}{|c|c|}
\hline 2008 & 0 \\
\hline 2009 & - \\
\hline 2010 & - \\
\hline 2011 & -7431 \\
\hline 2012 & -3812 \\
\hline 2013 & -12667 \\
\hline 2014 & -331 \\
\hline 2015 & -14405 \\
\hline 2016 & -22355 \\
\hline 2017 & -57630 \\
\hline
\end{tabular}

Thorpness Cumulative Volume Change $\mathrm{m}^{3}$ (over $0.64 \mathrm{~km}$ of coastline) 


\subsection{References}

Abellán, A., Oppikofer, T., Jaboyedoff, M., Rosser, N.J., Lim, M., Lato, M.J., 2014. Terrestrial laser scanning of rock slope instabilities. Earth Surf. Process. Landforms 39, 80-97. https://doi.org/10.1002/esp.3493

Amaro, V.E., Gomes, L.R.S., de Lima, F.G.F., Scudelari, A.C., Neves, C.F., Busman, D.V., Santos, A.L.S., 2015. Multitemporal Analysis of Coastal Erosion Based on Multisource Satellite Images, Ponta Negra Beach, Natal City, Northeastern Brazil. Mar. Geod. 38, 1-25. https://doi.org/10.1080/01490419.2014.904257

Andersen, M.S., Gergely, Á., Al-Hamdani, Z., Steinbacher, F., Larsen, L.R., Ernstsen, V.B., 2017. Processing and performance of topobathymetric lidar data for geomorphometric and morphological classification in a high-energy tidal environment. Hydrol. Earth Syst. Sci. 21, 43-63. https://doi.org/10.5194/hess-21-43-2017

Appeaning Addo, K., Walkden, M., Mills, J.P., 2008. Detection, measurement and prediction of shoreline recession in Accra, Ghana. ISPRS J. Photogramm. Remote Sens. 63, 543-558. https://doi.org/10.1016/j.isprsjprs.2008.04.001

Aragonés, L., Pagán, J.I., López, M.P., García-Barba, J., 2016. The impacts of Segura River (Spain) channelization on the coastal seabed. Sci. Total Environ. 543, 493-504. https://doi.org/10.1016/j.scitotenv.2015.11.058

Atkinson, J., Esteves, L.S., Williams, J.W., McCann, D.L., Bell, P.S., 2018. The Application of XBand Radar for Characterization of Nearshore Dynamics on a Mixed Sand and Gravel Beach. J. Coast. Res. 85, 281-285. https://doi.org/10.2112/SI85-057.1

BBC, 2017. Thorpeness cliff collapse: Cordon in place after death [WWW Document]. URL https://www.bbc.com/news/uk-england-suffolk-38625067 (accessed 6.10.19).

Bell, P.S., Bird, C.O., Plater, A.J., 2016. A temporal waterline approach to mapping intertidal areas using $X$-band marine radar. Coast. Eng. 107, 84-101. https://doi.org/10.1016/j.coastaleng.2015.09.009

Brooks, S.M., Spencer, T., 2010. Temporal and spatial variations in recession rates and sediment release from soft rock cliffs, Suffolk coast, UK. Geomorphology 124, 26-41. https://doi.org/10.1016/j.geomorph.2010.08.005

Burningham, H., French, J., 2016. Shoreline - Shoreface Dynamics on the Suffolk Coast.

Burningham, H., French, J., 2011. Seabed dynamics in a lage coastal embayment: 180 years of morphological change in the outer Thames estuary. Hydrobiologia 672, 105-119. https://doi.org/10.1007/s10750-011-0760-y

Calder, B.R., 2003. Automatic Statistical Processing of Multibeam Echosounder Data. Int. Hydrogr. Rev. 4, 53-68. https://doi.org/10.1029/2002gc000486

Cantrill, B.O., Kruimel, D., 2013. The CARIS Engineering Analysis Module assisting in the management of Queensland's waterways. Int. Hydrogr. Rev. 7-14.

Channel Coastal Observatory, 2016. Cliff Laser Scan Survey Report -Telscombe Cliffs, 4d-SU10. 
Corbí, H., Riquelme, A., Megías-Baños, C., Abellan, A., 2018. 3-D Morphological Change Analysis of a Beach with Seagrass Berm Using a Terrestrial Laser Scanner. ISPRS Int. J. Geo-Information 7, 234. https://doi.org/10.3390/ijgi7070234

Cove, K., Lavoie, F., 2007. Addressing the Need for a Bathymetric Data Management System, in: Proceeding of the US Hydro 2007 Conference. Norfolk, VA, USA, pp. 14-17.

Dawson, J.L., Smithers, S.G., 2010. Shoreline and beach volume change between 1967 and 2007 at Raine Island, Great Barrier Reef, Australia. Glob. Planet. Change 72, 141-154. https://doi.org/10.1016/j.gloplacha.2010.01.026

Defra, 2012. Coastal Pathfinder Evaluation: An Assessment of the Five Largest Pathfinder Projects.

Earlie, C.S., Masselink, G., Russell, P.E., Shail, R.K., 2015. Application of airborne LiDAR to investigate rates of recession in rocky coast environments. J. Coast. Conserv. 19, 831845. https://doi.org/10.1007/s11852-014-0340-1

Eisemann, E.R., Wallace, D.J., Buijsman, M.C., Pierce, T., 2018. Response of a vulnerable barrier island to multi-year storm impacts: LiDAR-data-inferred morphodynamic changes on Ship Island, Mississippi, USA. Geomorphology 313, 58-71. https://doi.org/10.1016/j.geomorph.2018.04.001

Environment Agency, 2016. Anglian Coastal Monitoring 2015-16 programme report RP046A.

Environment Agency, 2013. Coastal Trends Report - North East Norfolk and North Suffolk (Kelling Hard to Lowestoft Ness).

Environment Agency, 2012. Coastal Trends Report North Norfolk (Old Hunstanton to Kelling).

Environment Agency, 2011. Coastal Trends Report Suffolk (Lowestoft to Languard Point, Felixstowe).

Esposito, G., Salvini, R., Matano, F., Sacchi, M., Troise, C., 2018. Evaluation of geomorphic changes and retreat rates of a coastal pyroclastic cliff in the Campi Flegrei volcanic district, southern Italy. J. Coast. Conserv. 22, 957-972. https://doi.org/10.1007/s11852018-0621-1

Foster, B., Hamilton, T., Cover, K., Mcleay, C., 2017. Automating the Ping-To-Chart Workflow, in: US Hydro 2017.

Ganju, N.K., Suttles, S.E., Beudin, A., Nowacki, D.J., Miselis, J.L., Andrews, B.D., 2017. Quantification of Storm-Induced Bathymetric Change in a Back-Barrier Estuary. Estuaries and Coasts 40, 22-36. https://doi.org/10.1007/s12237-016-0138-5

Gorman, L., Morang, A., Larson, R., 1998. Monitoring the coastal environment; part IV: mapping, shoreline changes, and bathymetric analysis. J. Coast. Res. 61-92.

GOV.UK, 2017. Open data for better ourcomes [WWW Document]. URL https://quarterly.blog.gov.uk/2017/02/02/open-data-for-better-outcomes/ (accessed 9.16.17).

Halls, J.N., Frishman, M.A., Hawkes, A.D., 2018. An automated model to classify barrier island 
geomorphology using lidar data and change analysis (1998-2014). Remote Sens. 10, 121. https://doi.org/10.3390/rs10071109

Hobbs, P., 2008. Coastal cliff monitoring. Geo-connection UK 6, 16-17.

Hobbs, P., Gibson, A., Jones, L., Poulton, C., Jenkins, G., Pearson, S., Freeborough, K., 2010. Monitoring coastal change using terrestrial LiDAR, Geological Society, London, Special Publications. https://doi.org/10.1144/SP345.12

Iwen, D., WAz, M., 2019. Benefits of using ASV MBES surveys in shallow waters and restriced areas. 2019 Eur. Navig. Conf. 1-3. https://doi.org/10.1109/euronav.2019.8714128

Jackson, C.W., Alexander, C.R., Bush, D.M., 2012. Application of the AMBUR R package for spatio-temporal analysis of shoreline change: Jekyll Island, Georgia, USA. Comput. Geosci. 41, 199-207. https://doi.org/10.1016/j.cageo.2011.08.009

Kaliraj, S., Chandrasekar, N., Ramachandran, K.K., 2017. Mapping of coastal landforms and volumetric change analysis in the south west coast of Kanyakumari, South India using remote sensing and GIS techniques. Egypt. J. Remote Sens. Sp. Sci. 20, 265-282. https://doi.org/10.1016/j.ejrs.2016.12.006

Kemp, J., Brampton, A., 2007. The development of a time trend analysis tool for GIS and its application in the assessment of Nash Bank, South Wales. J. Hydroinformatics 9, 193. https://doi.org/10.2166/hydro.2007.022

Krolik-Root, C., Stansbury, D.L., Burnside, N.G., 2015. Effective LiDAR-based modelling and visualisation of managed retreat scenarios for coastal planning: An example from the southern UK. Ocean Coast. Manag. 114, 164-174. https://doi.org/10.1016/j.ocecoaman.2015.06.013

Kromer, R.A., Abellán, A., Hutchinson, D.J., Lato, M., Chanut, M.A., Dubois, L., Jaboyedoff, M., 2017. Automated terrestrial laser scanning with near-real-time change detection Monitoring of the Séchilienne landslide. Earth Surf. Dyn. 5, 293-310. https://doi.org/10.5194/esurf-5-293-2017

Kromer, R.A., Abellán, A., Hutchinson, D.J., Lato, M., Edwards, T., Jaboyedoff, M., 2015. A 4D filtering and calibration technique for small-scale point cloud change detection with a terrestrial laser scanner. Remote Sens. 7, 13029-13058. https://doi.org/10.3390/rs71013029

Kulawiak, M., Chybicki, A., 2018. Application of Web-GIS and Geovisual Analytics to Monitoring of Seabed Evolution in South Baltic Sea Coastal Areas. Mar. Geod. 41, 405426. https://doi.org/10.1080/01490419.2018.1469557

Lague, D., Brodu, N., Leroux, J., 2013. Accurate 3D comparison of complex topography with terrestrial laser scanner: Application to the Rangitikei canyon ( $\mathrm{N}-\mathrm{Z}$ ). ISPRS J. Photogramm. Remote Sens. 82, 10-26. https://doi.org/10.1016/j.isprsjprs.2013.04.009

Leyland, J., Hackney, C.R., Darby, S.E., Parsons, D.R., Best, J.L., Nicholas, A.P., Aalto, R., Lague, D., 2017. Extreme flood-driven fluvial bank erosion and sediment loads: direct process measurements using integrated Mobile Laser Scanning (MLS) and hydro-acoustic techniques. Earth Surf. Process. Landforms 42, 334-346. 
https://doi.org/10.1002/esp.4078

Lindenbergh, R., Pietrzyk, P., 2015. Change detection and deformation analysis using static and mobile laser scanning. Appl. Geomatics 7, 65-74. https://doi.org/10.1007/s12518014-0151-y

$\begin{array}{lllll}\text { M3C2 } & \text { (Plugin) } & \text { [WWW } & \text { Document }], & \text { URL }\end{array}$ http://www.cloudcompare.org/doc/wiki/index.php?title=M3C2_(plugin) (accessed 11.28.18).

Michoud, C., Carrea, D., Costa, S., Derron, M.H., Jaboyedoff, M., Delacourt, C., Maquaire, O., Letortu, P., Davidson, R., 2015. Landslide detection and monitoring capability of boatbased mobile laser scanning along Dieppe coastal cliffs, Normandy. Landslides 12, 403418. https://doi.org/10.1007/s10346-014-0542-5

Miller, P., Mills, J., Edwards, S., Bryan, P., Marsh, S., Hobbs, P., Mitchell, H., 2008. A robust surface matching technique for coastal geohazard assessment and management. ISPRS J. Photogramm. Remote Sens. 63, 529-542. https://doi.org/10.1080/01490410701296598

Mitasova, H., 2015. Terrain Dynamics Analysis Using Space-Time Domain Hypersurfaces and Gradient Trajectories Derived From Time Series of 3D Point Clouds.

Mitasova, H., Drake, T., Harmon, R., Hofierka, J., Mcninch, J., 2002. Spatio-temporal monitoring of evolving topography using LIDAR, Real Time Kinematic GPS and sonar data. Processing 11-13.

Mitasova, H., Overton, M.F., Recalde, J.J., Bernstein, D.J., Freeman, C.W., 2009. Raster-Based Analysis of Coastal Terrain Dynamics from Multitemporal Lidar Data. J. Coast. Res. 252, 507-514. https://doi.org/10.2112/07-0976.1

Nicholls, R.J., Dawson, R.J., Day, S.A. (Eds.), 2015. Broad Scale Coastal Simulation, Advances in Global Change Research. Springer Netherlands, Dordrecht. https://doi.org/10.1007/978-94-007-5258-0

Obu, J., Lantuit, H., Grosse, G., Günther, F., Sachs, T., Helm, V., Fritz, M., 2017. Coastal erosion and mass wasting along the Canadian Beaufort Sea based on annual airborne LiDAR elevation data. Geomorphology 293, 331-346. https://doi.org/10.1016/j.geomorph.2016.02.014

Payo, A., Antelo, B.J., Hurst, M., Palaseanu-Lovejoy, M., Williams, C., Jenkins, G., Lee, K., FavisMortlock, D., Barkwith, A., Ellis, M.A., 2018a. Development of an automatic delineation of cliff top and toe on very irregular planform coastlines (CliffMetrics v1.0). Geosci. Model Dev. https://doi.org/10.5194/gmd-11-4317-2018

Payo, A., Walkden, M., Ellis, M.A., Barkwith, A., Favis-Mortlock, D., Kessler, H., Wood, B., Burke, H., Lee, J., 2018b. A quantitative assessment of the annual contribution of platform downwearing to beach sediment budget: Happisburgh, England, UK. J. Mar. Sci. Eng. 6. https://doi.org/10.3390/jmse6040113

Pollard, J.A., Brooks, S.M., Spencer, T., 2019. Harmonising topographic \& remotely sensed datasets, a reference dataset for shoreline and beach change analysis. Sci. data 6, 42. 
https://doi.org/10.1038/s41597-019-0044-3

Poulton, C.V.L., Lee, J.R., Hobbs, P.R.N., Jones, L., Hall, M., 2006. Preliminary investigation into monitoring coastal erosion using terrestrial laser scanning : case study at Happisburgh, Norfolk. Bull. Geol. Soc. Norfolk 56, 45-64.

Quinn, R., Boland, D., 2010. The role of time-lapse bathymetric surveys in assessing morphological change at shipwreck sites. J. Archaeol. Sci. 37, 2938-2946. https://doi.org/10.1016/J.JAS.2010.07.005

Rosser, N.J., Brain, M.J., Petley, D.N., Lim, M., Norman, E.C., 2013. Coastline retreat via progressive failure of rocky coastal cliffs. Geology 41, 939-942. https://doi.org/10.1130/G34371.1

Rosser, N.J., Petley, D.N., Lim, M., Dunning, S.A., Allison, R.J., 2005. Terrestrial laser scanning for monitoring the process of hard rock coastal cliff erosion. Q. J. Eng. Geol. Hydrogeol. 38, $363 \mathrm{LP}-375$.

Rumson, A.G., Hallett, S.H., 2018. Opening up the coast. Ocean Coast. Manag. 160. https://doi.org/10.1016/j.ocecoaman.2018.04.015

Sagar, S., Tan, P., Lymburner, L., Roberts, D., 2016. Coastal change detection tools utilising 28 years of Earth Observation data in the Australian Geoscience Data Cube.

Schimel, A.C.G., lerodiaconou, D., Hulands, L., Kennedy, D.M., 2015. Accounting for uncertainty in volumes of seabed change measured with repeat multibeam sonar surveys. Cont. Shelf Res. 111, 52-68. https://doi.org/10.1016/J.CSR.2015.10.019

Seker, D.Z., Goksel, C., Kabdasli, S., Musaoglu, N., Kaya, S., 2003. Investigation of coastal morphological changes due to river basin characteristics by means of remote sensing and GIS techniques. Water Sci. Technol. 48, 135-142. https://doi.org/10.2166/wst.2003.0558

Sergeev, A., Ryabchuk, D., Zhamoida, V., Leont, I., Kolesov, A., Kovaleva, O., Orviku, K., 2018. Coastal dynamics of the eastern Gulf of Finland, the Baltic Sea : toward a quantitative assessment. BALTICA 31, 49-62. https://doi.org/10.5200/baltica.2018.31.05

Shrestha, R.L., Carter, W.E., Sartori, M., Luzum, B.J., Slatton, K.C., 2005. Airborne Laser Swath Mapping: Quantifying changes in sandy beaches over time scales of weeks to years. ISPRS J. Photogramm. Remote Sens. 59, 222-232. https://doi.org/10.1016/j.isprsjprs.2005.02.009

Spencer, T., Brooks, S.M., Evans, B.R., Tempest, J.A., Möller, I., 2015. Southern North Sea storm surge event of 5 December 2013: Water levels, waves and coastal impacts. EarthScience Rev. 146, 120-145. https://doi.org/10.1016/j.earscirev.2015.04.002

Stanley, R., Staley, P., 2017. Cliff recession in the Anglian Coastal monitoring area : Report $\mathrm{RPO47/A/2017.}$

The Crown Estate, 2019. Marine Data Exchange [WWW Document]. URL http://www.marinedataexchange.co.uk/ (accessed 6.8.19).

The Environment Agency, 2016. The costs and impacts of the winter 2013 to 2014 floods, 
Report-SC140025/R1.

Thieler, E.R., Himmelstoss, E.A., Zichichi, J.L., Ergul, A., 2009. The Digital Shoreline Analysis System (DSAS) version 4.0-an ArcGIS extension for calculating shoreline change. https://doi.org/doi.org/10.3133/ofr20081278

VisitMyHarbour.com, 2019. Marina Information, Lowestoft Harbour [WWW Document]. URL http://www.visitmyharbour.com/harbours/east-coast/lowestoft-

marinas/expanded.asp (accessed 6.7.19).

Westoby, M.J., Lim, M., Hogg, M., Pound, M.J., Dunlop, L., Woodward, J., 2018. Cost-effective erosion monitoring of coastal cliffs. Coast. Eng. 138, 152-164. https://doi.org/10.1016/j.coastaleng.2018.04.008

Wheaton, J.M., Brasington, J., Darby, S.E., Sear, D.A., 2010. Accounting for uncertainty in DEMs from repeat topographic surveys: Improved sediment budgets. Earth Surf. Process. Landforms 35, 136-156. https://doi.org/10.1002/esp.1886

White, S.A., Wang, Y., 2003. Utilizing DEMs derived from LIDAR data to analyze morphologic change in the North Carolina coastline. Remote Sens. Environ. 85, 39-47. https://doi.org/10.1016/S0034-4257(02)00185-2

Williams, J.G., Rosser, N.J., Hardy, R.J., Brain, M.J., Afana, A.A., 2018. Optimising 4-D surface change detection: an approach for capturing rockfall magnitude-frequency. Earth Surf. Dyn. 6, 101-119. https://doi.org/10.5194/esurf-6-101-2018

Williams, R., 2012. DEMs of Difference. Geomorphol. Tech. 2, 1-17. https://doi.org/10.1016/j.ympev.2009.06.014

Young, A.P., 2018. Decadal-scale coastal cliff retreat in southern and central California. Geomorphology 300, 164-175. https://doi.org/10.1016/j.geomorph.2017.10.010

Young, A.P., Ashford, S.A., 2006. Application of Airborne LIDAR for Seacliff Volumetric Change and Beach-Sediment Budget Contributions. J. Coast. Res. 1423-1436. https://doi.org/10.2112/05

Young, A.P., Olsen, M.J., Driscoll, N., Flick, R.E., Gutierrez, R., Guza, R.T., Johnstone, E., Kuester, F., 2010. Comparison of Airborne and Terrestrial Lidar Estimates of Seacliff Erosion in Southern California. Photogramm. Eng. Remote Sens. 76, 421-427. https://doi.org/10.14358/PERS.76.4.421

Zhou, G., Xie, M., 2009. Coastal 3-D Morphological Change Analysis Using LiDAR Series Data: A Case Study of Assateague Island National Seashore. J. Coast. Res. 252, 435-447. https://doi.org/10.2112/07-0985.1

Zischg, A.P., Mosimann, M., Bernet, D.B., Röthlisberger, V., 2018. Validation of 2D flood models with insurance claims. J. Hydrol. 557, 350-361. https://doi.org/10.1016/j.jhydrol.2017.12.042 